\title{
Impact Study on the Use of Biomass-Derived Fuels in Gas Turbines for Power Generation
}

Dr. Clifford A. Moses

Dr. Henry Bernstein

Southwest Research Institute

San Antonio, Texas

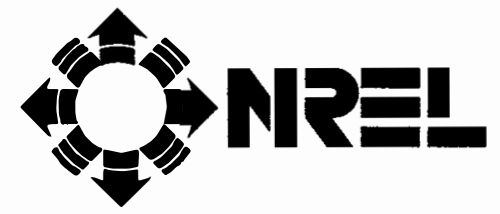

National Renewable Energy Laboratory 1617 Cole Boulevard Golden, Colorado 80401-3393

A national laboratory of the U.S. Department of Energy Operated by Midwest Research Institute for the U.S. Department of Energy

Under Contract No. DE-AC02-83CH10093 


\section{Impact Study on the Use of Biomass-Derived Fuels in Gas Turbines for Power Generation}

Dr. Clifford A. Moses

Dr. Henry Bernstein

Southwest Research Institute

San Antonio, Texas

NREL technical monitor: Tom Milne

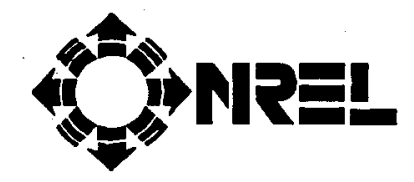

National Renewable Energy Laboratory 1617 Cole Boulevard Golden, Colorado 80401-3393

A national laboratory operated for the U.S. Department of Energy under contract No. DE-AC02-83CH10093

Prepared under Subcontract No. AV-2-12148-1

January 1994 


\section{NOTICE}

NOTICE: This report was prepared as an account of work sponsored by an agency of the United States government. Neither the United States government nor any agency thereof, nor any of their employees, makes any warranty, express or implied, or assumes any legal liability or responsibility for the accuracy, completeness, or usefulness of any information, apparatus, product, or process disclosed, or represents that its use would not infringe privately owned rights. Reference herein to any specific commercial product, process, or service by trade name, trademark, manufacturer, or otherwise does not necessarily constitute or imply its endorsement, recommendation, or favoring by the United States government or any agency thereof. The views and opinions of authors expressed herein do not necessarily state or reflect those of the United States government or any agency thereof.

Printed in the United States of America

Available from:

National Technical Information Service

U.S. Department of Commerce

5285 Port Royal Road

Springfield, VA 22161

Price: Microfiche A01

Printed Copy A07

Codes are used for pricing all publications. The code is determined by the number of pages in the publication. Information pertaining to the pricing codes can be found in the current issue of the following publications which are generaily available in most libraries: Energy Research Abstracts (ERA); Government Reports Announcements and Index (GRA and I); Scientific and Technical Abstract Reports (STAR); and publication NTIS-PR-360 available from NTIS at the above address. 


\section{FOREWORD/ACKNOWLEDGEMENTS}

This study was conducted in the Division of Engines, Fuels, and Vehicle Research of Southwest Research Institute(SwRI), San Antonio, TX, under Subcontract No. AV-212148-1 to the National Renewable Energy Laboratory, Golden, CO 80401-3393. The Technical Monitor was Dr. Thomas Milne, Principal Chemist, of the Process Research Branch. The Program Manager was Dr. Richard Bain. The work was supported by the U.S. Department of Energy, Office of Energy Efficiency and Renewable Energy, under the Solar Thermal and Biomass Power Program directed by Mr. Gary Burch.

The authors wish to acknowledge the technical support of the following persons, their associates, and staff:

Mr. Don Bahr

Mr. Berkeley Davis

Dr. Robert Lohman

Mr. G. A. Ludwig

Dr. Hookum Mongia
General Electric Aircraft Engines

Cincinnati, $\mathrm{OH}$

General Electric Power Generation

Schenectady, NY

Pratt \& Whitney

East Hartford, CT

Solar Turbines, Inc

San Diego, CA

Allison Gas Turbine Div

Indianapolis, $\mathbb{N}$

Much of the information gathered during this study was provided to the authors during visits to these companies or came from literature suggested by these persons. The final report was also reviewed for the authors by persons from General Electric Aircraft Engines, General Electric Power Generation, and Pratt \& Whitney.

The authors also wish to thank Ms. Rebecca Sears and Ms. Loretta Mesa for the typing and final organization of this report. 


\section{TABLE OF CONTENTS}

FOREWORD $\ldots \ldots \ldots \ldots \ldots \ldots \ldots \ldots \ldots \ldots \ldots \ldots \ldots \ldots \ldots \ldots$

LIST OF FIGURES $\ldots \ldots \ldots \ldots \ldots \ldots \ldots \ldots \ldots \ldots \ldots \ldots$

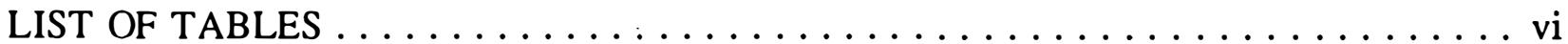

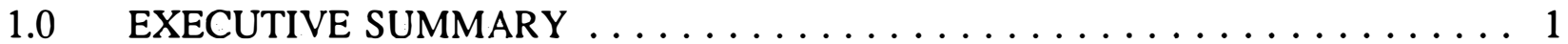

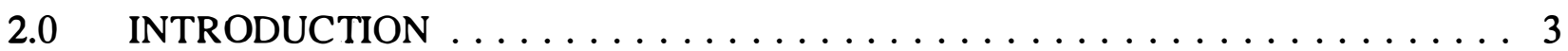

3.0 GAS TURBINE MACHINES AND SYSTEMS $\ldots \ldots \ldots \ldots \ldots \ldots$

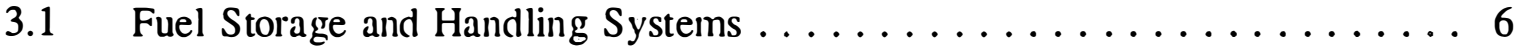

3.2 Gas Turbines ....................... 7

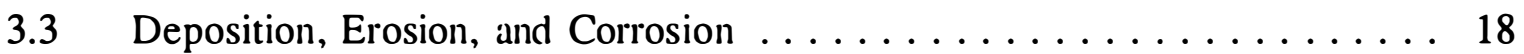

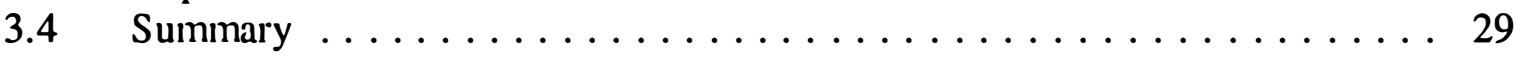

4.0 GASEOUS FUELS FROM BIOMASS $\ldots \ldots \ldots \ldots \ldots \ldots \ldots \ldots$

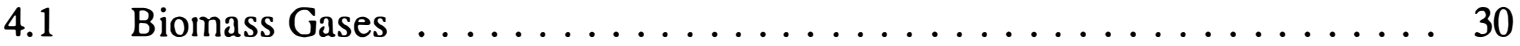

4.2 Evaluation of Properties of Biomass Gases . . . . . . . . . . . . 34

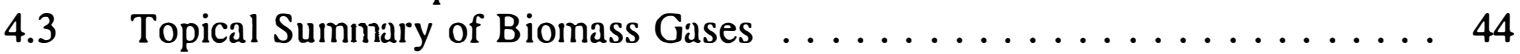

5.0 PYROLYSIS LIQUIDS FROM BIOMASS $\ldots \ldots \ldots \ldots \ldots \ldots$

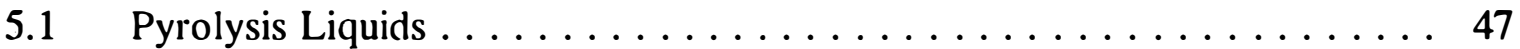

5.2 Evaluation of Properties of Pyrolysis Liquids . . . . . . . . . 47

5.3 Topical Summary on Pyrolysis Licuids . . . . . . . . . . . . 74

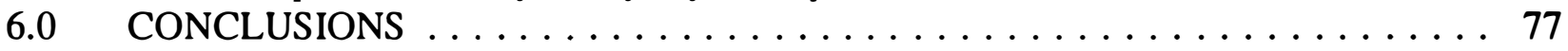

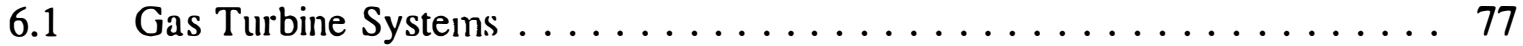

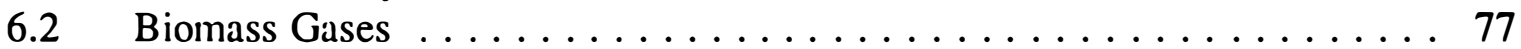

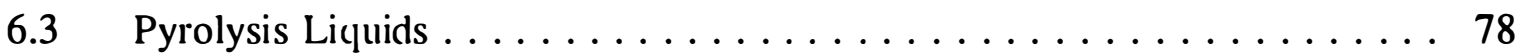

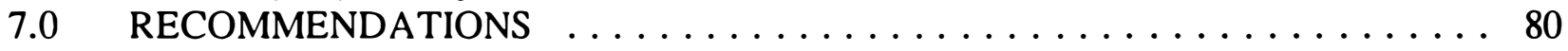

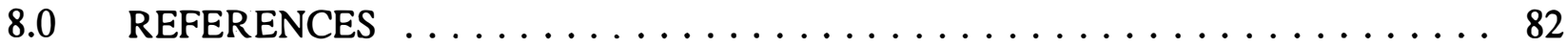

APPENDIX A. CORROSION, EROSION, DEPOSITION,

AND HIGH-TEMPERATURE COATINGS

$1.0 \quad$ HIGH-TEMPERATURE ENVIRONMENTAL ATTACK $\ldots \ldots \ldots \ldots \ldots \ldots$

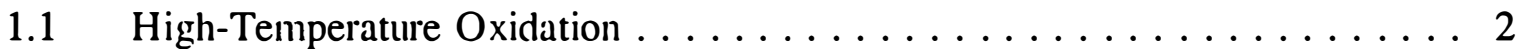

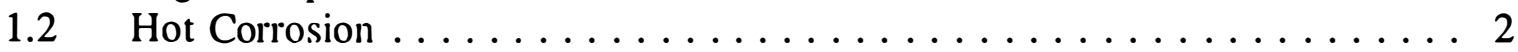

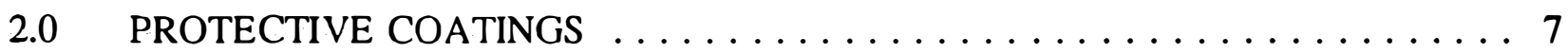

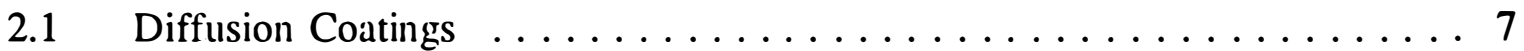

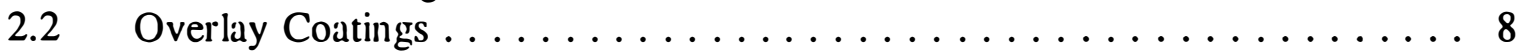

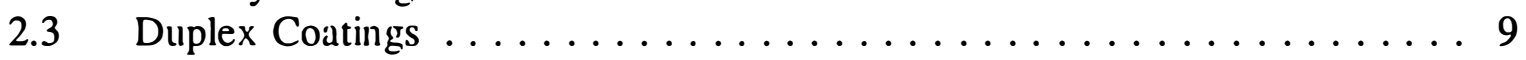

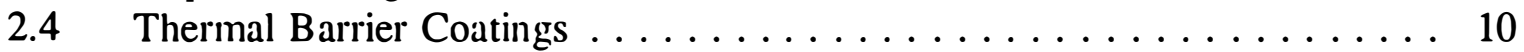

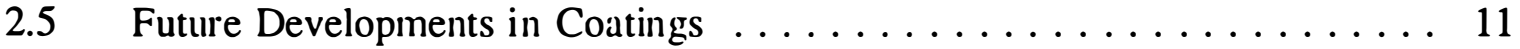

3.0 DEPOSITION, EROSION, AND CORROSION $\ldots \ldots \ldots \ldots \ldots \ldots \ldots$

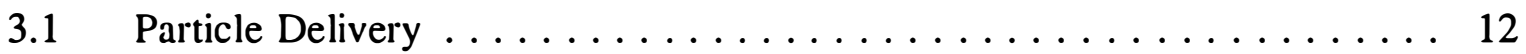

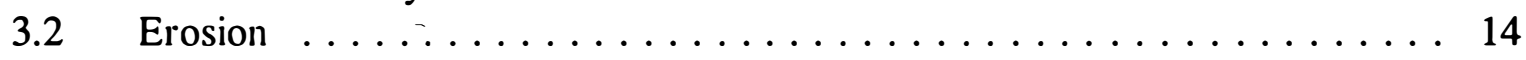

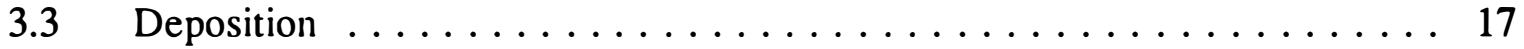


$4.0 \quad$ CONTAMINANTS $\ldots \ldots \ldots \ldots \ldots \ldots \ldots \ldots \ldots \ldots \ldots \ldots \ldots \ldots \ldots$

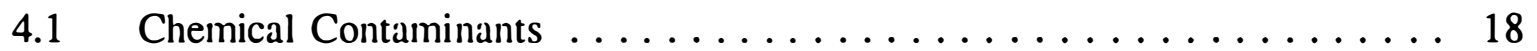

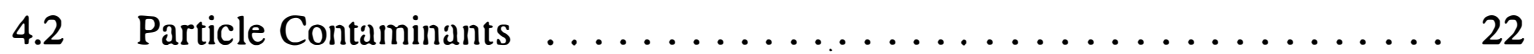

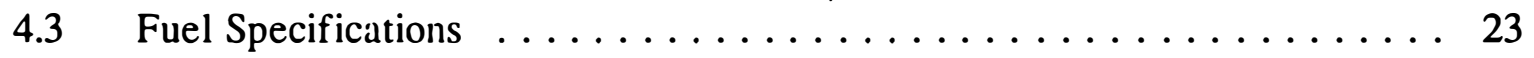

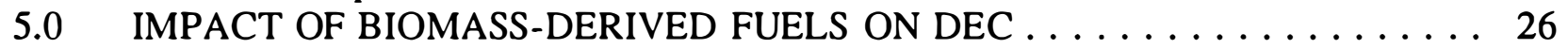

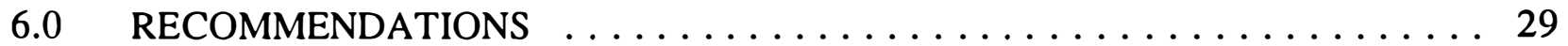

6.1 Recommendations on Using Biomass Fuels . . . . . . . . . . . . . . . 29

6.2 Recommendations for Additional Research . . . . . . . . . . . . . 31

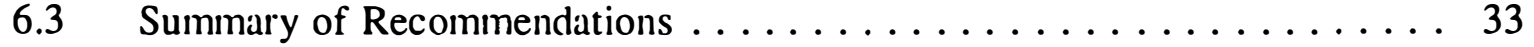

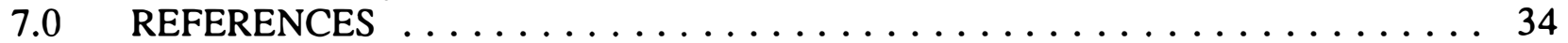




\section{LIST OF FIGURES}

1. Features of a Generic Gas Turbine Combustor $\ldots \ldots \ldots \ldots \ldots \ldots \ldots$

2. Effect of Drop Size on Burning Time for Various Fuels ........... 11

3a. Example of Drop-Size Distribution in a Fuel Spray $\ldots \ldots \ldots \ldots \ldots \ldots$

3b. Cumulative Volume Distribution in a Fuel Spray .............. 13

4. Effect of Fuel Hydrogen Content on Liner Temperature Parameter . . . . . 17

5. Effect of Fuel Hydrogen Content on Liner Life . . . . . . . . . . . . . 19

6. Effect of Liner Temperature Increases on Liner Life $\ldots \ldots \ldots \ldots \ldots \ldots 20$

7. Effect of Fuel Hydrogen Content on Exhaust Particulates ........... 21

8. Effect of Particle Size on Impingement of Particles on Airfoils . . . . . . . 22

9. Trajectories of $6 \mu \mathrm{m}$ Size Particles Through the First Stage of a $50 \mathrm{Mw}$ Turbine . . . . . . . . . . . . . . . . . . . 24

10. Relative Trailing Edge Erosion Rate on First Rotor

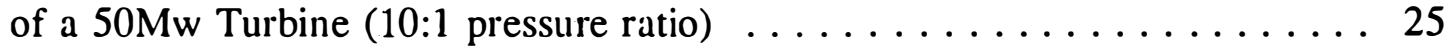

11. Temperature Effects on Hot Corrosion of Turbine Blades and Vanes ...... 26

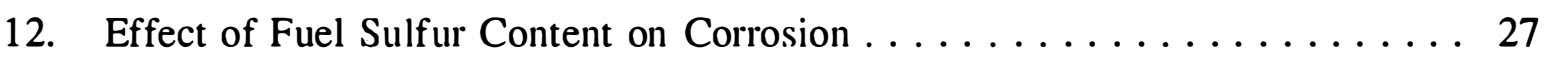

13. Effects of Energy Content of Gases on Flame Temperature and Combustor Design Modifications ................. 36

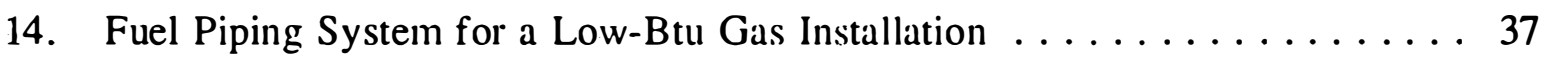

15. Particulate Loadings in Gasifier Fuels $\ldots \ldots \ldots \ldots \ldots \ldots \ldots \ldots \ldots$

16. Boiling Point Distribution of a Pyrolysis Licuuid

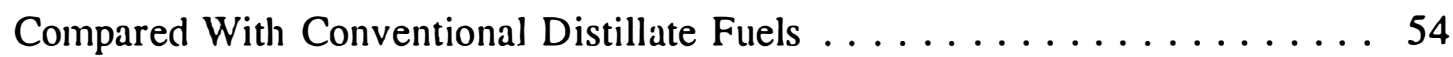

17. Comparison of Viscosities of Pyrolysis Liquids with

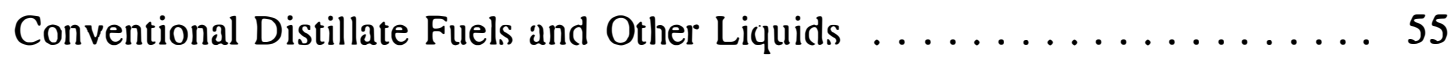

18. Effect of Fuel Atomization and Boiling Range on Ignition

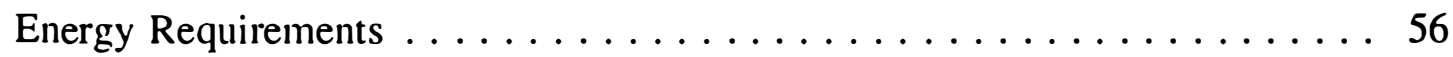

19. Effect of Fuel Atomization and Boiling Range on

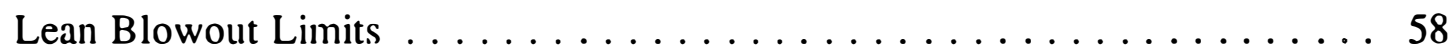

20. Effect of Fuel Atomization on Combustion Efficiency ........... 59

21. Effect of Combustor Residence Time on Combustion Efficiency .........6 61

22. Combustion Efficiency for a Pyrolysis Liquid in a Gas Turbine ....... 62

23. Calculated Burning Times for Drops Containing Char ............ 64

24. Hydrocarbon Emissions from the Combustion of a Pyrolysis

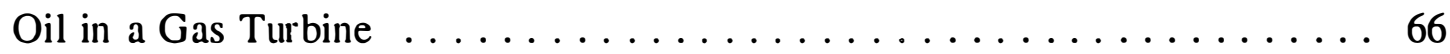


25. CO Emissions from the Combustion of a Pyrolysis Oil in a Gas Turbine ......................... 67

26. NOx Emissions from the Combustion of a Pyrolysis Oil. in a Gas Turbine ......................... 68

27. Liner Temperature Parameter for the Combustion of a Pyrolysis Oil in a Gas Turbine Combustor . . . . . . . . . . . 70

28. Smoke Emissions from the Combustion of a Pyrolysis Liquid in a Gas Turbine Combustor . . ................... 71

29. Correlation Between SAE Smoke Number and Exhaust Carbon $\ldots \ldots \ldots 72$

30. Schematic of a Gas Turbine with an External Combustor and Hot-Gas Cleanup ......................... 76

\section{APPENDIX}

1. Types of High-Temperature Attack: Approximate

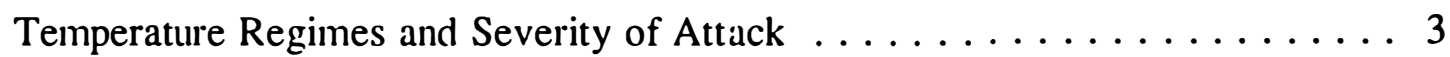

2. Weight Change Versus Time for the Cyclic Hot Corrosion of $\mathrm{Na}_{2} \mathrm{SO}_{4}$-coated (applied every $20 \mathrm{~h}$ ) $\mathrm{Ni30}(\mathrm{Cr}-4 \mathrm{Al}$ in Air $\ldots \ldots \ldots \ldots$

3. Trajectories for 6um Particles in the First State of a $50 \mathrm{Mw}$ Turbine (10:1 pressure ratio) $\ldots \ldots \ldots \ldots \ldots \ldots \ldots \ldots \ldots$

4. Effect of Particle Size on Impingement of Particles on Airfoils . . . . . . 15

5. Relative Trailing Edge Erosion Rate on First Rotor of a $50 \mathrm{Mw}$

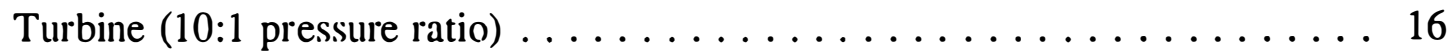

6. Weight Loss Due to High-Temperature Hot Corrosion as a Function of Sulfur Level for Aluminide-Coated MAR M-246 . . . . . . . 20

7. Weight Loss Due to High-Temperature Hot Corrosion as a Function of Sulfur Level for Chromium-Modified Aluminide-Coated $1 \mathrm{~N}-738$ and MAR M-246 .............. 21 


\section{LIST OF TABLES}

1. Summary of Critical Fuel Properties and Their Impact on Gas Turbine Systems . . . . . . . . . . . . . . . . . 5

2. Examples of Gas Turbines for Power Generation $\ldots \ldots \ldots \ldots \ldots \ldots$

3. Examples of Characteristics of Biomass Gases $\ldots \ldots \ldots \ldots \ldots \ldots \ldots$

4. Sample Biomass Gasification Products from an Oxygen-Blown Gasifier 32

5. Composition and Properties of Various Gaseous Fuels $\ldots \ldots \ldots \ldots \ldots 33$

6. Properties of Sample Biomass Pyrolysis Oils $\ldots \ldots \ldots \ldots \ldots \ldots \ldots .48$

7. Fuel Specifications for Gas Turbine Power Plants . . . . . . . . . . . 49 APPENDIX

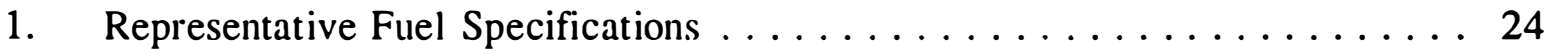

2. Comparison of Contaminants in Pyrolysis Liquids

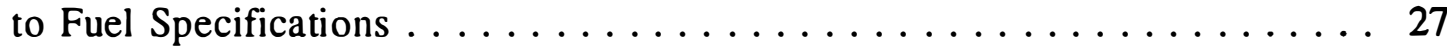




\subsection{EXECUTIVE SUMMARY}

Biomass-derived fuels, both gases and pyrolysis liquids, have been evaluated for their potential use in gas turbine engines. Unlike many previous studies, this investigation has concentrated solely on the technical questions of engine performance and durability.

The major barrier to the use of biomass gases is the presence of significant amounts of alkali metals which, in the presence of sulfur, causes hot corrosion of the turbine blades and vanes. Depending on size and composition, ash and char can also cause corrosion in addition to erosion and deposition. Several methods of clean-up have been developed for use with coal gasification units that should be applicable.

The only other difficulty in using biomass gases is their low energy content. Offsetting this with higher fuel flow rates requires larger fuel pumps, controls, and injectors, but these have been developed for other low- and medium-Btu gases. Also, associated problems with ignition, stability, efficiency, and cooling can generally be addressed by changing the airflow splits in the combustor. These are methods which have been done for other gases, but some engine/combustor designs are more tolerant than others. It is generally necessary to verify the changes with combustor rig tests before putting the combustor in an engine. Once the combustor has been modified and the machine placed in service, it is important that the gas quality remain fairly constant.

High alkali content is a much more formidable problem with the pyrolysis liquids. Standard methods for alkali removal from residual fuels by water washing are not applicable because of the mutual solubility of the water and the fuel. If the concentration of sulfur is sufficiently low, it may be possible to relax the allowable alkali depending on the turbine inlet temperature. Also there may opportunities to apply advanced blade coatings to gain sufficient protection. Another opportunity is to modify an engine to incorporate an external combustor and hot-gas cleanup system before directing the combustion gases to the turbine.

For the pyrolysis liquids, the high viscosity and boiling range pose problems for ignition and flame stabilization, i.e. lean blowout, but these can be addressed by using a distillate fuel for startup and shutdown providing certain precautions are taken. These two properties also lead to reductions in combustion efficiency because burning time is increased. Viscosity cannot be reduced by fuel heating because of the low thermal stability of the fuels. Some industrial machines may have sufficient residence time for bumout, but other machines, especially aeroderivatives, will need improved atomizers to reduce drop size. The presence of char slurried into the liquid aggravates this problem both by increasing the viscosity and by taking even longer to burn out. Typical values for viscosity and boiling range are too far out of the range of experience to immediately apply standard correlation equations to predict the required degree of atomization for satisfactory combustion.

Along with the high viscosity and boiling range, the low hydrogen content of the pyrolysis 
liquids will cause a significant increase in soot and particulate formation during combustion. This will increase the radiation heat load to the liner, raising the temperature and possibly reducing the thermal fatigue life of the liner. Also there will be an increase in exhaust smoke and particulates, except possibly in the case of some industrial machines with their longer residence times. Again, typical levels of hydrogen content for pyrolysis liquids are much less than even that for the low-quality alternative fuels that have been studied, so there are no valid empirical models to predict the severity of the problem.

Thus, biomass-derived fuels, both gases and pyrolysis liquids, offer significant technical challenges to their use in gas turbines. In general, industrial machines are more fuel tolerant than aeroderivatives because of their longer residence times, lower temperatures, and larger flow passages. Some of the problems in performance and durability, especially with the gases, can be resolved with standard design modifications which are well understood. Because of the lack of an applicable data base, many of the problems associated with the pyrolysis liquids will require some experimental investigations to determine their significance and provide guidance to reduce the costs of design changes. Dealing with the high alkali and ash content, especially in the liquids, will be the major challenge, and may require some new strategies or technology to control corrosion, erosion, and deposition. 


\subsection{INTRODUCTION}

Over the last two decades there has been a growing interest in the use of biomass products for power generation. Initially this interest was driven by concerns over potential shortages of petroleum, but in recent years the ecological advantages of biomass fuels have become an important driving factor. Biomass fuels are considered essentially neutral in the production of $\mathrm{CO}_{2}$, and they have low sulfur content as compared to many coals and oils.

The cost of biomass fuels depends largely on whether the raw material is considered to be a waste product, such as wood chips, bagasse, and rice hulls, or to be a crop grown specifically for fuel; the costs of collection, processing, and distribution are also important factors.

Biomass fuels can be in any one of three states: the original solid material, or as processed into gases or pyrolysis liquids. Since one of the more promising uses of biomass fuels is in gas turbines for electric power generation, the latter two have the advantage of being easier to meter and control for use in gas turbines, or possibly even diesels.

Gaseous products are potentially cleaner than pyrolysis liquids but more difficult to transport, so the power plant would probably have to be integrated to the gasifier. This could limit the size of the power plant according to how much feedstock can be harvested or collected within a reasonable distance. Because it is impractical to operate gasifiers on an intermittent basis, such units would probably be for base load, i.e., continuous operation.

Liquid products have the advantage of being more transportable from a processing unit to a power plant thus easing siting requirements. (6) Also the liquids are easier to store, and therefore could be used in peaking units.

The purpose of this study was to evaluate the properties of fuels derived from biomass, both gaseous and liquid, against the fuel requirements of gas turbine systems for generating electrical power. Where possible, this evaluation has attempted to be quantitative rather than merely qualitative in order to establish the significant variations in the properties of biomass fuels from those of more conventional fuels. This study did not address the techniques of gasification or liquefaction nor the economics of utilization. The fuel properties that were used to characterize the biomass derived fuels were either taken from the open literature or were supplied by the National Renewable Energy Laboratory, NREL.

There has long been a general feeling that gas turbines can burn any fuel, and certainly in comparison to piston engines, both spark ignition and compression ignition, this seems to be true. It would be more correct to say that gas turbines can be designed to burn any fuel. However, once optimized for that fuel, or class of fuels, operation of the gas turbine system on other fuel types may cause reductions in performance and/or durability. In some cases it is possible to derate an engine to reduce the impact to acceptable levels. In more extreme cases, 
one can expect to have to modify or even redesign certain components in the fuel system or hot section to accommodate variant fuel properties.

Such problems are controlled by the manufacturer with a fuel specification which describes the limits of critical fuel properties which are known to affect various aspects of fuel storage and handling as well as engine performance and durability. Such fuel specifications are developed as a balance of quality, availability, and cost.

Table 1 lists the critical areas of performance and durability in gas turbine systems which are affected by fuel properties. These problems can be seen to fall into the three general categories of Performance, Durability, and Storage and Handling. These three areas will be described in the next chapter from the standpoint of the gas turbine power plant. In the succeeding chapters, first for the gaseous fuels and then for the liquids, the role of the relevant fuel properties for each area will be addressed. Technical voids will be identified, and recommendations made for filling those voids. 
TABLE 1. SUMMARY OF CRITICAL FUEL PROPERTIES AND THEIR IMPACT ON GAS TURBINE SYSTEMS

FUEL PROPERTIES

Hydrogen content

Hydrocarbon composition

er

Viscosity and boiling range

Thermal stability

Contaminants

Temperature
IMPORTANT AREA

Soot formation

Flashback

Materials compatibility

Atomization and fuel-air mixing

Hot fuel deposits

Deposition, erosion, and corrosion

Materials compatibility
PERFORMANCE/DURABILITY PROBLEM

Combustor liner life

Exhaust smoke

Venturi overheating

O-rings, gaskets, seals, and diaphragms

in fuel system components

Ignition lean blow-out limit

Combustion efficiency

Gaseous emissions

Control valves

Atomizers

Turbine blades and vanes

Control valves, piping, and fuel inlet nozzles 


\subsection{GAS TURBINE SYSTEMS}

From the standpoint of fuel concerns, a gas turbine power plant can be conveniently divided into two entities: the fuel storage and handling system and the gas turbine itself. For the purposes of this report, the metering and fuel controls will be addressed as part of the fuel handling system, while the gas-turbine discussion will address issues of performance and durability of the combustor and the turbine sections.

\subsection{FUEL STORAGE AND HANDLING SYSTEMS}

Fuel storage and handling systems generally include the storage tanks and associated transfer pumps, the fuel clean-up systems and the flow metering systems. Five areas are critical:

- materials compatibility

- energy content of the fuel

- pumpability of the fuel, i.e. viscosity

- contaminants

- vapor pressure/dew point

Materials compatibility includes the metals used in the storage tanks, fuel lines, and valves, as well as the non-metallic seals and gaskets that are used. With gaseous fuels the temperature of the gas will be an important consideration with materials compatibility. With the pyrolysis liquids, the acidity of the liquid is of concern.

The sizing of fuel-handling components depends on the energy content of the fuel. This is an area that makes it difficult to use biomass-derived fuels in an existing power plant system. A proportionately larger fuel flow rate is necessary to of fset the lower energy content necessitating larger valves and metering equipment both in the storage system and on the engine itself. In some engines, there physically is not enough room to install the size of injector required for low-Btu gases.

For liquids, the pumpability of the fuel is important not only when sizing the pumps and their power requirements, but also for low temperature considerations when viscosity increases. If liquid fuels are extremely viscous, they must be heated in order to pump them. This must be done carefully so as not to overheat the fuel and cause decomposition and deposition. Vapor pressure can be a concern when heating the fuel to prevent vaporlock and/or cavitation in the pump.

As a further complication, the fuel lines cannot be shutdown when they are filled with viscous fluids because it is almost impossible to start them flowing again. A related problem exists with liquid fuels that contain tars or char, as is possible with the pyrolysis liquids, as these materials will separate in a stagnate liquid and interfere with the normal operation of pumps, valves, metering systems, and atomizers. 
These problems also exist with residual fuels, and the remedy is to use heat-traced fuel lines and to always start-up and shut-down the system on distillate fuels. This means a dual fuel system. As a further precaution, it is necessary to heat the distillate fuel to bring pumps and other components up to the temperature of the residual fuel/pyrolysis liquid before switching over. If this precaution is not taken, the thermal gradient caused by having a cold fuel in one part of the pump and a hot fuel at the other will cause the shaft to bind and seize; similar problems can happen in fuel controls. (28)

A similar problem can occur with machines fired with low Btu gases where natural gas is used to start the machine. Normally natural gas might be delivered at $150^{\circ} \mathrm{F}$, but if the delivery temperature of the biogas is high, say $700^{\circ} \mathrm{F}$ or more, the starting gas must be heated to avoid thermal gradients in the manifolds and injectors which would eventually cause cracks.

Also with gases, it is important the temperature be above the dew point of the condensibles to prevent condensation.

\subsection{GAS TURBINES}

Traditionally gas turbines have been divided into two general classifications: industrial and aircraft. (Other components and classifications to improve efficiency, such as steam injection and co-generation, are not of concern in this discussion as they do not directly interface with the fuel.) Industrial gas turbines are physically large and of very rugged design, exchanging size for cost. On the other hand, aircraft gas turbines have been designed for higher pressures and temperatures, using exotic materials and aggressive cooling schemes, in order to reduce their size and fuel consumption for aircraft application. Aircraft gas turbines have found their way into the power plant market in applications where size is very important, such as on offshore drilling platforms or where a need exists to bring the unit rapidly on line, such as peaking units. In recent years, as fuel costs have become a more important factor in power plant operations, some of the design techniques used in aeroderivative engines have been incorporated into the larger industrial machines, along with combined cycle opportunities, so that both classes of systems can achieve comparable efficiencies.

Table 2 lists a number of industrial and aeroderivative gas turbines that are commonly used for stationary power generation for the purpose of showing the wide range of sizes that are available. (Note: The characteristics provided in Table 2 are representative of the basic design; actual values depend on the model and the specific application.) The important thing to note is the fueling requirements which have been provided for both liquids and gases assuming nominal properties for a distillate fuel and natural gas. Fuels with lower energy contents than these would have correspondingly higher fueling requirements to maintain the power rating.

One factor that is pertinent to this study is that, in general, the industrial class of machines are more fuel tolerant; that is to say they are less sensitive to variations in fuel properties. They can be modified to accept lower quality fuels, and to some degree can tolerate more contaminants 
TABLE 2. EXAMPLES OF GAS TURBINES FOR POWER GENERATION

\begin{tabular}{|c|c|c|c|c|c|c|}
\hline MFR & MODEL & $\begin{array}{l}\text { RATING } \\
\text { (MW) }\end{array}$ & $\begin{array}{l}\text { HEAT RATE } \\
(\mathrm{Btu} / \mathrm{KwHr})\end{array}$ & $\begin{array}{l}\text { Liquid FUEL*RATE } \\
(1000 \# / \mathrm{Hr})\end{array}$ & $\begin{array}{l}\text { Gas FUEL**RATE } \\
(1000 \mathrm{SCF} / \mathrm{Hr})\end{array}$ & $\begin{array}{l}\mathrm{t}(\mathrm{res}) \\
\text { (msec) }\end{array}$ \\
\hline \multirow[t]{3}{*}{ Allison } & 501 & 3.9 & 11,700 & 2.5 & 46 & 5 \\
\hline & 570 & 4.8 & 11,500 & 3.1 & 56 & 5 \\
\hline & 571 & 5.9 & 10,200 & 3.4 & 60 & 5 \\
\hline \multirow[t]{6}{*}{ GE } & LM2500 & 22 & 10,000 & 12 & 216 & 5 \\
\hline & LM5000 & 33 & 9,800 & 18 & 324 & 5 \\
\hline & F5 & 26 & 11,800 & 17 & 306 & 10 \\
\hline & F6 & 38 & 10,800 & 23 & 414 & 10 \\
\hline & F7 & $83-150$ & 10,000 & $45-80$ & $810-1440$ & 10 \\
\hline & F9 & $116-212$ & 10,000 & $65-117$ & $1200-2100$ & 10 \\
\hline \multirow[t]{2}{*}{ P\&W (T.P.) } & FT4 & & & & & 5 \\
\hline & FT8 & 25 & 9,000 & 12.5 & 225 & 5 \\
\hline (Can.) & ST6 & $0.5-0.8$ & 15,000 & 0.5 & 9 & 3 \\
\hline \multirow[t]{4}{*}{ Solar } & Satum & 1 & $11-15,000$ & 1 & 18 & 4 \\
\hline & Centaur & $2.5-4.5$ & 12,000 & $1.6-2$ & $29-36$ & 4 \\
\hline & Mars & 9 & 11,000 & 5.5 & 100 & 4 \\
\hline & Jupiter & 17 & 10,600 & 10 & 180 & 4 \\
\hline
\end{tabular}

* assuming $28,000 \mathrm{BTU} / \mathrm{b}$

** assuming 1,000 BTU/SCF 
in the fuel. This is attributed to the fact that they operate at lower temperatures and pressures and have larger combustors and larger flow passages in the turbine section. For liquid fuels, the larger combustors mean that there is more residence time for the burnout of heavier fuels; for gaseous fuels, there is more opportunity to accommodate larger fuel nozzles and mixing problems with gases of low energy content. The larger flow passages can tolerate more deposition before performance is significantly deteriorated, although any deposition is undesirable.

Figure 1 illustrates the generic features of gas turbine combustors. The combustor is divided into three reaction zones:

- the primary zone, where the fuel is mixed with the air and most of the combustion takes place; this is also where the flame is stabilized.

- the secondary zone, where more air is added, but the temperatures are still high enough to complete the $\mathrm{CO}$ oxidation.

- the quench zone, where still more air is added to achieve a uniform gas temperature that is compatible with the materials of the turbine section.

There are a number of system elements and processes in a gas turbine whose performance and durability are directly affected by fuel properties. These are identified below and will be discussed separately to identify important factors with special emphasis on atomization and evaporation and on liner durability. Specific effects of the biomass gases and pyrolysis liquids will be addressed in the subsequent chapters.

- fuel atomization and evaporation

- ignition

- flame stabilization

- combustion efficiency

- exhaust emissions

- soot formation

- combustor liner durability

- deposition, erosion, and corrosion

\subsubsection{ATOMIZATION AND EVAPORATION}

Atomization of the fuel is possibly the most important aspect of the combustion process. Fine atomization, i.e., small droplets, is necessary to achieve ignition since very little evaporation occurs at the ambient temperatures during startup. Once the combustor is operating, fine atomization is still required to increase the surface area and permit the liquid fuel to evaporate, mix with the air, and burn all within the residence time of a combustor, which is about 3 to 5 msec for aeroderivatives and $10 \mathrm{msec}$ for industrial machines. Figure 2 illustrates this point by showing the droplet burnout time as a function of size for various fuels; the fuels with higher 


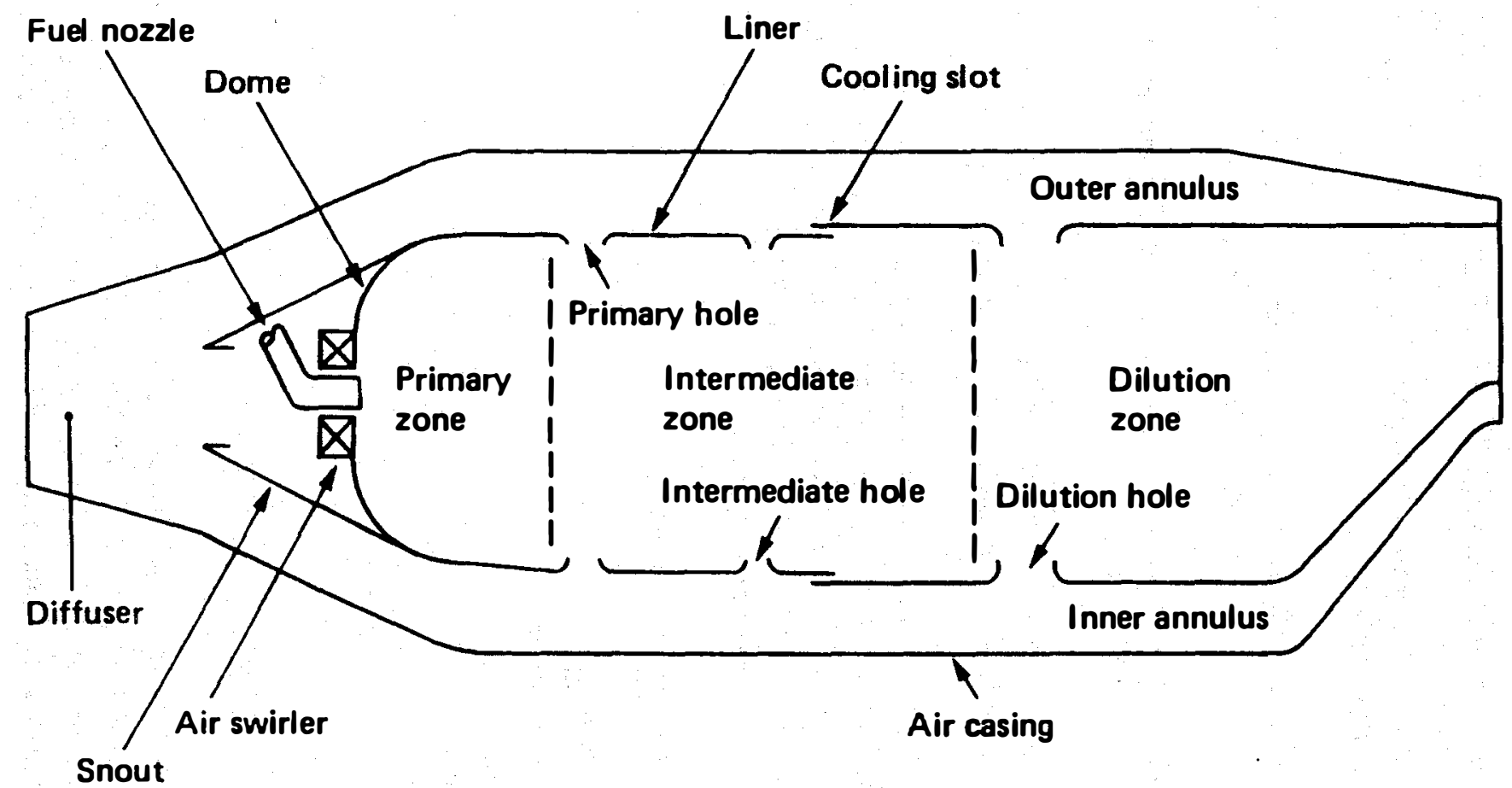

FIGURE 1. Features of a Generic Gas Turbine Combustor (Ref. 1) 


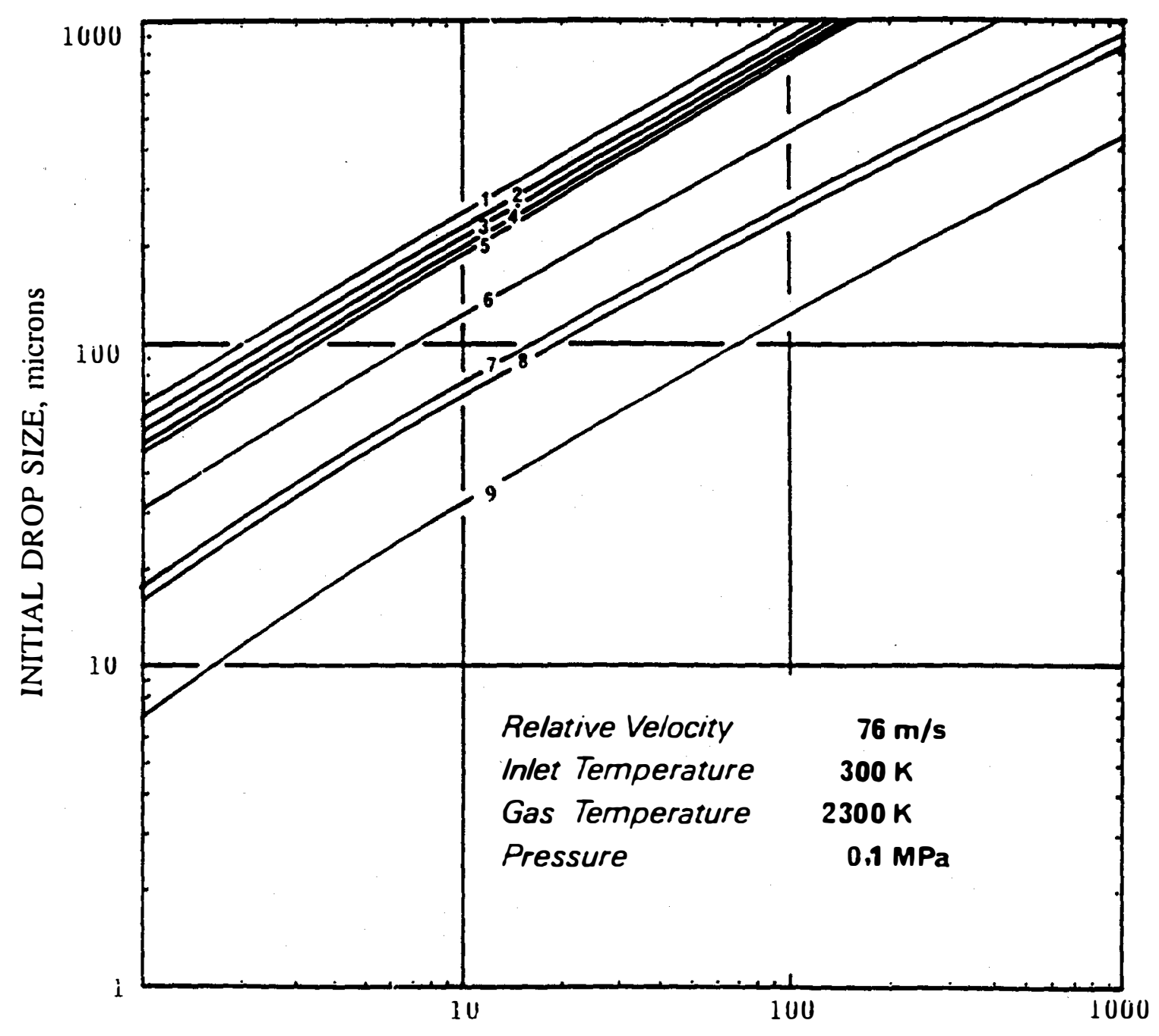

BURNING TIME, msec

Legend:

1. Pentane

6. Marine Diesel (5\% Residue)

2. 100 Octane

7. Pool Fuel Oil (45\% Residue)

3. $\mathrm{RDE} / \mathrm{F} / \mathrm{KER} 210$

8. Bunker Fuel (70\% Residue)

4. Kerosene

9. Carbon

5. Gas Oil

FIGURE 2. Effect of Drop Size on Burning Time for Various Fuels (Ref. 7) 
viscosity and boiling range are to the right on the graph and have longer burning times for the same size drop.

The fuel spray from an atomizer is not of uniform size, however; it is a distribution of sizes that are characterized for combustion purposes by the Sauter mean diameter, SMD, defined as the ratio of the average droplet volume to the average surface area, or:

$$
S M D=\frac{\sum n r^{3}}{\sum n r^{2}}
$$

Sometimes this is designated as $\mathrm{D}_{32}$. Figure 3a shows a typical distribution of drop sizes in two sprays, one with an SMD of 50 microns, the other with 100 microns; the vertical axis is the percent of the spray at a given size.(45) (The variation in "q" is not important to this discussion.) Figure $3 \mathrm{~b}$ shows the cumulative volume distribution for the same sprays. The important point is that even though the SMD is small, there are many drops that are much larger, and they contain a significant amount of the fuel.

Atomization is strongly affected by fuel properties, but the sensitivity depends upon the type of atomizer used. Lefebvre (1) provides a very comprehensive discussion of the various kinds of atomizers that have been used in gas turbines; the two most common types of atomizers used in gas turbines are pressure-swirl, sometimes called simplex atomizers, and air-blast atomizers. For pressure-swirl atomizers, a rather simple expression has been found relating the SMD of the spray to the viscosity, $v$, the surface tension, $\sigma$, and the density, $\rho$, as follows:(2)

$$
\mathrm{SMD} \approx v^{0.16} \sigma^{0.6} \rho^{0.2}
$$

For typical hydrocarbon fuels, viscosity varies much more than surface tension or density, both among fuels and with temperature, and is considered the dominant fuel property affecting atomization from this type of atomizer.

For airblast atomizers the expression is more complicated since the factors of air and fuel flow rates are also included. Several empirical expressions have been developed to predict SMD for airblast atomizers, for example Jasuga (2) and Lefebvre and coworkers $(3,4)$, that are usually of the form:

$$
\operatorname{SMD}=k_{1}\left(\frac{\sigma \rho_{f}}{\rho_{\mathrm{a}} U_{\mathrm{a}}}\right)^{0.5}\left(1+\frac{1}{\mathrm{AFR}}\right)^{0.5}+k_{2}\left(\frac{\mu}{\sigma \rho_{\mathrm{a}}}\right)^{0.425}\left(1+\frac{1}{\mathrm{AFR}}\right)^{0.5}
$$

where: $\quad \mathrm{k}_{1}$ and $\mathrm{k}_{2}$ are constants

$U_{a}$ is the air velocity

AFR is the air to fuel ratio with atomizer 


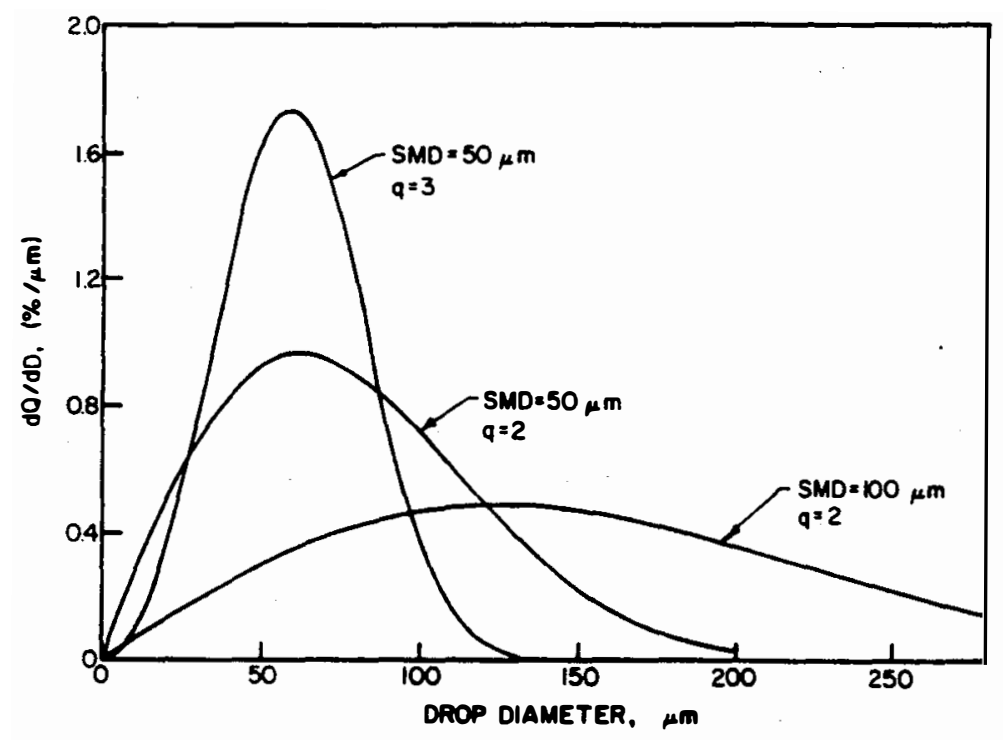

FIGURE 3a. Examples of Drop-Size Distribution in a Fuel Spray (Ref. 45)

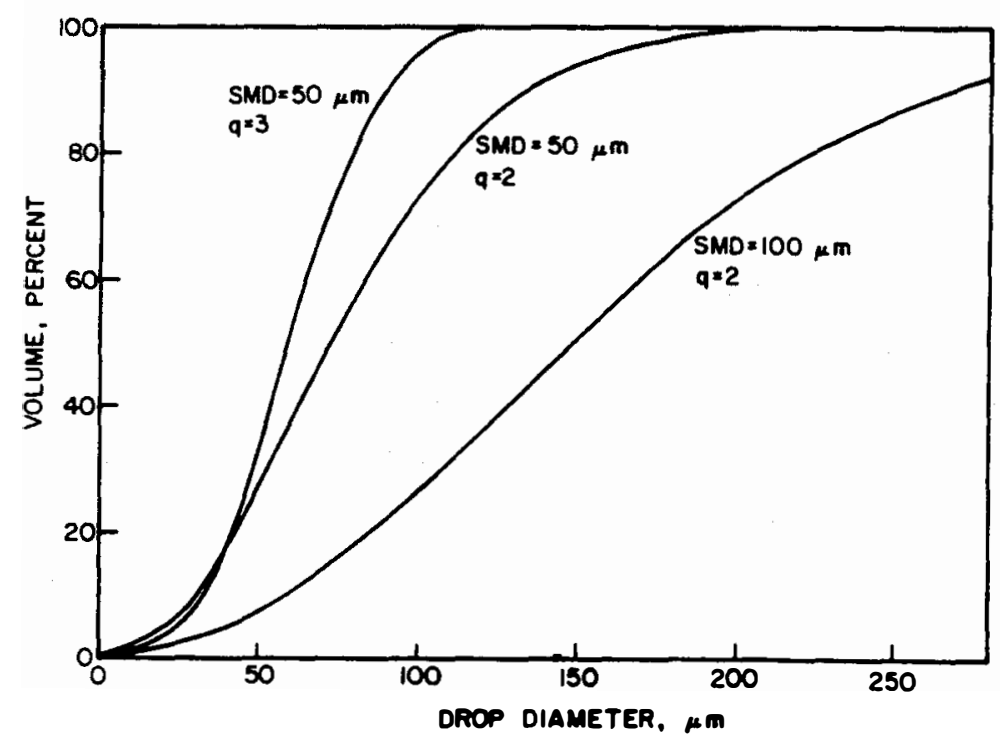

FIGURE 3b. Cumulative Volume Distribution in a Fuel Spray (Ref. 45) 
Air blast atomizers are generally considered to be less sensitive to viscosity, and hence to fuels, than pressure-swirl atomizers.

In addition to drop size, the evaporation rate is affected by the boiling point of the fuel since higher droplet temperatures must be reached before these higher boiling materials can evaporate. This was shown earlier in Figure 2.

\subsubsection{Ignition}

Ignition requirements for stationary gas turbines are much simpler than for aircraft turbines because there is no need for altitude relight at extremely low temperature and pressure conditions. Also, the light off time is not as critical except to prevent a collection of fuel in the combustor which could burn uncontrolled or explode once ignition is achieved.

Experimental studies have shown that with conventional distillate fuels at standard temperature, combustor performance characteristics such as ignition, lean blowout, and combustion efficiency can be adequately correlated with simply the fuel viscosity, i.e. atomization.(29) At cold temperatures, however, fuels with high volatility have better ignition characteristics. A similar data base for heavy fuels that would be applicable to the pyrolysis liquids was not found in the literature.

\subsubsection{Flame Stabilization}

Gas turbines are designed to maintain stable combustion over a wide range of conditions from idle, where temperatures are relatively low, to full power, where temperatures are high and air-fuel mixing much more complete. Blowout can occur either because the fuel-air ratio is too rich or because it is too lean. Generally it is the lean blowout condition that is of concern in gas turbines where the fuel flow is suddenly reduced to cut power but the air flow remains high until the engine speed drops. Industrial combustors have little problem with stability because the low air flow velocities are conducive to stable combustion, but there can be problems when transitioning from a start-up fuel to the operating fuel if there is a significant difference in flame temperatures and burning rates.

For the combustion of liquid fuels, the major parameters affecting the stability limits are the inlet air temperature and pressure, the flow velocity, the atomization, and the fuel volatility. As previously discussed, these last two determine the evaporation and burning rate of the fuel. 
Thus, fuels with low viscosity and high volatility would be expected to permit stable operation at leaner conditions than high-viscosity, low-volatility fuels such as pyrolysis liquids.

Gases generally have poorer lean limits than liquid fuels, and the lower the energy content of the fuel, the narrower the limits. (7) This is because the flame temperatures are lower and the flame speed of the gas is reduced. The exception to this is that gases which contain a significant amount of hydrogen can have very high flame speeds.

\subsubsection{Combustion Efficiency}

Combustion efficiency is very important in gas turbines not only because poor combustion efficiency is a waste of fuel, but also because it is manifested in the exhaust of unburned hydrocarbons and $\mathrm{CO}$. Typically gas turbines operate at design conditions with combustion efficiencies of better than 99 percent. From the fuel standpoint, it is necessary that the fuel be atomized and evaporated, in the case of liquids, mixed with the air, and burned in a time scale that is less than the residence time in the combustor.

\subsubsection{Exhaust Emissions}

The exhaust emissions of concern are hydrocarbons, carbon monoxide, and the oxides of nitrogen. It is obvious from the preceding discussion that the first two are increased by fuels with higher viscosity and boiling range; $\mathrm{CO}$ and hydrocarbons are highest at idle conditions when temperatures are lower and mixing is less efficient.

The oxides of nitrogen, $\mathrm{NO}_{\mathrm{x}}$, found in gas turbine exhausts are related to high temperature combustion rather than incomplete combustion; for this reason, $\mathrm{NO}_{\mathrm{x}}$ is highest at full power when the combustion temperature is the highest. The nitrogen can either come from the atmosphere or from contaminants in the fuel. Other significant fuel effects are confined to effects on flame temperature.

\subsubsection{SOOT FORMATION}

In the primary zone of a gas turbine combustor, large amounts of free carbon or soot are formed during the initial stages of the combustion process. Almost all of this soot is consumed in the secondary zone, with only perhaps two percent or less escaping in the form of exhaust smoke. The soot particles in the primary zone are essentially at the flame temperature and act as black-body radiators; as such, they can be responsible for a significant amount of the heat load 
to the combustor liner.

The fuel can affect the formation of soot. The fuel property which most closely correlates with soot formation in gas turbine combustors is the hydrogen-carbon ratio, even if the fuel contains water or significant amounts of oxygen.(30,31) Since distillate fuels are composed almost entirely of hydrogen and carbon, this is usually simplified to just the hydrogen content which can be directly measured. General Electric bases its specification for combustion quality on hydrogen content and requires a minimum of 12.8 wt percent. (21)

\subsubsection{Liner Durability}

As the hydrogen content decreases and more soot is formed, there is a corresponding increase in flame radiation and liner temperature. This increase in liner temperature has been shown to significantly reduce the low-cycle thermal fatigue life of combustor liners, the major cause of liner failure.(40) (Thermal fatigue is caused by repeated heating and cooling and results in crack formation much like the cracks which form in metals that are mechanically fatigued by repeated bending. In gas turbine operation, the time from startup to shutdown constitutes one thermal cycle for the combustor; steady-state run time causes very little damage.(47))

Blazowski has developed a generalized correlation parameter for the effects of hydrogen content on the increase in liner temperature:

$$
\mathrm{B} \equiv \frac{T_{L}-T_{L O}}{T_{L O}-T_{3}}
$$

where: $\quad T_{L}=$ the liner temperature on the test fuel

$\mathrm{T}_{\mathrm{Lo}}=$ the liner temperature on the base fuel

$\mathrm{T}_{3}=$ combustor inlet temperature

This parameter assumes that when changing fuels, the fuel-air mixing does not significantly change and the convective heat load to the liner remains constant. Figure 4 illustrates the use of this parameter to correlate the effects of hydrogen content on liner temperature rise for a number of engines. The upper set of data points are for a several older engines with rich primary zones. Modern "smokeless" combustors have a lower sensitivity to hydrogen content which is also shown. To put this into perspective, a good quality jet fuel has 


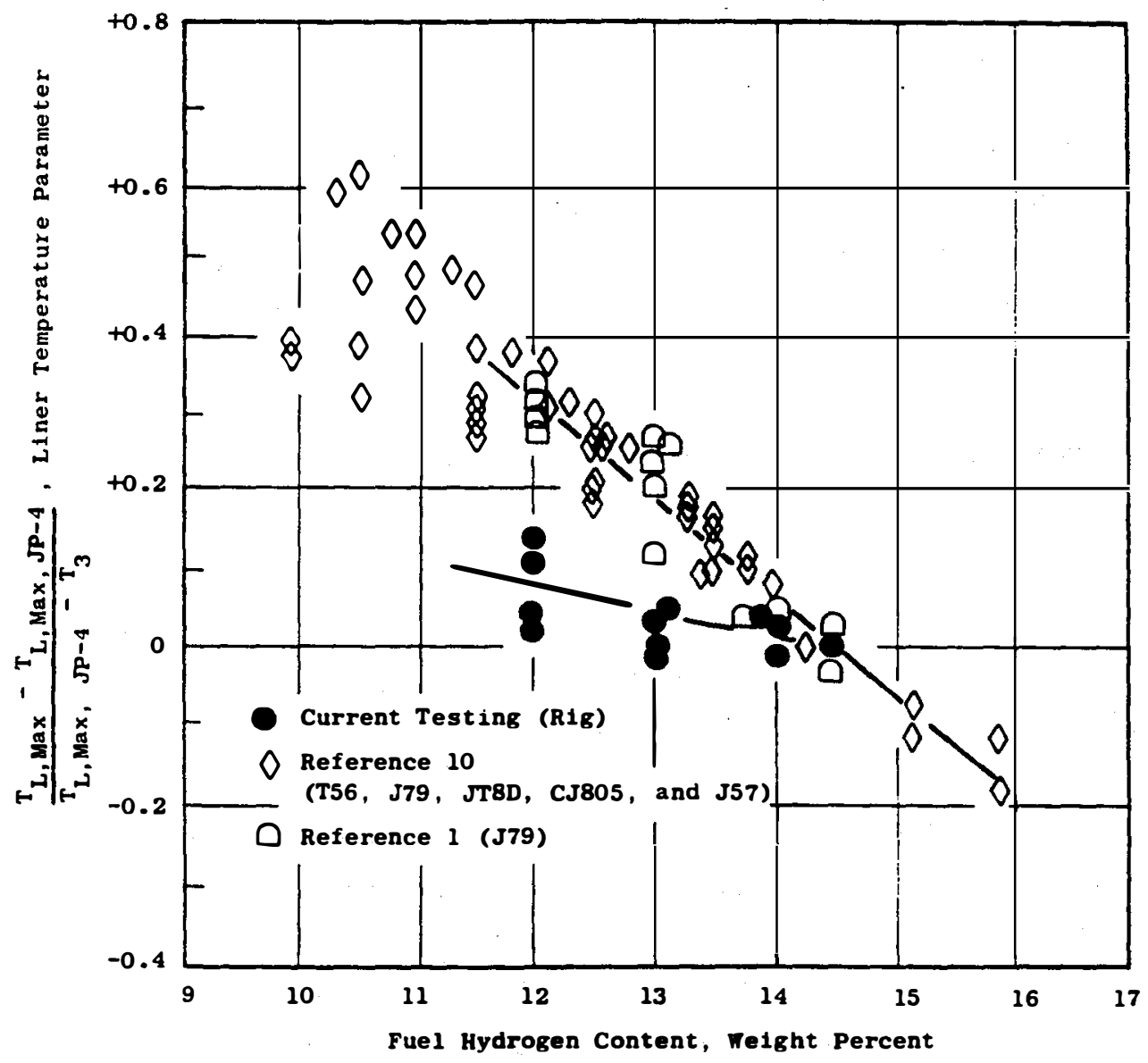

FIGURE 4. Effect of Fuel Hydrogen Content on Liner Temperature Parameter (Ref. 39) 
a hydrogen content of around 14 wt percent. A typical diesel fuel might have a hydrogen content around $13 \mathrm{wt}$ percent. This reduction of $1 \mathrm{wt}$ percent can have a significant effect on liner life as illustrated in Figure 5.(40) In this figure, "LCF Life" is the low-cycle thermal fatigue life where one cycle is related to one startup and shutdown. A correlation of results from 11 different engines is shown in Figure 6; this shows that an increase of $10^{\circ} \mathrm{K}$ in liner temperature can result in a 13 percent decrease in liner life.(40)

\subsubsection{Exhaust Smoke and Particulates}

As might be expected, reductions in hydrogen content are also manifested by increases in exhaust smoke and particulates. This is illustrated quite well in Figure 7 which contains data from six different engines.(7) It is expected that the presence of tar and char would increase this even further. The effect would be less in industrial combustors with their longer residence times for tar and particulate burnout.

\subsection{DEPOSITION, EROSION, AND CORROSION}

This problem area will be shown to be the major technical barrier in the utilization of biomass fuels because of their high alkali and ash content. A thorough treatment on this topic is therefore warranted, and is provided as Appendix A: Corrosion, Erosion, Deposition, and HighTemperature Coatings. Only the highlights will be addressed here.

Deposition, erosion, and corrosion all result from materials in the hot gas stream from the combustor being delivered to the surface of the turbine blades and guide vanes. These materials can be either in the solid, liquid, or gaseous state. There are several mechanisms for this delivery, with the dominant mechanism depending on the size or state of the material.(32). The dominant mechanism for particles larger than a few microns is inertial impaction. The result of the impaction can lead to either deposition, erosion, or corrosion depending on the nature of the material and the temperature.

\subsubsection{Deposition}

The highest deposit buildup rates are caused by the impaction of molten ash or condensed liquid phases because of their high sticking coefficient; these are also the most difficult to remove. (32) Figure 8 illustrates the effect of particle size on impingement of blades and vanes. Because of the high flow rates in gas turbines, even small ash concentrations result in a lot of 


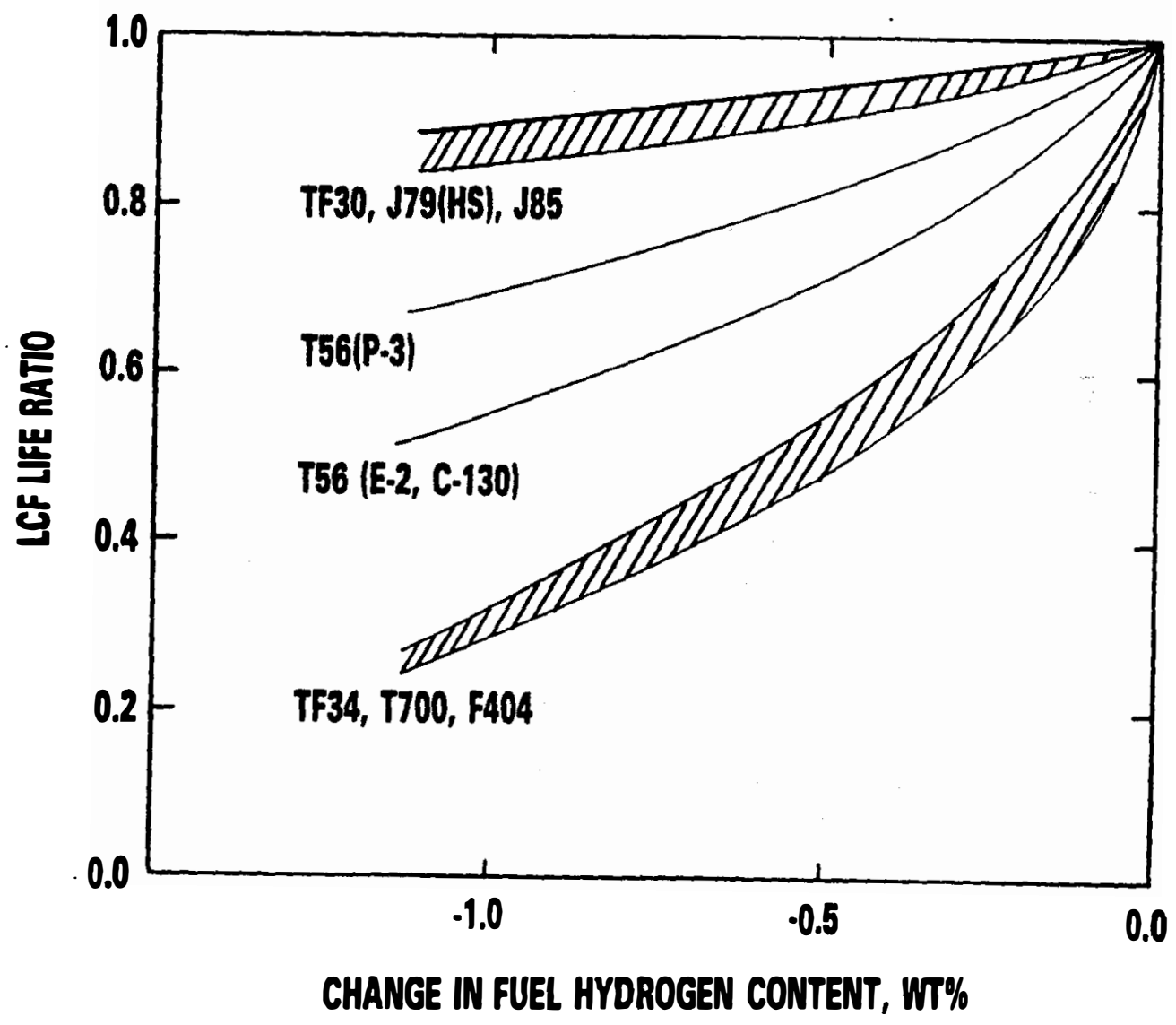

FIGURE 5. Ef fect of Fuel Hydrogen Content on Liner Life (Ref. 40) 


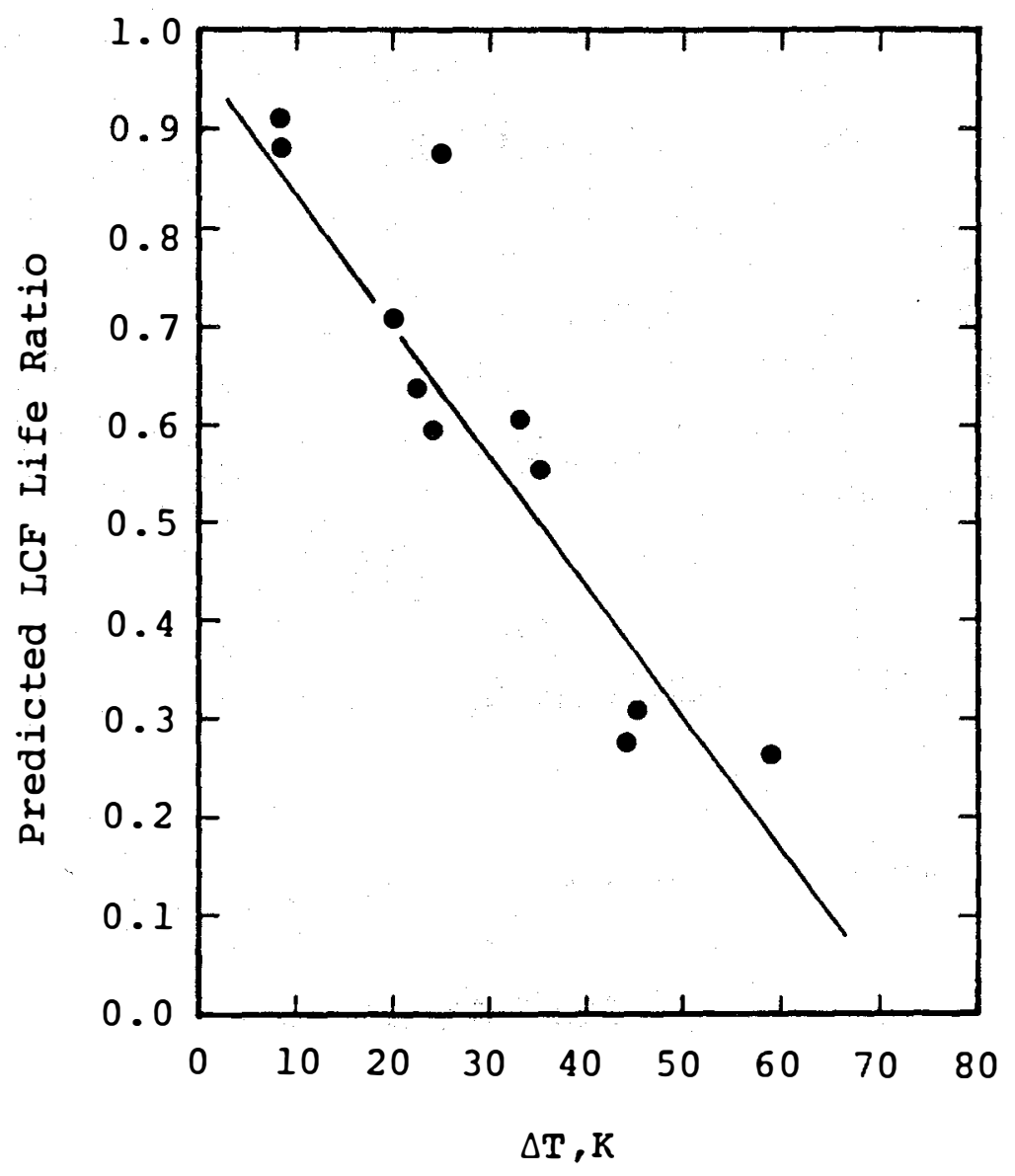

FIGURE 6. Effect of Liner Temperature Increases on Liner Life (Ref. 40) 


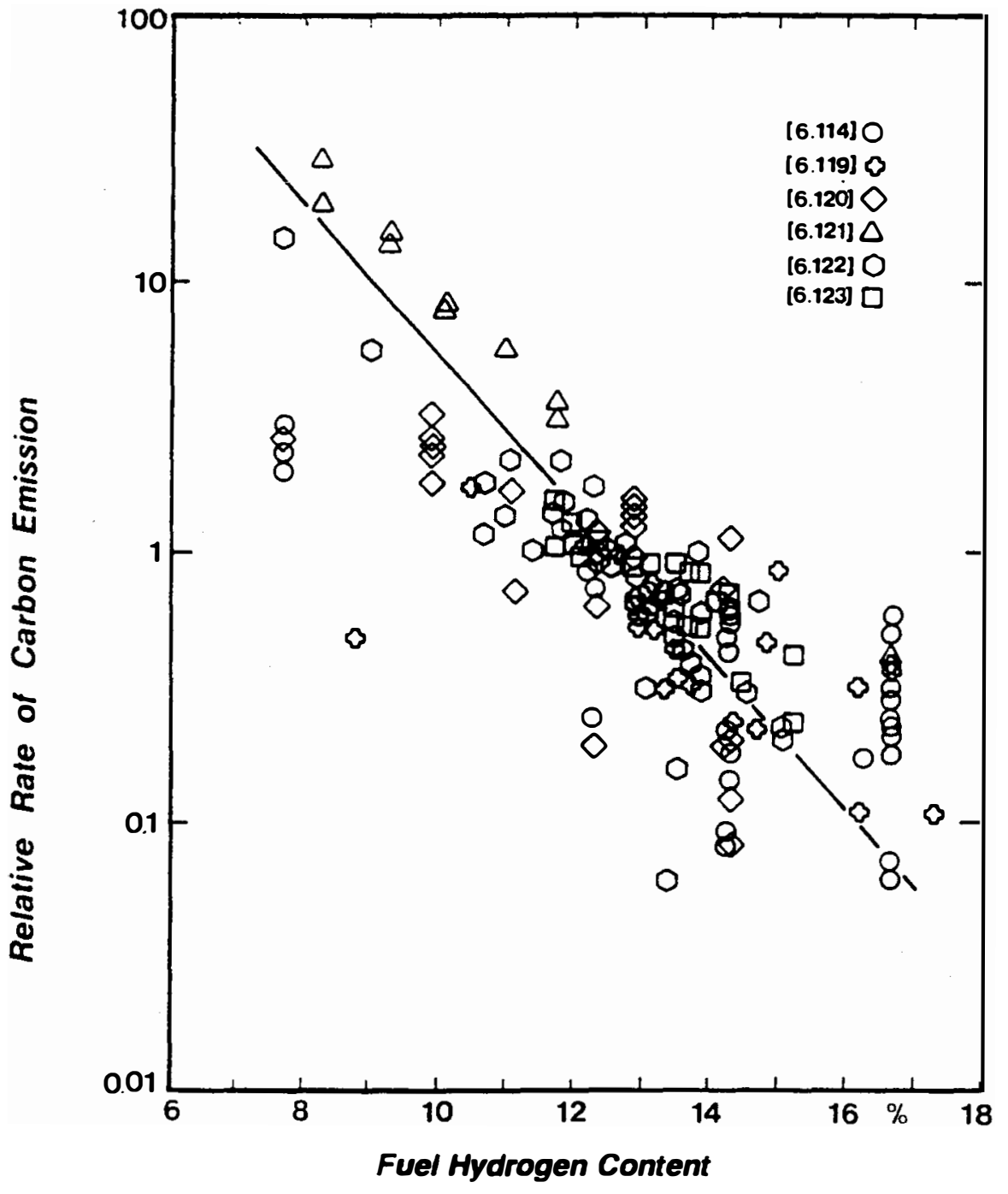

FIGURE 7. Effect of Fuel Hydrogen Content on Exhaust Particulates (Ref. 7) 


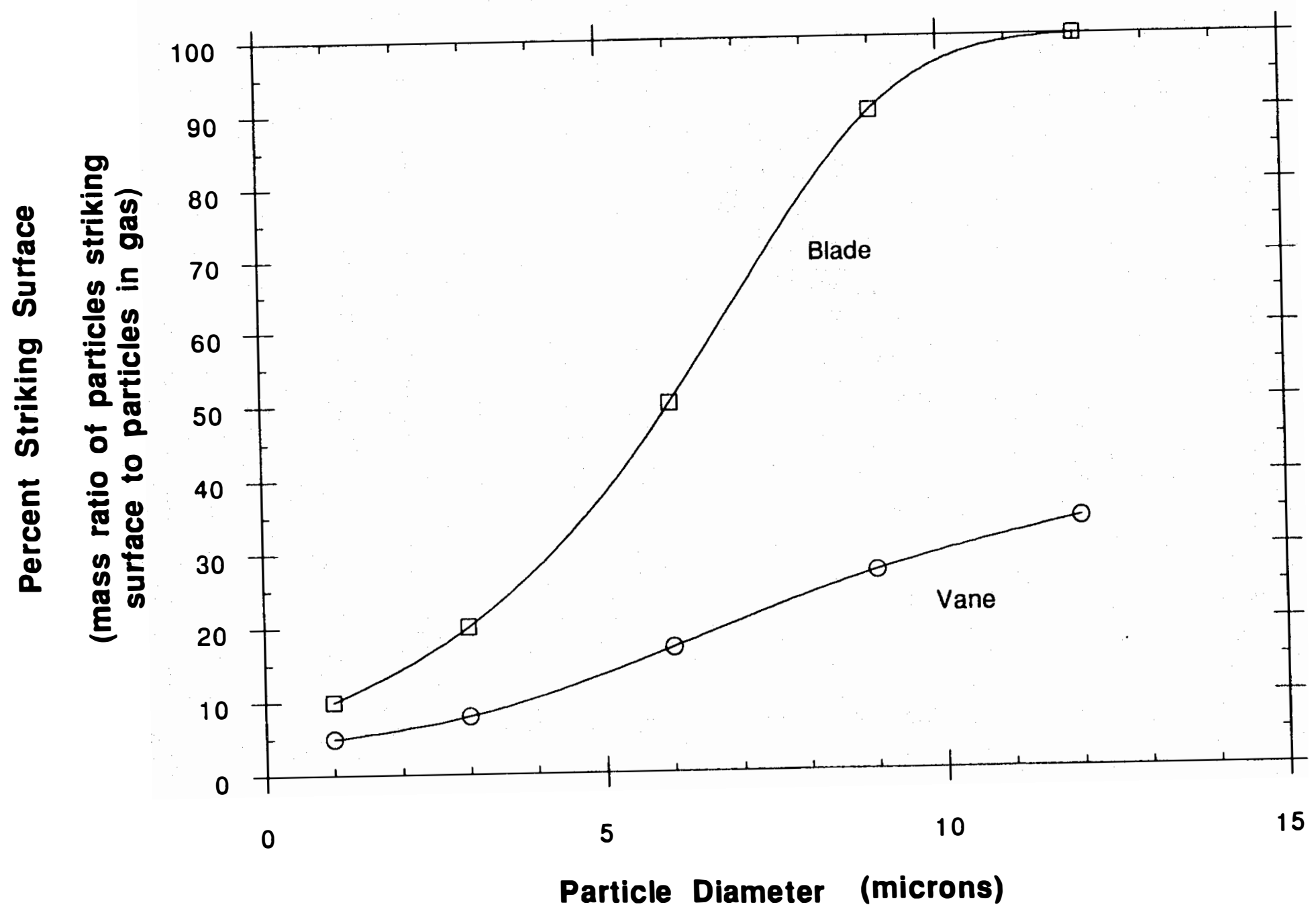

FIGURE 8. Effect of Particle Size on Impingement of Particles on Airfoils (Ref. 41) 
material to consider. In a 50MW machine, burning a fuel with 0.5 percent ash could result in about 1.5 tons/day of ash flowing through the turbine. Deposit buildup blocks the flow passages and reduces the efficiency of the turbine section. Considering this example for the flow shown in Figure 9, if only 10 percent of particles adhered to the vane, the result would be a 20 percent blockage of the flow area in less than 10 hours requiring shutdown and cleaning.(32) Smaller turbines would require even more frequent cleaning because the flow passages are smaller.

\subsubsection{Erosion}

If the gas temperature is lower than the melting point of the particle, the impaction of solid particles can cause erosion depending on the abrasiveness of the material. Figure 10 shows the effect of particle size on erosion rate for the blades shown in Figure 8. Smaller particles follow the streamlines more closely and do not impact. Some studies have shown that to maintain a lifetime on the order of 10,000 hours, a turbine can accept on a continuous basis only a very small fraction of particles larger than 10 microns, probably less than 1 to $5 \mathrm{ppm}$. (32)

\subsubsection{Hot Corrosion}

Hot corrosion is usually associated with liquid phase reactions on the blade surface. There are two basic types of hot corrosion that occur in different temperature regimes as illustrated in Figure 11. High-temperature hot corrosion, Type I, occurs between $1500^{\circ} \mathrm{F}$ and $1750^{\circ} \mathrm{F}$ when sulfur is present along with sodium or potassium. In the hot gas stream, the alkali sulfates are formed which, when deposited on the surface, destroy the protective oxide layer. This allows sulfidation and oxidation to occur which results in rapid destruction of the surface. Low-temperature hot corrosion, Type II, is caused by the reaction of alkali sulfates with the elements of the alloy as well as the coating.

\subsubsection{Corrosion Control}

Since it is the alkali sulfate that are responsible for high-temperature hot corrosion on blade alloys, the attack is controllable by removal of either the sulfur or the alkali.

Figure 12 illustrates the effect of sulfur concentration on corrosion rate; this data shows that the sulfur concentration needs to be in the range of 1 to $4 \mathrm{ppm}$ to significantly reduce hot corrosion in the presence of alkali. Typical sulfur concentrations in distillate fuels are 0.1 to 0.3 percent, and the removal of sulfur to these lower levels is more expensive than removing the alkali. 


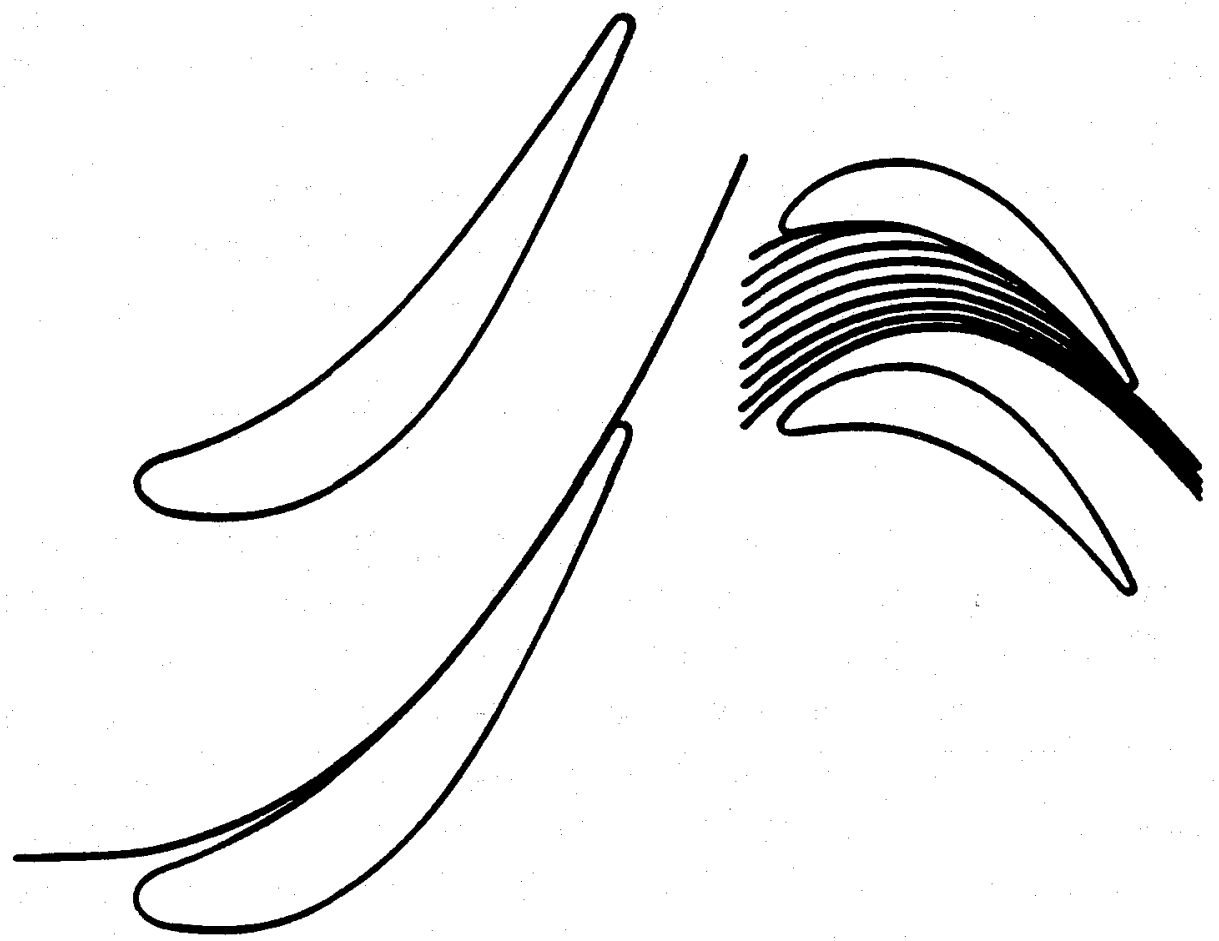

FIGURE 9. Trajectories of 6um Size Particles Through the First Stage of a 50Mw Turbine (Ref. 41) 


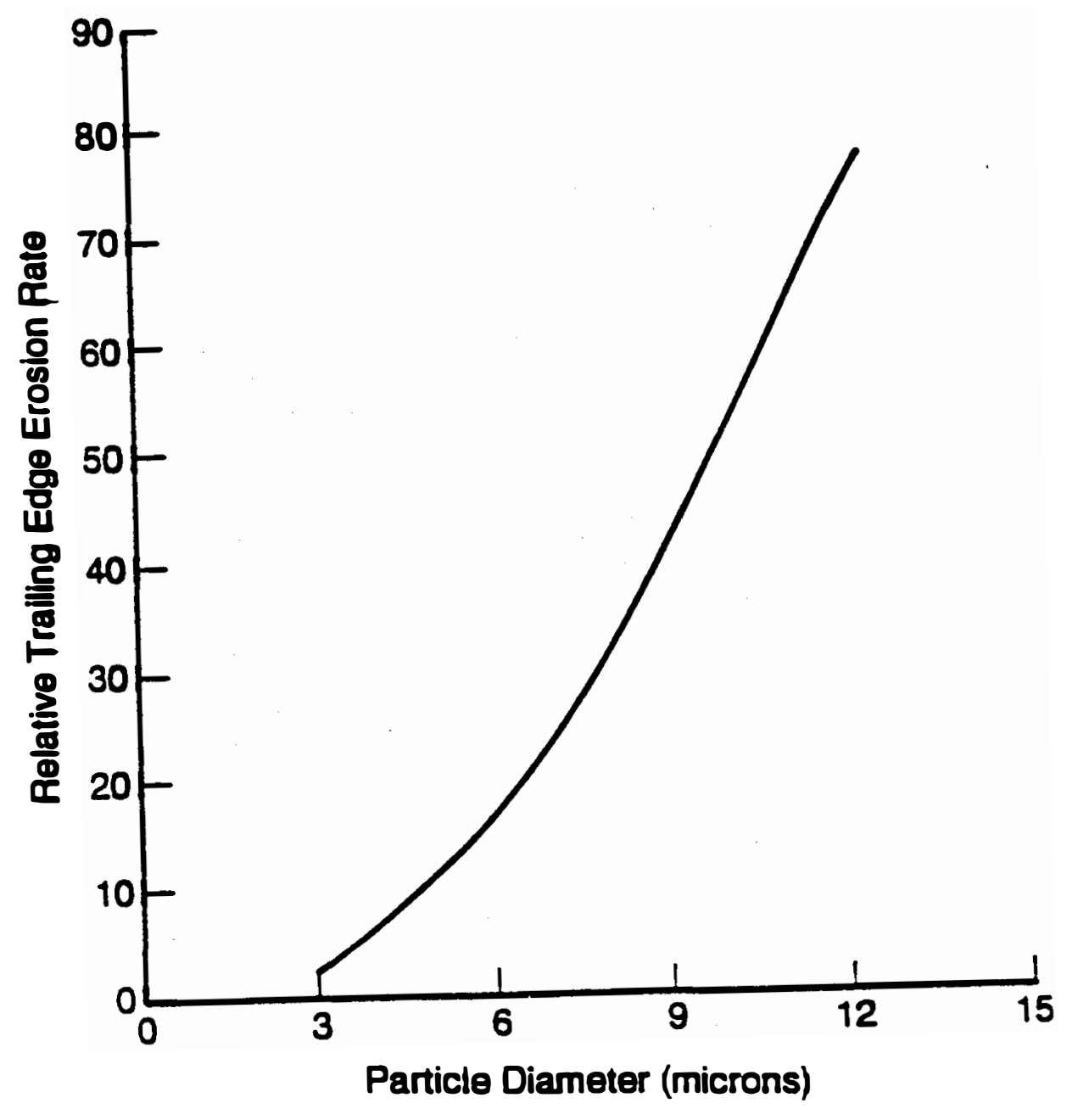

FIGURE 10. Relative Trailing Edge Erosion Rate on First Rotor of a $50 \mathrm{Mw}$ Turbine (10:1 pressure ratio) (Ref. 32) 


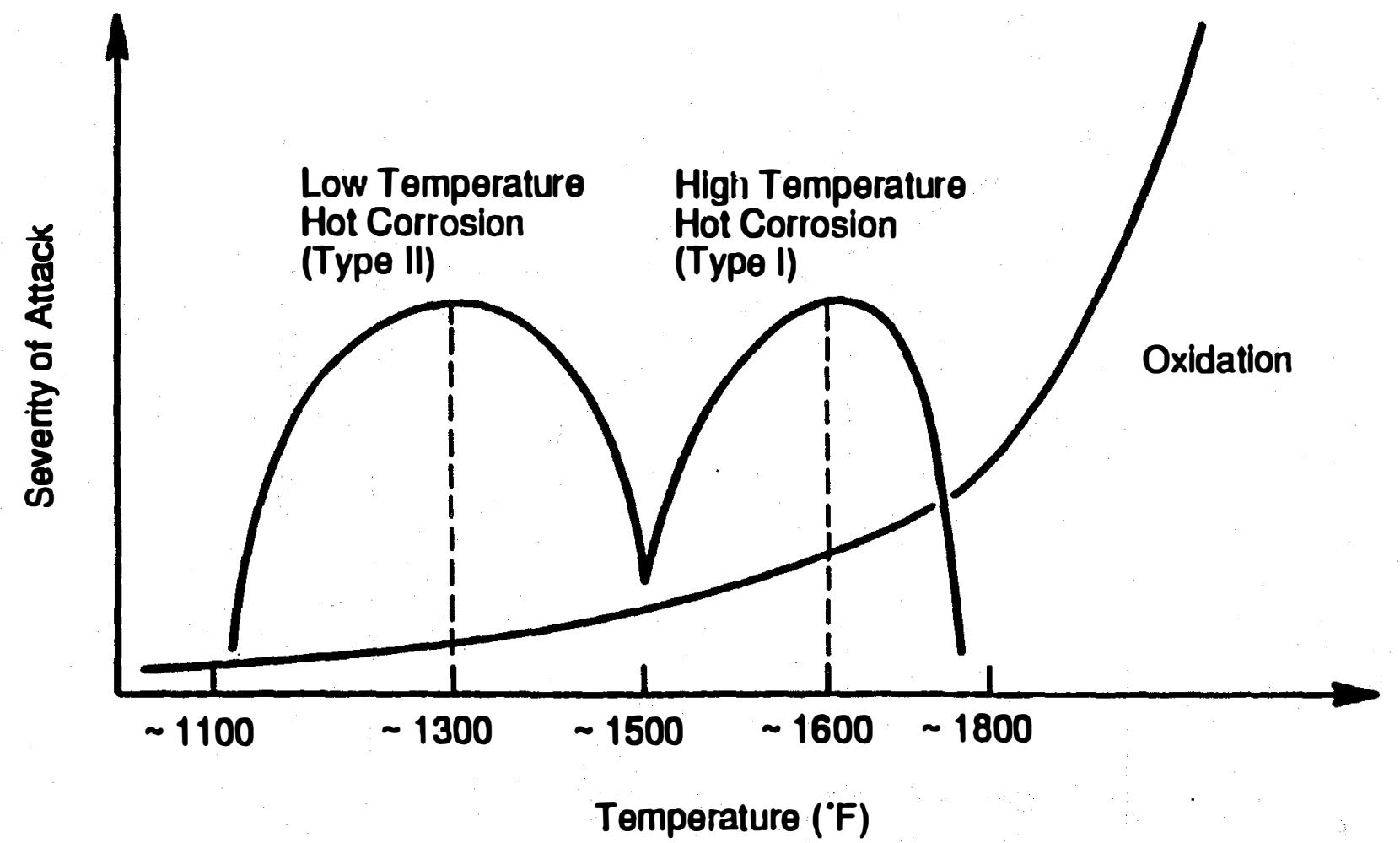

FIGURE 11. Temperature Effects on Hot Corrosion of Turbine Blades and Vanes (Ref. 42) 
Aluminlde Coating

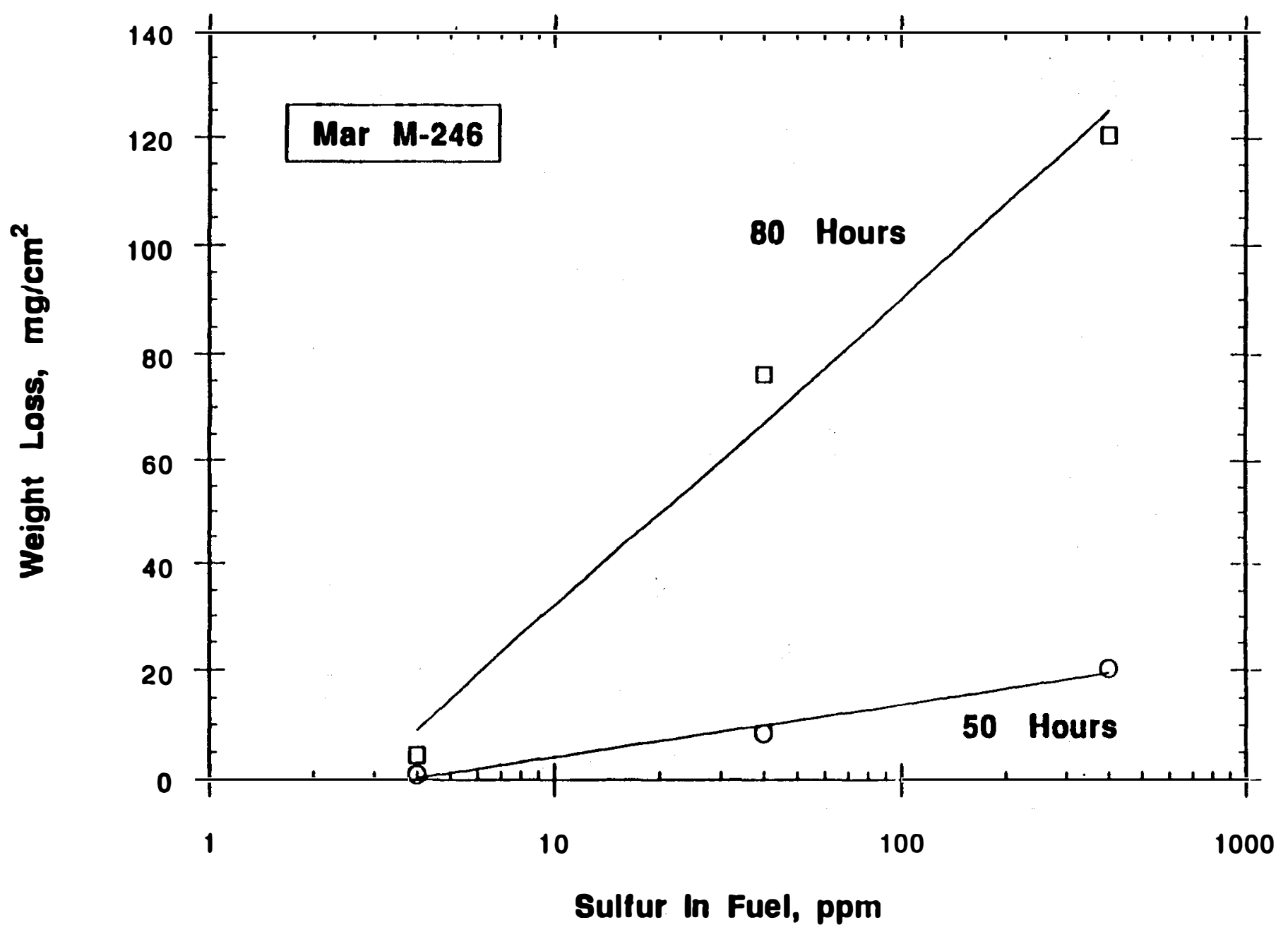

FIGURE 12. Effect of Fuel Sulfur Content on Corrosion 
The common method of removing alkali from fuel is by water washing. In distillates the alkali content is generally negligible, but in fuels containing residual fraction, it can be well over $100 \mathrm{ppm}$. This can be reduced to 0.5 to $1 \mathrm{ppm}$ by water washing. The alkali salts are readily soluble in water, and the water is easily separated from the fuel by gravity or by centrifuge.

Coatings have been developed to protect the blades from hot corrosion as well as oxidation (see Figure 11), but the composition depends upon the alloy being protected and the temperature regime. These coatings are meant to be sacrificial and have to be periodically replaced in order to maintain protection. Coatings are generally not designed for protection against calcium since it is not generally found in hydrocarbon fuels, and calcium has been found to diff use through some coatings which are effective against sodium and potassium attack.

\subsubsection{Effects of Chlorine on Corrosion}

The presence of chlorine, as alkali chlorides, in the hot gas flow has been shown to accelerate the high-temperature corrosion and oxidation of blades and vanes. Protective coatings typically involve a thin, but dense, external layer of aluminum oxide, $\mathrm{Al}_{2} \mathrm{O}_{3}$, which is formed in-situ by the oxidation of the coating.(51) At concentrations of 10 and $130 \mathrm{ppm}, \mathrm{NaCl}$ has been found to modify the oxidation process so that whiskers of $\mathrm{Al}_{2} \mathrm{O}_{3}$ are formed rather than the desired dense coating.(51) At concentrations of less than $1 \mathrm{ppm}, \mathrm{NaCl}$ has been found to degrade existing $\mathrm{Al}_{2} \mathrm{O}_{3}$ coatings by promoting spallation.(51,52) Unlike alkali sulfates which act in the liquid phase, alkali chlorides have been found to act in the vapor phase.(50,51) Quantitative effects on life were not found.

In addition to corrosion, $\mathrm{NaCL}$ has also been shown to affect the mechanical strength of superalloys at elevated temperatures. Paton et al found reductions in tensile strength and increases in creep rate of six pertinent alloys following exposure to $\mathrm{NaCl}$; however, the surface of the specimen was coated with $\mathrm{NaCl}$, and the stresses were much higher than are typically found in turbine blades.(49)

It should be noted that in both of the above effects, the results on are specific to the material and environment tested; no general rules on limiting chlorine have been developed. Therefore, additional confirmation is needed on the quantitative effects of alkali chlorides on blade/vane durability before generalizing to conditions of biomass-fueled systems. 


\subsection{Summary}

It is evident that there are many areas where fuel properties affect the performance and durability of gas turbines and the supporting systems for the storage and handling of fuels. As a result, fuel specifications have been developed to prevent problems and also assure the availability of quality fuels at a reasonable price. This is true for both gases and liquids.

Most gas turbines have been designed to operate on either distillate fuels or natural gas. These fuels are clean and free of alkali and ash. Other important properties such as heat content, viscosity, boiling range, and hydrogen content are maintained within in a fairly narrow range compared to the wide range of fuels that actually exist.

The use of alternate fuels of lower quality is a tradeoff of fuel cost and maintenance. Usually design modifications are required to minimize the durability effects while maintaining performance. 


\subsection{GASEOUS FUELS FROM BIOMASS}

\subsection{BIOMASS GASES}

Gasification of biomass is a thermal decomposition process of the material in the presence of a limited supply of air, i.e., partial oxidation, to produce combustible fuel gases. When this process takes place in air, the product fuel gas consists primarily of carbon monoxide (CO), hydrogen $\left(\mathrm{H}_{2}\right)$, and volatile organics plus water, carbon dioxide $\left(\mathrm{CO}_{2}\right)$, nitrogen $\left(\mathrm{N}_{2}\right)$ as diluents. The quantity of hydrogen can be increased by adding steam to the air. Because of the diluents, the heating value of this fuel is relatively low, typically around $200 \mathrm{Btu} / \mathrm{scf}$ or less. This puts it in the category of "low Btu gas". If oxygen is used instead of air, the nitrogen is eliminated and the heating value is increased to around $350 \mathrm{Btu} / \mathrm{scf}$ putting it in the category of "medium Btu gas". Depending on the feedstock, there will be some pyrolysis liquid generated along with tars, char, and ash. These are supposed to be removed, but can be carried over with the gas as contaminants.

Table 3 provides a summary of the characteristics of a number of biomass gases from different gasifier concepts.(5) Table 4 presents properties of sample gases from both a direct and an indirect fired gasifier operated at different temperatures to show the variation in properties with operating condition. This set of properties also provides quantitative values of the contaminants, tar and char; while these are a concern by themselves, it is also important to know the size of the char and if it contains alkali.

Table 5 presents a summary of gaseous fuels that have been used or considered for use in gas turbines. Natural gas is the most common gaseous fuel, and is the reference fuel for properties of other gases. From this one can see that not all medium- and low-Btu fuels are alike, and the biomass gases can have some of the poorest combinations of low hydrogen and high diluents.

To the engine manufacturer, the properties that are of most concern for the biomass gaseous fuels are the following:

- Energy content, Btu/scf (lower heating value)

- Composition (including condensibles)

- Gas temperature and pressure

- Water content 
TABLE 3. EXAMPLES OF CHARACTERISTICS OF BIOMASS GASES

\begin{tabular}{|c|c|c|c|c|c|c|}
\hline & \multicolumn{5}{|c|}{ Gas Composition, dry basis, vol\% } & \multirow{2}{*}{$\begin{array}{c}\mathrm{HHV} \\
\mathrm{MJ} / \mathrm{m}^{3} @ \\
15^{\circ} \mathrm{C} \\
\end{array}$} \\
\hline & $\mathrm{H}_{2}$ & $\mathrm{CO}$ & $\mathrm{CO}_{2}$ & $\mathrm{CH}_{4}$ & $\mathrm{~N}_{2}$ & \\
\hline Typical Air-Blown Updraft & 11 & 24 & 9 & 3 & 53 & 5.33 \\
\hline Typical Air-Blown Downdraft & 17 & 20 & 13 & 3 & 47 & 5.58 \\
\hline Typical Air-Blown Fluidbed & 9 & 14 & 20 & 7 & 50 & 5.40 \\
\hline Oxygen-Blown Downdraft (SERI) & 32 & 48 & 15 & 2 & 3 & 10.37 \\
\hline Oxygen Donor Fluidbed Gasifier & 31 & 38 & 14 & 12 & 5 & 12.82 \\
\hline Pyrolysis, Horizontal Moving Bed & 20 & 25 & 17 & 21 & 17 & 13.33 \\
\hline Multi-Solid Fluid Bed (Battelle) & 15 & 47 & 15 & 23 & 0 & 16.11 \\
\hline $\begin{array}{l}\text { Twin Fluidised Bed Steam } \\
\text { Gasification (Ebara) }\end{array}$ & 31 & 48 & 0 & 21 & 0 & 17.41 \\
\hline
\end{tabular}

Source: Reference 5 


\section{TABLE 4 \\ SAMPLE BIOMASS GASIFICATION PRODUCTS \\ FROM AN OXYGEN BLOWN GASIFIER}

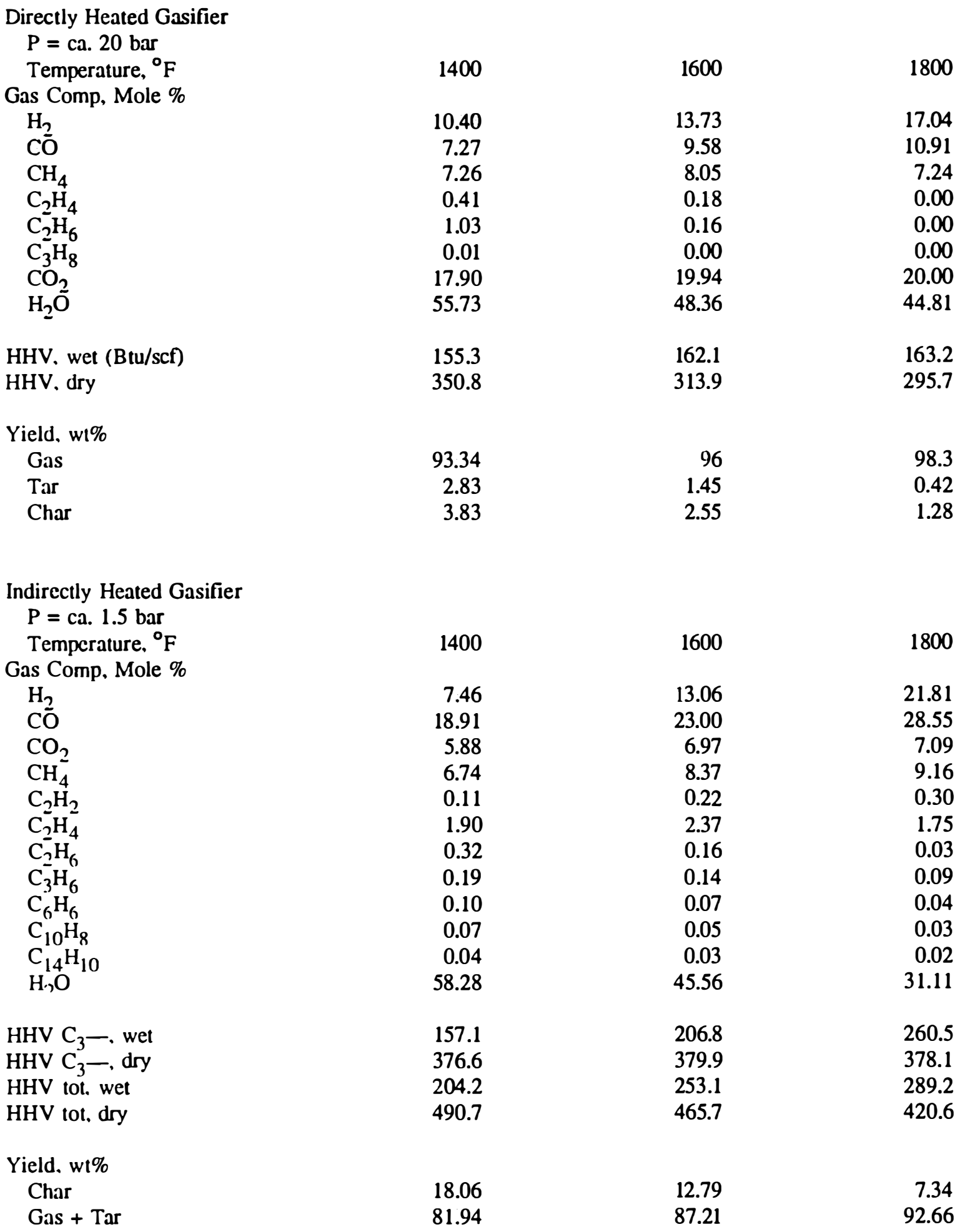

Source: R. Bain and T. Milne. NREL. August 21, 1992 
TABLE 5. COMIPOSITION ANI) PROPERTIES OF VARIOUS GASEOUS FUELS

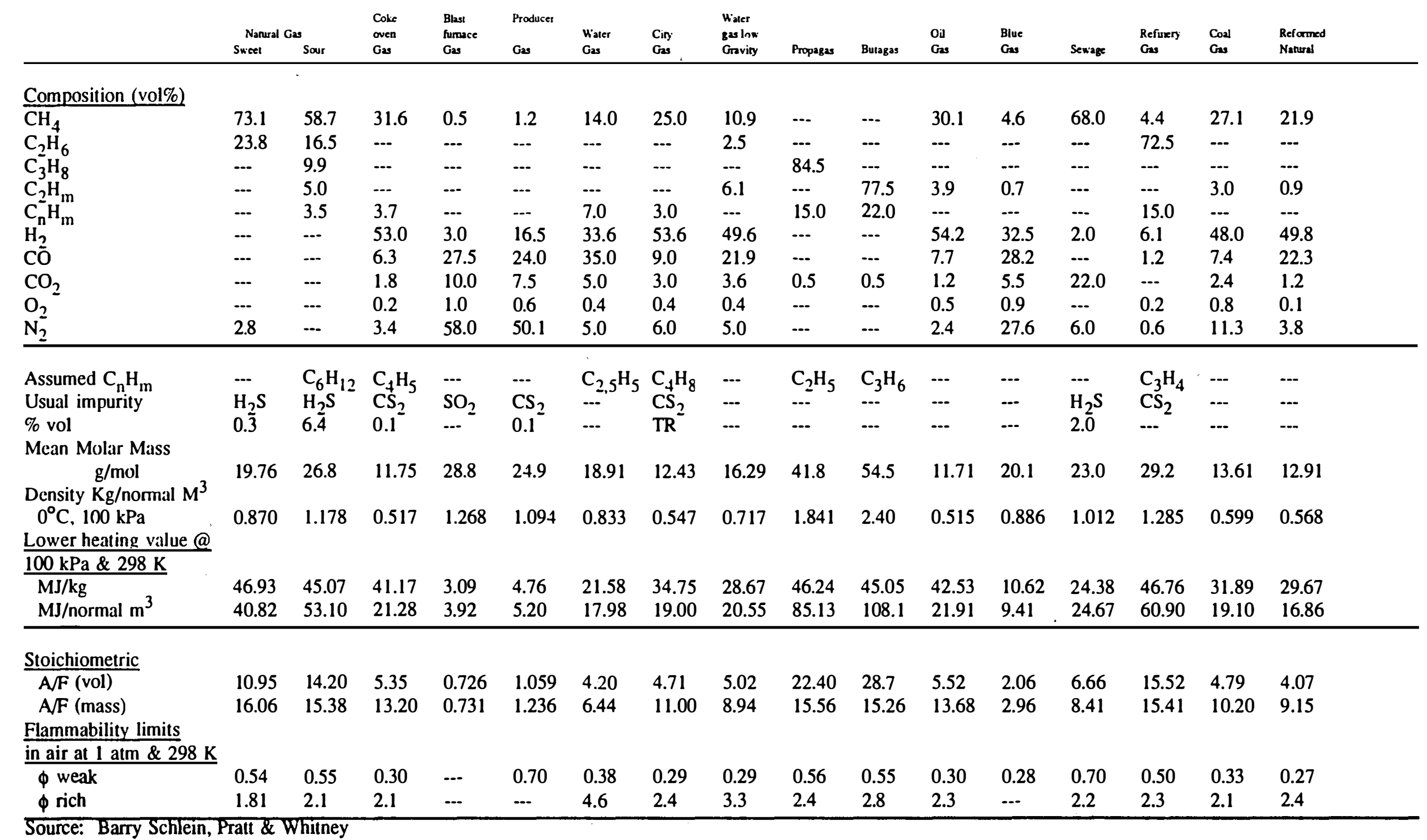

Source: Barry Schlein, Pratt \& Whitney 
- Flammability limits

- Contaminants

- Char

- Tar

- Alkali (may be contained in the char)

Comparison of biomass gases with natural gas is awkward in some important areas because the data are not always reported. For example the water and $\mathrm{CO}_{2}$ content of the gases in Table 4 is extremely high while the source for the data in Table 3 only reported properties on a dry basis. The combustibles in the biomass gases are primarily $\mathrm{CO}$ and hydrogen along with a small amount of $\mathrm{CH}_{4}$. Also, energy content is generally reported as "higher heating value" for biomass gases, whereas "lower heating value" is more relevant to gas turbine efficiency calculations since the water going through the turbine will be in the vapor phase.

\subsection{EVALUATION OF PROPERTIES OF BIOMASS GASES}

\subsubsection{Energy Content}

The energy content is much more important in gaseous fuels than with liquid fuels since the variation among gases is much greater. It not only determines the size of the fuel system components including the injectors, but it serves as a good indicator of the difficulty in using the fuel in a gas turbine. The energy content along with the composition determine the flame temperature and hence the flammability and emissions characteristics.

Gaseous fuels are generally divided into three categories by their energy content roughly as follows:

- High-Btu gases, 600 - $1100 \mathrm{Btu} / \mathrm{scf}$

- Medium-Btu gases, 200 - $600 \mathrm{Btu} / \mathrm{scf}$

- Low-Btu gases, $100-200 \mathrm{Btu} / \mathrm{scf}$

Most industrial gas turbines in the United States were originally designed to operate on natural gas, No. 2 distillate fuel, or both. Aeroderivatives were originally designed to burn kerosene, but they have been successfully adapted to natural gas use. This dual fuel capability is due, in part, to the fact that natural gas does not significantly increase the mass flow through the turbine; also, the mixing and reaction rates are such that combustor lengths are satisfactory. 
Substitution of a fuel with different density and energy content can significantly affect the stability, efficiency, and emissions characteristics of the engine. The lower part of Figure 13 provides some insight on the design modifications which may be necessary at various levels of energy contents; the upper part of Figure 13 will be addressed in the next section.

Fuels of lower energy density require correspondingly higher flow rates to maintain the desired firing temperatures. The following size data for components in a fuel system for a GE MS5001 illustrates the significant increase in size for low-Btu gas:(44)

$\begin{array}{llc} & \begin{array}{l}\text { Normal } \\ \text { MS5001 }\end{array} & \begin{array}{c}\text { Low-Btu } \\ \text { MS5001 }\end{array} \\ & 3 \text { inch } & 10 \text { inch } \\ \text { Fuel Gas Manifold } & 1 \text { inch } & 4 \text { inch } \\ \text { Fuel Gas Pigtail } & 3 \text { inch } & 10 \text { inch }\end{array}$

Figure 14 illustrates how this fuel piping system might look.

For gas turbines with combustor cans that are more or less external to the housing, such large injector systems can be accommodated. However, in aeroderivative engines, the combustor(s) is contained within the housing, and size of the injector is severely limited. This can effectively limit the use of low-Btu gas for some engines.

In order to maintain adequate flow control over the entire range of operating conditions without impairing combustor operation, it is necessary to keep similar combustion conditions. To do this the fuels should have approximately the same energy release for a given pressure drop across the injector.(8) The Wobbe Index, WI, is one measure of the interchangeability of a fuel in a given fuel system. It is based on providing a constant heat input for a given pressure drop across the injector and is expressed as follows:

$$
\mathrm{WI}=\mathrm{LHV} /\left[\rho_{\mathrm{gas}}(\mathrm{P}, \mathrm{T}) / \rho_{\mathrm{air}}(\mathrm{P}, \mathrm{T})\right]^{1 / 2}
$$

This version of the definition takes into account compressibility effects which could be important when comparing biomass gases to other gases.(8) 


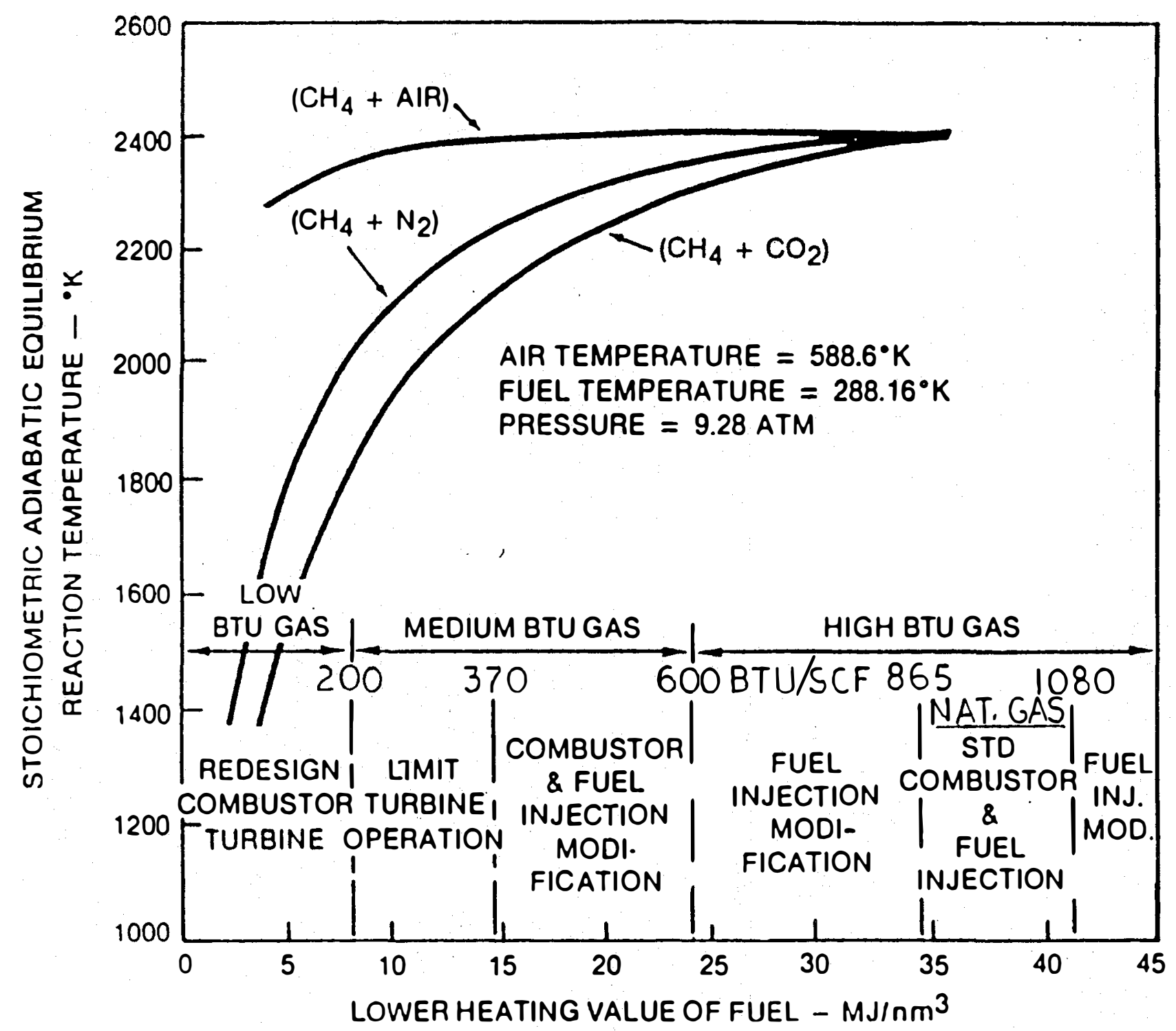

FIGURE 13. Effects of Energy Content of Gases on Flame Temperature and Combustor Design Modifications (Ref. 8) 


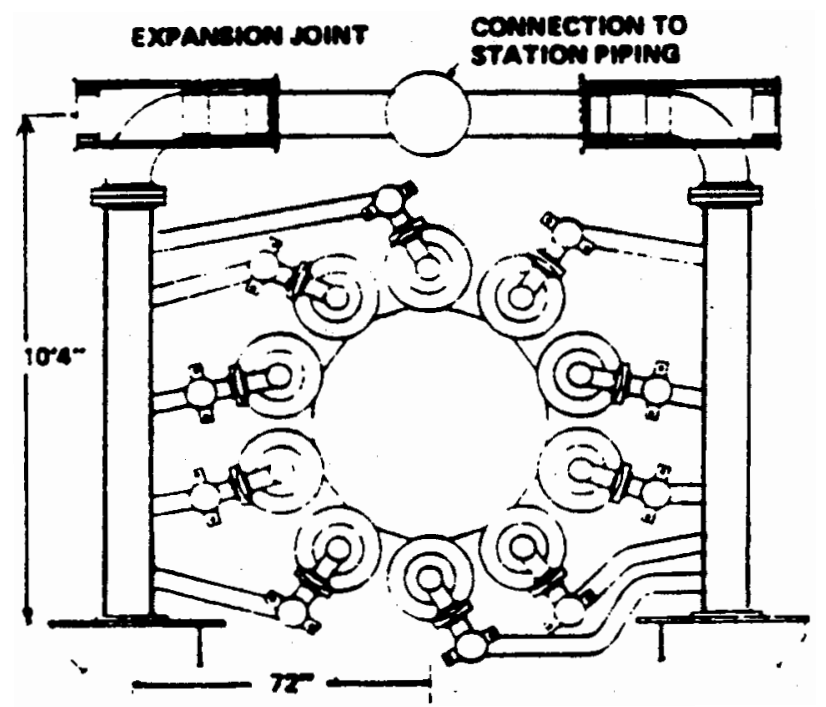

FIGURE 14. Fuel Piping System for a Low-Btu Gas Installation (Ref. 44) 
If fuels of differing Wobbe Index are used, the fuel valve may be the biggest problem; it is desirable to operate over 20-80 percent of the flow range of the valve for quick response and good metering. Standard fuel gas control systems are designed to handle variations in WI on the order of \pm 5 to \pm 10 percent without adjustments. This points out the need for a consistent fuel gas supply once the gas turbine system has been set up.

\subsubsection{Flammability Limits}

The major fuel factors affecting combustion stability are the rich and lean flammability limits, and in particular, the ratio of these limits.(10) The wider the flammability limits, the more likely the combustion will be stable at off-design conditions. This is particularly true at start-up conditions where mixing and combustion efficiencies are relatively poor.(14) If the limits are narrow, the machine will likely have to be started and shut down on natural gas or distillate. The concern then is unscheduled shutdowns or trips.

Generally gas turbines have narrower stability limits when burning gaseous fuels than when burming liquid fuels, and the lower the energy content, the narrower the limits.(7,13) An exception to this is when the fuel contains a significant amount of hydrogen, usually around 50 vol percent. $(7,11)$ Natural gas has a flammability ratio around 3 , depending on the exact composition. GE requires a flammability ratio of 2.2 for its aeroderivative machines.

The flammability limits of the biomass gases presented in Table 3 and 4 are not known. A high gas temperature will act favorably to lower the lean blowout limit, but high concentrations of diluents, such as water, $\mathrm{N}_{2}$, and $\mathrm{CO}_{2}$, are detrimental because they lower the flame temperature. The effect of diluents on flame temperature can be seen in the upper part of Figure 13.

\subsubsection{Emissions}

The emissions of concern are $\mathrm{CO}$ and $\mathrm{NO}_{\mathrm{x}}$. The adiabatic flame temperature is a useful parameter in evaluating fuel effects on these emissions.

Exhaust $\mathrm{NO}_{\mathbf{x}}$ from a gas turbine comes from three sources:

- Thermal $\mathrm{NO}_{\mathrm{x}}$

- Non-equilibrium or prompt NOx

- Fuel-bound nitrogen 
Of the first two, thermal $\mathrm{NO}_{\mathrm{x}}$ is dominant for combustors with near-stoichiometric primary zones. The formation of $\mathrm{NO}_{\mathrm{x}}$ from fuel-bound nitrogen can be important for biomassderived gases from an air-blown gasifier where ammonia can be formed. The conversion efficiency of ammonia to NO is greater than 50 percent.(15)

The formation of thermal Nox inside a gas turbine combustor follows the well-known Zeldovich reaction. $(15,1)$ The exponential effect of flame temperature on $\mathrm{NO}_{\mathrm{x}}$ formation is useful in comparing fuel effects. The following can be used:(14)

$$
\mathrm{NO}_{x}(1)=\mathrm{NO}_{x}(2) \exp \left[\frac{\mathrm{T}_{f}(1)-\mathrm{T}_{f}(2)}{250}\right]
$$

For reference, the adiabatic flame temperature of natural gas is about $2400 \mathrm{~K}$ or $3870 \mathrm{~F}$, depending on the exact composition. Not all low-Btu gases will have low $\mathrm{NO}_{\mathrm{x}}$; gases with high hydrogen content will have a higher flame temperature and $\mathrm{NO}_{\mathrm{x}}$ levels greater than that of natural gas. For the biomass gases it is safe to assume that the thermal $\mathrm{NO}_{\mathrm{x}}$ levels will be lower than natural gas.

Of more concern may be $\mathrm{CO}$ with low-Btu gases, both from an emission standpoint and for combustion efficiency. CO oxidation is relatively slow, and the low flame temperatures of these gases presents a potential problem when burned in existing combustors, especially aeroderivatives with their shorter residence time. One rule of thumb given was that the flame temperature should be above $2800^{\circ} \mathrm{F}\left(1880^{\circ} \mathrm{K}\right)$ to get satisfactory burnout. Alternately, a flame temperature of less than $3200^{\circ} \mathrm{F}$ is desirable to prevent thermal $\mathrm{NO}_{\mathrm{x}}$.

\subsubsection{Combustor Design}

When designed, the length of the combustion chamber is determined to provide the necessary volume and residence time to completely bum the fuel, and to provide adequate pressure drop to insure proper mixing of air jets. The position and penetration of the air jets is critical to adequate mixing not only for low emissions and smoke formation but also to control turbine inlet temperature.

In order to properly account for the change in mass flow for gaseous fuels of lower energy content, the lower heat of combustion by mass, LHVm, is compared. Gas turbines designed for kerosene or No. 2 distillate have been readily adaptable to natural gas because the 
lower heat of combustion is about $20,700 \mathrm{Btu} / \mathrm{Abm}$ compared to about $18,500 \mathrm{Btu} / \mathrm{hbm}$ for conventional liquid fuels. The fuel mass ratio, $\mathrm{Rm}$, is defined as the $\mathrm{LHVm}$ of methane divided by the LHVm of the subject gas. Increasing Rm means an increase in the gas flow through the turbine. Whereas natural gas accounts for only 1.5 to 2.0 percent of the flow, achieving the same firing temperature with a low Btu gas of $4000 \mathrm{Btu} / \mathrm{bm}$ requires five times more fuel mass flow, or 7.5 to 10 percent of the airflow.

This creates a flow mismatch between the compressor and the turbine and reduces the compressor stall margin. If this is addressed by bleeding off compressor discharge air so as to reduce the combustor airflow, then the pressure drop across the combustor is lowered which reduces the velocity of the air jets and their mixing effectiveness. Also the amount of air in the film cooling slots will be reduced which will result in increases in liner temperature.

For single-shaft turbines, such as industrial types, one effective approach is to open the first stage nozzle area in order to pass the additional gas flow through the turbine and restore the compressor surge margin. For two-shaft systems, the power-turbine nozzle area could be opened to correctly match the output of the gas producer to the turbine for maximum performance. For some systems, adjustments can be made in the turbine-nozzle area to accommodate fuels with $\mathrm{Rm}$ as high as 9 , but beyond that, either compressor air must be bled off or the turbine redesigned. (8) Different engine manufacturers may have different approaches to this depending on the individual engine design.

There's no question that a combustion system can be designed to burn low Btu gases; however, there isn't enough demand to make a new design economical, so conversion of existing equipment will be the likely approach. Dry, low- $\mathrm{NO}_{\mathrm{x}}$ combustors are less suitable to conversion to medium- and low-Btu gases than conventional combustors because they are much more sensitive to air-fuel mixing in order to achieve low $\mathrm{NO}_{\mathrm{x}}$ values. For a medium-Btu gas, the modifications to a conventional combustor would probably be limited to sizing the fuel system. For a low-Btu gas, some modifications to the combustor may be necessary to get the correct firing temperature, satisfactory stability, and acceptable emissions. After getting the fuel control and injectors sized, the air holes can be filled and new ones drilled to adjust the air flow splits. This would then be checked in a rig test to verify temperatures, stability limits, and pressure oscillations before placing the combustor in an engine.

\subsubsection{Contaminants}

The contaminants in biomass gases, which can be carried over from the gasifier, fall into 
three categories, each with its own problem area(s):

- Tar: deposition and burnout (combustion efficiency)

- Particulate (char and ash): hot corrosion, erosion, and burnout

- Alkali: hot corrosion

Tars are high-boiling hydrocarbon materials that, if not burned out, can form deposits on the combustor walls and distort the flow patterns. They are a potential problem with updraft, or counter flow, gasifiers.(19) As was shown in Table 4, they can be several percent of the total fuel mass depending on operating conditions; thus, if not burned out, they can also contribute significantly to combustion inefficiency. This will be discussed further in the chapter on liquids, but the lower flame temperatures in the combustion of low-Btu gases will make it more difficult for these compounds to completely burn out. If tars are present in the gas, the valves, manifolds, and injectors should be preheated before charging to prevent these tars from condensing out in critical areas.

Char carryover from the gasifier can be significant, see Table 4, and, like the tars, will also contribute to combustion inefficiency if not burned out. Depending on their size and abrasiveness, they can also cause erosion in the turbine section. No information was available on these characteristics.

Char burnout will be discussed more in the chapter on pyrolysis liquids, but the burnout time is relevant here. The time scales for combustion in aeroderivative and industrial combustors are about 3 and $10 \mathrm{msec}$ respectively. In furnaces, the sizes which can burn out in 3 and 10 msec are 5 and 20 microns respectively. However, for the lower temperatures associated with low-Btu gas combustion, the maximum size for particulate burn out may be much smaller. This point does not seem to have been addressed in the literature.

Erosion will generally not be a problem if the particles are less than 5 microns, in which case they will follow the streamlines through the turbine section. A specification for size limitations on particulates, which includes char and ash, has been developed by GE and is shown in Figure 15.(17) No information was found on the size distribution of the char and ash in the biomass gases to compare with this specification. Information on the abrasiveness and melting point must known in order to establish an upper limit on concentration.

The concentration of alkali sulfates should be less than $20 \mathrm{ppb}$ entering the turbine section. Fuels with lower Btu content use less air and therefore are more restricted in the 


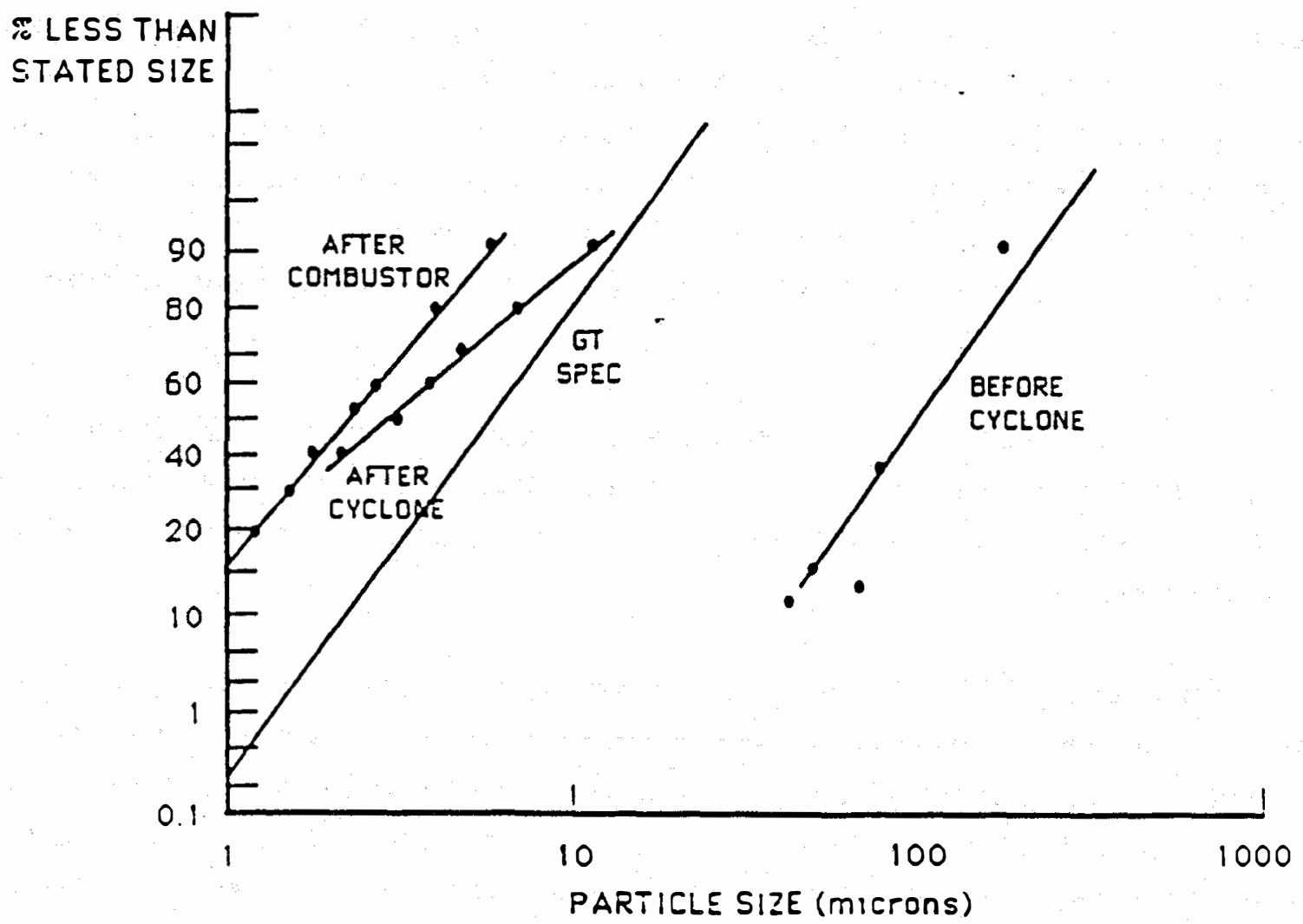

FIGURE 15. Particulate Loadings in Gasifier Fuels (Ref. 17) 
allowable alkali content. Based on coal gasification results, the gasifier exit temperature seems to be the most important controlling parameter.(18) Alkali in gasifier streams appears to condense onto the particulates when the gasifier temperature is less than $1100 \mathrm{~F}$, e.g., updraft fixed-bed gasifiers.(18) In these cases, alkali can be controlled by removing the particulates. In cases where the gasifier exit temperature is much higher, e.g., fluidized bed gasifiers, an appreciable amount of the alkali will be in the vapor phase.

There is some question about the chemical nature of the alkalis. It is the alkali-sulfates that are particularly corrosive. If the alkali is chemically tied up when leaving the gasifier such that sulfates are not formed, or if the fuel is sulfur free, it is speculated that the alkali limit could be relaxed for a biomass gas.

\subsubsection{Gas Temperature}

The delivery temperature of the gas is an important consideration for materials compatibility and to prevent leakage. At elevated temperatures, safety becomes a major issue because of the potential for leakage of hot hydrogen. Gas temperatures at the exit of the gasifier depend upon the type of gasifier used but typical temperatures range from 900 to $1100^{\circ} \mathrm{F}$ for fixed bed gasifiers to 1400 to $1600^{\circ} \mathrm{F}$ for fluidized bed gasifiers. Cooling the gases to more conventional temperatures would mean a significant loss in the enthalpy of the fuel and, therefore, overall system efficiency. Conventional valves and controls are used up to about $300^{\circ} \mathrm{F}$.(33) By using better steels, similar designs could probably go to about $700^{\circ} \mathrm{F}$. Engineers at GE Schenectady felt that 1000 to $1050^{\circ} \mathrm{F}$ would be about the maximum practical temperature and would require an all welded system, i.e., no gaskets or seals. Valves are available that can be used at $1200^{\circ} \mathrm{F}$, but at much higher cost. With high-temperature alloys and special cooling techniques, gas systems can be used to $2000^{\circ} \mathrm{F}$.

\subsubsection{Gas Pressure}

One of the major factors in determining the pressure of the gasifier will be the operating pressure of the gas turbine. The pressure of the fuel manifold is typically about 1.2 times the combustor pressure at operating conditions. Industrial machines have operating pressures ranging from around 6:1 for older machines to around 10:1 to 12:1 for large, modern units. For these machines, the pressure of the gas manifold would be about 106 psia for the 6:1 machine to 212 psia for a 12:1 machine. Aero-derivative machines operate at higher pressures, ranging from around 15:1 for the Allison 501KC and 20:1 for the GE-LM2500, to about 30:1 for the GELM5000. For these machines, the gas-manifold pressure requirements would be 265 psia, 353 
psia, and 530 psia respectively. Other losses such as for control valves and line lengths would have to be added to these to determine minimum gasifier pressure.

\subsection{TOPICAL SUMMARY ON BIOMASS GASES}

Generally speaking, high-Btu gases are easily burned in existing gas turbines, while medium-Btu gases can usually be handled with minor modifications to the combustor. The problems become more severe as the energy content goes lower due primarily to the larger volumes of fuel required relative to the air flow. Below $100 \mathrm{Btu} / \mathrm{scf}$, it is very difficult to sustain combustion.

The problems may be summarized under three categories:

- those pertaining to the fuel system and combustor

- those pertaining to combustor performance

- those pertaining to durability

\subsubsection{Fuel Systems for Biomass Gases}

- The gas flow must be metered to produce the same temperature rise as natural gas. This may be done by simple orifice changes for gases down to $600 \mathrm{Btu} / \mathrm{scf}$. Larger or multiple fuel systems will be needed for lower energy contents. Aeroderivative systems are limited in the size of the injectors that can be located inside the housing.

- Dry, low- $\mathrm{NO}_{\mathrm{x}}$ combustors are less suitable to conversion to medium- and low-Btu gases than conventional combustors because they are much more sensitive to air-fuel mixing in order to achieve low $\mathrm{NO}_{\mathrm{x}}$ values.

- For low-Btu gas, a startup on distillate or natural gas is likely; a dual fuel system will allow this flexibility.

- Fuel-control schedules for startup, acceleration, and deceleration must be tailored to fuel characteristics of ignition, stability, flame temperature, etc.

- Consistency of gas supply is important for control and stability. 
- Fuel system components must be capable of handling high-temperature gas feed stock: $700^{\circ} \mathrm{F}$ is reasonable; $1000-1050^{\circ} \mathrm{F}$ is probably a maximum temperature that can be handled. At these elevated temperatures, gaskets and seals won't work, so all fittings should be welded to prevent leaks of hot hydrogen.

\subsubsection{Fuels Composition Effects on Performance}

- The fuel injection system must be appropriately increased in size to allow for the increase in volume flow rate of the fuels with lower heat content.

- The airflow splits in the combustor must be adjusted to provide the correct stoichiometry in the primary zone and the correct temperature rise across the combustor.

- Once the machine is modified, the fuel must stay fairly constant to maintain performance and durability.

- Fuels with high hydrogen content, $>50$ mole percent, will have good starting and stability characteristics but will have high flame temperatures compared to natural gas. Water/steam injection will be effective at controlling $\mathrm{NO}_{\mathbf{x}}$. These fuels should have low $\mathrm{CO}$ emissions, depending on the $\mathrm{CO}$ content of the fuel.

- Fuels with high CO content will also have high flame temperatures, but poorer starting and stability characteristics and higher levels of $\mathrm{CO}$ in the exhaust than with natural gas. Water/steam injection requirements would be the same for a given $\mathrm{NO}_{\mathrm{x}}$ level.

- Fuels with high diluents, i.e. $\mathrm{CO}_{2}, \mathrm{~N}_{2}$, and $\mathrm{H}_{2} \mathrm{O}$, will have low flame temperatures and correspondingly, poor ignition characteristics, stability limits, and combustion efficiency. $\mathrm{NO}_{\mathrm{x}}$ should be low and water/steam injection may not be required to meet emission levels if fuel-bound nitrogen is not significant. CO will likely be higher. Significant modifications to the combustor and turbine air flow may be necessary to get satisfactory performance and reliability.

\subsubsection{Fuel Contaminant Effects on Durability}

- The allowable alkali content for a biomass gas will be determined by the sulfur content of the fuel and air-fuel ratio of the machine. There is some indication that if the fuel 
has very low sulfur, it may be possible to relax the alkali limit as long as the total amount of alkali sulfate is kept below an acceptable limit. For natural gas, GE places this limit at $0.2 \mathrm{ppm}$ of the fuel. For fuels with lower energy content, this limit will have to be proportionally lower.

- The ash must be evaluated for size, abrasiveness, and melting point before establishing an upper limit on concentration.

- The amount of allowable tar and char carryover will depend on the machine and the firing temperature. Industrial machines will be able to tolerate more of these because of the longer combustor residence time. Data and/or models of the burning times for char and tar at reduced flame temperatures are needed to establish upper limits on size and concentration. 


\subsection{PYROLYSIS LIQUIDS FROM BIOMASS}

\subsection{PYROLYSIS LIQUIDS}

Pyrolysis liquids will be much more difficult to use as fuels in gas turbines than the biomass gases. Compared to light and middle distillates they are very viscous, have high density, high tar and alkali content, and may even contain significant amounts of char as an attempt to improve the overall energy efficiency of the pyrolysis process. Furthermore, they are not very thermally stable so they can't be heated to reduce viscosity.

Pyrolysis liquids are produced by the thermal decomposition of solid carbonaceous fuels in the absence of air, however, some gases and char are also produced. In reality, most pyrolysis processes use a small amount of air to bum some of the char to produce the heat for the pyrolysis. The major differences between gasification and pyrolysis are the temperatures and the amount of air/oxygen used. Since gasification uses more air, higher temperatures are reached.

The relative yield and quality of the liquid depends upon the process and the feedstock. The product oil can be described as a highly oxygenated viscous liquid that is mildly corrosive.(34) Whereas petroleum distillates are composed primarily of pure hydrocarbons, i.e., paraffins, aromatics, and naphthenes, the organic composition of pyrolysis liquids is primarily carbohydrates, organic acids, aldehydes, and other oxygenated organics. Also, they may contain large amounts of water.

Table 6 provides a list of properties for a number of biomass pyrolysis liquids; these include liquids from woods $(46,35)$ as well as grasses (35). Generally, liquids from grasses seem to be of lower quality than those from woods. The oils from the grasses have higher alkali content and higher viscosities; the wood oils have higher water content and are more acidic.

Table 7 provides a list of properties for distillate liquid fuels that are normally specified for gas turbine power plants. $(20,21)$ The first column provides properties for \#2 GT fuel which is the most common liquid fuel for gas turbine power plants. The second column is a list of additional requirements specified by $G E$ for their aeroderivative engines.

\subsection{EVALUATION OF PROPERTIES OF PYROLYSIS LIQUIDS}

The properties of concern were listed in Table 1 along with the general performance and 


\section{TABLE 6. PROPERTIES OF SAMPLE BIOMASS PYROLYSIS OILS}

\begin{tabular}{|c|c|c|c|c|c|c|c|c|c|c|c|c|c|c|c|}
\hline \multirow[b]{2}{*}{ Property } & \multirow{2}{*}{$\begin{array}{l}\text { Typical } \\
\text { \#2 Fuel }\end{array}$} & \multicolumn{4}{|c|}{ Switchgrass Oils } & \multicolumn{4}{|c|}{ Oakwood Oils } & \multirow{2}{*}{$\frac{\text { S. Pine }}{151}$} & \multirow{2}{*}{$\frac{\text { Var.Woods }}{\text { (Ref. 46) }}$} & \multicolumn{4}{|c|}{ Teledyne Pyrolysis Oils (Ref. 26,27) } \\
\hline & & NREL \# & $146 \mathrm{~A}$ & 146B & $146 \mathrm{C}$ & $\overline{143 \mathrm{~A}}$ & $143 \mathrm{~B}$ & $143 C$ & 154 & & & $0 \%$ Char & $10 \%$ Char & $20 \%$ Char & $30 \%$ Char \\
\hline \multicolumn{16}{|l|}{ Viscosity } \\
\hline cSt @ 25C & 3.5 & & 18 & 71 & 100 & 58 & 17 & Undef. & -.- & -- & $\ldots$ & 250 & 450 & 2238 & 13,250 \\
\hline @ 35C & 2.2 & & 10 & 30 & 42 & 22 & 10 & 475 & 63 & 42 & --- & 113 & 138 & 300 & 675 \\
\hline @ 45C & 1.5 & & 7 & 12 & 16 & 10 & 6 & 84 & --- & -- & -- & 38 & 100 & 225 & 425 \\
\hline \multicolumn{16}{|l|}{ Specific } \\
\hline Gravity & 0.8 & & 1.18 & 1.16 & 1.12 & 1.19 & 1.13 & 0.94 & 1.23 & 1.21 & 1.2 & 1.2 & 1.22 & 1.3 & 1.3 \\
\hline Hydrogen & $13-14 w+\%$ & & 6.3 & 6.2 & 6.5 & 7.5 & 7.1 & 7.6 & 5.0 & 6.5 & $6.4-7.1$ & 7.3 & 6.8 & 6.3 & 5.9 \\
\hline Carbon & $86-87$ wt \% & & 42.5 & 40.4 & 47.7 & 42.4 & 54.7 & 49.5 & 55.6 & 56.3 & $53-56$ & 55.9 & 58 & 60 & 62 \\
\hline Oxygen & --- & & 50.9 & 52.2 & 45.2 & 50.0 & 38.1 & 42.5 & 39.2 & 36.9 & $\cdots$ & $\cdots$ & --- & $\cdots$ & $\cdots$ \\
\hline Nitrogen & -- & & 0.3 & 0.4 & 0.6 & 0.1 & 0.2 & 0.4 & 0.1 & 0.3 & $\cdots$ & 0.15 & -- & $\cdots$ & $\cdots$ \\
\hline Sulfur & $0.1-1.0$ & & 0.03 & 0.04 & 0.03 & 0.03 & 0.01 & 0.02 & --- & --- & --- & 0.07 & 0.07 & 0.08 & 0.08 \\
\hline \multicolumn{16}{|l|}{ Alkali ppm } \\
\hline $\mathrm{Na}$ & $<0.5$ & & 20 & 40 & 40 & 38 & 36 & 52 & 10 & 10 & $\cdots$ & --- & $\cdots$ & $\ldots$ & $\cdots$ \\
\hline $\mathrm{K}$ & $<0.5$ & & 740 & 1380 & 580 & 32 & 24 & 35 & 40 & $<10$ & $\cdots$ & --- & --- & $\cdots$ & -- \\
\hline $\mathrm{Ca}$ & $<0.5$ & & 490 & 660 & 590 & 33 & 31 & 23 & 80 & 60 & $\cdots$ & $\cdots$ & $\ldots$ & --. & --. \\
\hline Ash wt\% & 0.01 & & 0.79 & 0.95 & 0.12 & $<0.05$ & $<0.05$ & $<0.05$ & 0.05 & 0.05 & $\ldots$ & 0.32 & 2.1 & 3.8 & 5.5 \\
\hline Water wt\% & 0.05 & & 24.4 & 27.7 & 18.1 & 22.6 & 23.6 & 32.0 & 16.9 & 18.5 & $18-22$ & 29 & -- & -.- & --. \\
\hline LHV Btu/lb & 18,500 & & 9440 & 9964 & 9619 & 9161 & 8430 & 12,366 & 9155 & 9231 & $\cdots$ & --. & -- & --- & --. \\
\hline HHV Btu/h & & & 10,000 & 10,500 & 10,200 & 9700 & 9070 & 13,000 & 9700 & 9900 & --- & 10,500 & 10,500 & 10,450 & 10,400 \\
\hline \multicolumn{16}{|c|}{ Boiling Curve, See Fig. 16} \\
\hline $\mathrm{IBP},{ }^{\circ} \mathrm{C}$ & & & 90 & 95 & 95 & 97 & 99 & 99 & --- & -- & --. & See Fig. 16 & $\therefore$ & $\ldots$ & $\ldots$ \\
\hline $\mathrm{FPB},{ }^{\circ} \mathrm{C}$ & & & 161 & 139 & 151 & 187 & 184 & 172 & --. & --- & --- & --- & --. & --- & $\ldots$ \\
\hline \% Evap. & $>99$ & & 58 & 52 & 59 & 60 & 76 & 90 & $\cdots$ & -- & $\cdots$ & $\ldots$ & --. & $\cdots$ & -- \\
\hline Residue & $<1$ & & 42 & 48 & 41 & 40 & 24 & 10 & --- & $\cdots$ & --- & 45 & 47 & 49 & 51 \\
\hline ph & $\cdots$ & & 3.54 & 3.73 & 3.66 & 2.59 & 2.60 & 2.50 & 2.8 & 2.9 & $2.1-2.8$ & 2.95 & --- & $\therefore$ & -.- \\
\hline
\end{tabular}




\section{TABLE 7. FUEL SPECIFICATIONS FOR GAS TURBINE POWER PLANTS}

\begin{tabular}{ll} 
\#2-GT & GE GT \\
\hline & A-D \\
\hline
\end{tabular}

Flash Point, Min T, C

38

Distillation Temp, C

$90 \%$ rec. Max T 282

90\% rec. Min T 338

Kinematic viscosity

$\mathrm{mm} 2 / \mathrm{sec}$ or $\mathrm{cSt}$

@ $40^{\circ} \mathrm{C} \min$

1.9

$\max \quad 4.1$

Pour Point, ${ }^{\circ} \mathrm{C} \max$

$-6$

Density @ 15C, kg/m ${ }^{3}$

$775-840$

Hydrogen $w t \% \min$

12.7

Ramsbottom Carbon

Residue(10\%), mass $\quad 0.35$

$(100 \%)$

Ash, \% mass max

0.01

1.0

0.01

Particulates, mg/gal

10.0

Water \& Sediment.

0.05

0.10

\%vol, max

0.3

1.0

Sulfur, \% mass max

Trace metals ppm wt max

$\mathrm{V}$

$\mathrm{Na}+\mathrm{K}+\mathrm{Li}$

$\mathrm{Ca}$

$\mathrm{Pb}$
0.5

0.5

0.5

0.5
0.5

$0.2^{2}$

2.0

1.0

1: General Electric Aeroderivative Gas Turbines: in addition to meeting the requirements for \#2GT fuel. GE requires that the fuel meet additional criteria for its aeroderivative gas turbines: where the properties differ, these supercede.

2: For engines with marinized (corrosion-resistant) coatings, the limit is $0.2 \mathrm{ppm}$. including all sources (fuel, air, water, and steam); for non-marinized engines with stindard coatings. the total alkali is limited to $0.1 \mathrm{ppm}$. 
durability problems that are related to them. In the following discussion, these relationships will be individually addressed by presenting data and models which have been developed for conventional distillate fuels. The properties of the liquids provided in Table 6 will then be used to project impact statements. When possible these projections will be compared to data from the one gas turbine experiment using pyrolysis liquids that was found in the literature. $(26,27)$ None of the major manufacturers of gas turbines for power generation have tested any biomass pyrolysis liquids.

\subsubsection{Alkali Content}

The alkali content of all of the pyrolysis liquids shown in Table 6 far exceed the acceptable limits for gas turbines. This characteristic is probably the biggest barrier to the use of biomass pyrolysis liquids in existing industrial and aeroderivative gas turbines! The reason is the accelerated corrosion and deposition in the turbine section caused by the presence of alkali sulfate in the combustion gases, as briefly discussed earlier and more completely in Appendix A. The maximum allowed is $0.5 \mathrm{ppm}$ total alkali (sodium plus potassium). The real limit is based on the alkali in the hot gas stream entering the turbine which should be less than $20 \mathrm{ppb}$ of the total flow. Since the heat of combustion for the biomass liquids is considerably less than that of conventional fuels, the allowable alkali content must be reduced accordingly. This means the alkali limit in the fuel should be down around 0.2 to $0.3 \mathrm{ppm}$.

The practical problem lies in the high water content of biomass liquids as shown in Table 6. Unfortunately, a unique characteristic of the biomass pyrolysis liquids is that a high percentage of the materials are sugars and other compounds derived from carbohydrates that are soluble in the water. One study showed as much as 53-68 percent of the compounds in several pyrolysis oils from woods were water soluble.(46) Thus removal of the existing water might remove the alkali, but would take away a large fraction of the fuel. Also, there would be the matter of disposal, but this could be handled in a manner similar to water washing systems in systems that burn crude oils or residual oils.

As discussed with the biomass gases, there may be some opportunities to relax the conventional limits on alkali, but these would have to be thoroughly investigated as there is very little relevant data. First the chemical nature of the alkali in biomass fuels may be such that they are tied up in compounds that are preferred over the formation of sulfates. Also, the sulfur content may be low enough to permit higher alkali content,

From the hardware side, the use of modern blade coatings on older machines which 
operate at lower temperatures should be investigated. Alternately, machines could be operated at lower firing temperatures if cheaper fuel offsets the loss in thermal efficiency of the turbine.

Operationally, if the machine were used as a peaking machine, the number of hours per year could be significantly reduced to the point where the machine would be overhauled for some other purpose.

\subsubsection{Ash Content}

The high ash content is also a potential barrier to the use of biomass pyrolysis liquids. As discussed earlier with the biomass gases, not enough is known about the important characteristics of size, abrasiveness, and melting point.

Removal of the particulates by filtration of the liquid does not look practical because of the high fuel viscosity. It may be possible to perform a hot-gas clean up using cyclones or ceramic filters with industrial gas turbines, but these are less suitable for aeroderivatives.

Data on the ash properties and combustor rig data are needed to establish meaningful ash/particulate limits for the biomass pyrolysis liquids.

\subsubsection{Water Content and Solubility}

Distillate fuels contain no more than 100 to $500 \mathrm{ppm}$ of water. Higher concentrations are removed by filtration or centrifuge if necessary. Pyrolysis liquids contain on the order of 25 percent water. The presence of water in the pyrolysis liquids further reduces the already-low energy content.

The water content will add to the ignition stability difficulties with these fuels, and will probably reduce combustion efficiency with corresponding increases in $\mathrm{CO}$ and hydrocarbons. This effect has been seen in the combustion of water-fuel emulsions where the water content is usually only in the 5 to 10 percent range.(30,31) Two potential advantages are a reduction of $\mathrm{NO}_{\mathbf{x}}$ because of the lower flame temperature, and a reduction in soot and particulates which has also been seen in the combustion of water-fuel emulsions.(30,31)

The high solubility of water in biomass pyrolysis liquids prevents its removal by conventional means. In fact, if the water were separated by means other than distillation, a large fraction of the burnable fuel would be removed with it, causing not only a loss in overall fuel 
conversion efficiency, but creating a water disposal problem as well. The problem of removing the alkali has already been discussed.

In distillate fuels, the presence of free water in the fuel of ten leads to biological growth in storage facilities which can cause corrosive attack on metal tank walls and clog lines and filters. This is thought not to be a problem with biomass pyrolysis liquids because of the acidity of these fuels and the presence of phenols.

\subsubsection{Tar Content}

The problem of tar content was introduced in the discussion of biomass gases; similar problems will exist with the liquids but to a greater extent because of the higher concentrations and the liquid phase of the fuel.

In the combustion chamber, if the tars are not burned out in time, they will impinge on the walls or blades and form deposits which will distort the flow. This problem is more acute with the liquid fuels because the tars will be the last to evaporate from the droplets in the fuel spray. Thus they will have shorter time available for burning. The problem is compounded by the likelihood that the tars will undergo significant heating before they are ready for evaporation from the drop, and will actually pyrolysis to form cenospheres, i.e., small particles of char, which can cause turbine blade erosion and exhaust particulates. Cenosphere formation is a common problem with residual fuels. Tar burnout will be more of a problem in aeroderivative combustors than industrial combustors because of the shorter residence time. Droplet burning times will be discussed further in the next section.

\subsubsection{Viscosity and Boiling Range}

Viscosity and boiling range are the two most important fuel properties to consider for combustion parameters dependent upon droplet lifetime:

- Ignition

- Combustion efficiency

- Stability

- Exhaust emissions: $\mathrm{CO}$ and hydrocarbons

Since most liquid fuels are composed of thousands of compounds, each with a different boiling point, fuels are characterized by a boiling range, or boiling point distribution, rather than 
a single point. Figure 16 compares the boiling point distribution of one biomass liquid with several conventional distillate fuels: two aviation fuels and a \#2 Diesel. Two characteristics about the distillation curve for the pyrolysis liquid are of special note: First, the initial 20 percent of the pyrolysis liquid which evaporates at a little over $200^{\circ} \mathrm{F}$ is the water in the fuel. Secondly, the curve ends at a little over $500^{\circ} \mathrm{F}$ with only 60 percent of the fuel evaporated; the rest of the fuel was either decomposed to form a coke or tar deposit, or was tar to begin with. $(26,27)$ With distillate fuels, the fraction over about $650^{\circ} \mathrm{F}$ is usually considered carbon residue or tar, and is less than one percent in diesel fuel.

Only the initial and final boiling points were available for the pyrolysis liquids in Table 6. The initial boiling points of 95 to $100^{\circ} \mathrm{C}$ suggest initial water vaporization, and the low final boiling points in the range of 140 to $190^{\circ} \mathrm{C}\left(275\right.$ to $\left.375^{\circ} \mathrm{F}\right)$ along with a high residue, i.e., 100 minus the percent evaporated, indicate the fuel used by Teledyne $(26,27)$ was not untypical.

The viscosities of pyrolysis liquids are very high compared to conventional liquid fuels for gas turbines. Figure 17 compares the viscosities of the NREL pyrolysis liquids from switchgrass and from oak wood (Table 6) with that of typical distillate fuels along with other common fluids for reference.(27) The viscosity of the best NREL pyrolysis liquid (oak oil from a $650^{\circ} \mathrm{C}$ cracker) is almost an order of magnitude greater than that of a typical Diesel fuel at $75^{\circ} \mathrm{F}\left(25^{\circ} \mathrm{C}\right)$. The temperature dependency of the viscosity of these pyrolysis liquids is fairly typical of more conventional liquids, but considerable heating must be done to bring the viscosity down to less than $12 \mathrm{cSt}$, generally considered to be the maximum acceptable viscosity for aeroderivative engines. The Teledyne study $(26,27)$ provided some temperature-dependent viscosity data for the base fuel used as well as for cases with 10, 20, and 30 percent char. Even without the addition of char, the viscosity of their base fuel was almost two orders of magnitude greater than Diesel fuel; the viscosities of those with char were even greater.

Recalling the earlier discussion of the effects of viscosity on atomization, special atomizers would have to be used for most of the pyrolysis liquids in Table 6. The Teledyne combustor(26,27) used a unique rotary atomizer with large holes to prevent plugging. Correspondingly, the Teledyne combustor had a radial flow rather than an axial flow that most combustors have, so this type of atomizer would not be adaptable to other combustors.

\subsubsection{Ignition}

Figure 18 illustrates the impact of higher viscosity and boiling range on ignition. This 


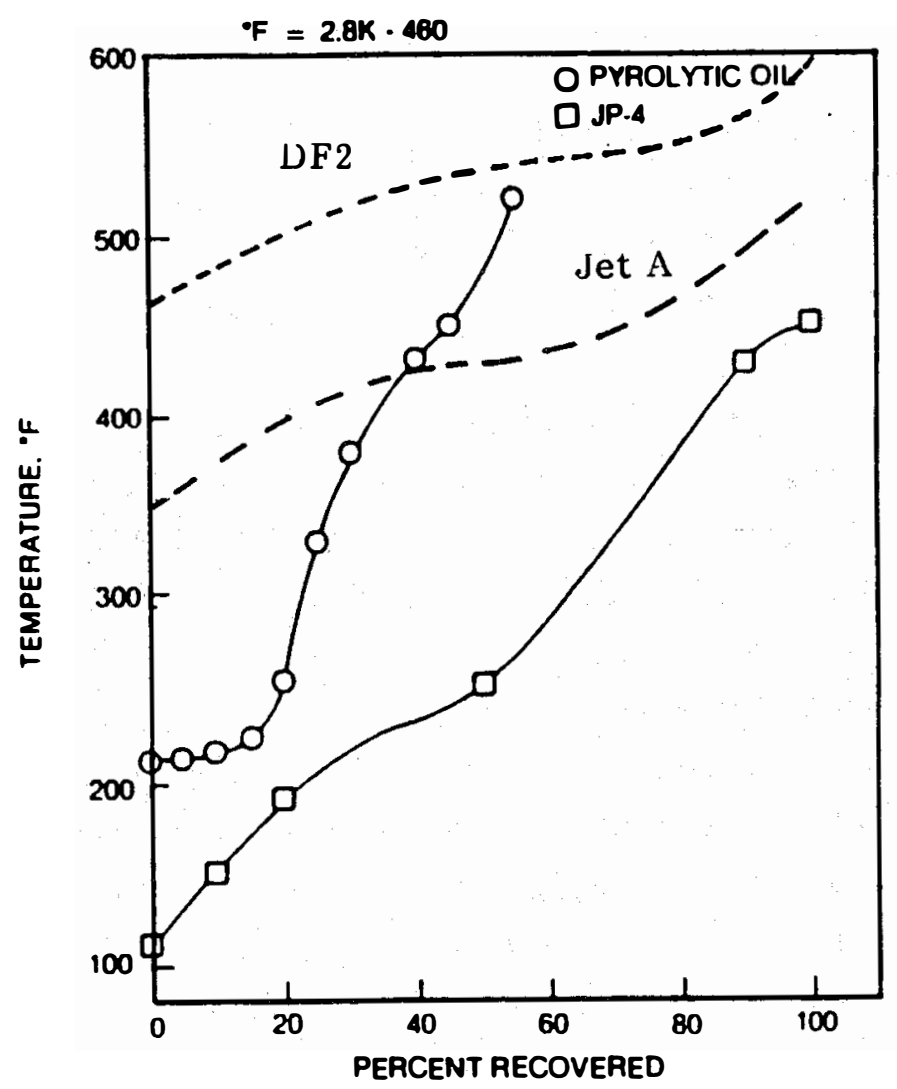

FIGURE 16. Boiling Point Distribution of a Pyrolysis Liquid Compared with Conventional Distillate Fuels (Ref. 27,1) 


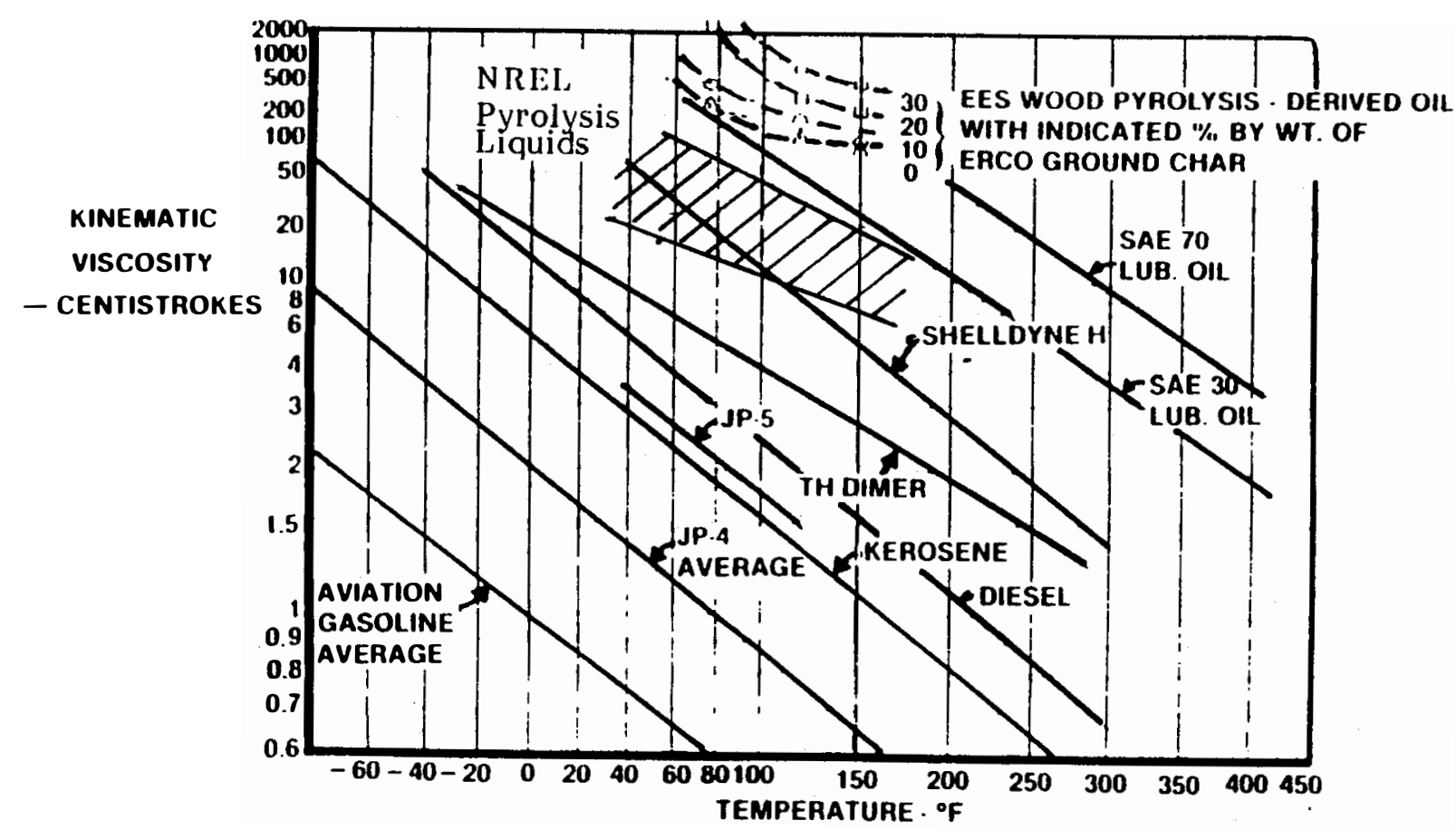

FIGURE 17. Comparison of Viscosities of Pyrolysis Liquids with Conventional Distillate Fuels and Other Liquids (Ref. NREL, 27) 


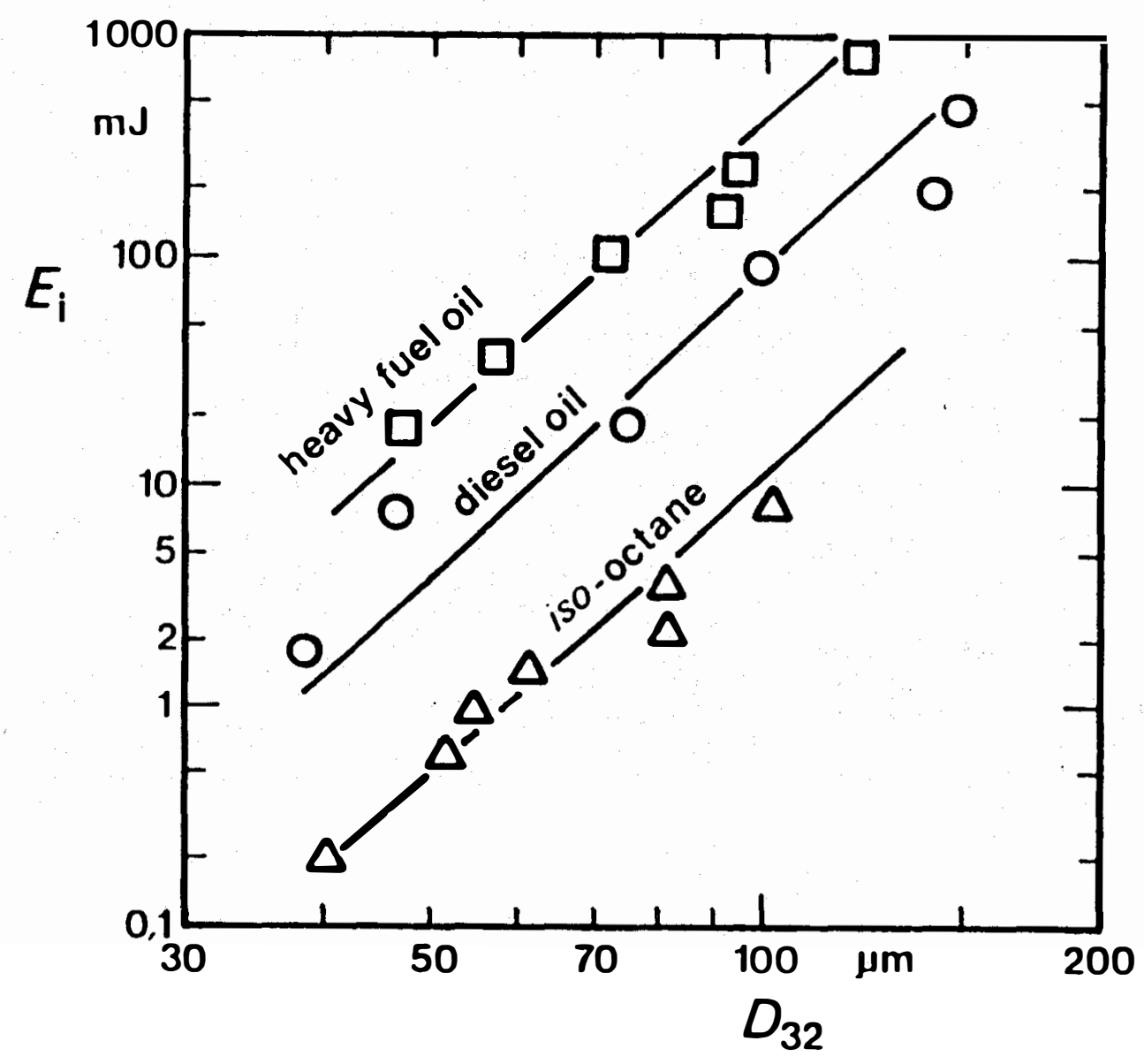

FIGURE I8. Effect of Fuel Atomization and Boiling Range on Ignition Energy Requirements (Ref. 7) 
figure shows that a coarser fuel spray, corresponding to a larger SMD (D32), requires a higher ignition energy. Furthermore, for the same SMD, a heavy fuel oil is more difficult to ignite than diesel fuel. Since a 10-fold increase in viscosity results in about a 50 percent increase in SMD, an atomizer producing a 50-micron SMD spray on diesel fuel would produce a 75-micron SMD on the NREL oak oil \#143b (Table 6). Using the data for "heavy fuel oil" to represent pyrolysis oil, the ignition energy would have to be about $100 \mathrm{~mJ}$ instead of about $3 \mathrm{~mJ}$. Alternately, the "heavy oil" would have to be atomized to about 35 microns SMD to have the same ignition characteristics as the diesel fuel.

The problem of ignition with low-volatility, viscous fuels also occurs when burning residual fuels. The problem is addressed by starting the machines on distillate fuels and then switching over to the heavier fuel that is to be burned. It will also be necessary to shut the machine down on distillate fuel to avoid pyrolysis liquids left standing in the lines. Problems associated with this practice were discussed earlier in Section 3.1.

\subsubsection{Stability}

Heavy fuels also affect the stability of the combustor as measured by the weak or lean extinction limit. This is illustrated in Figure 19 for the same three fuels showing that for a given level of atomization, the flame of the heavier fuel will blow out, i.e. extinguish, at a higher fuelair ratio, $\Phi$. (Note: $\Phi=1$ is a stoichiometric fuel-air ratio.) This means the turndown ratio is less for heavier fuels, i.e., they will be more difficult to burn at low-power or idle conditions. These effects on ignition and stability are the reasons that gas turbines which operate on heavy fuels are started and shutdown on light or middle distillate fuels.

In the Teledyne study, the combustor could not be operated on pyrolysis liquid with 15 percent char or greater because the flame would blow out during transition from JP-4 to slurry. $(26,27)$ The highest fraction of slurry they could burn was 65 percent slurry/35 percent JP-4. They had no problems is transitioning to the straight pyrolysis oil, i.e. without char. Not too surprisingly, this suggests that there is an upper limit to the amount of char that can be successfully burned as a slurry. This limit would not necessarily be the same for all engines.

\subsubsection{Combustion Efficiency}

Figure 20 shows the effect of atomization on combustion efficiency, $\eta_{c}$. The bottom of the shaded band is for the heavier fuels. Combustion efficiency is less for the heavier/more viscous fuels because the droplet lifetime is longer, and therefore, there is less time for 


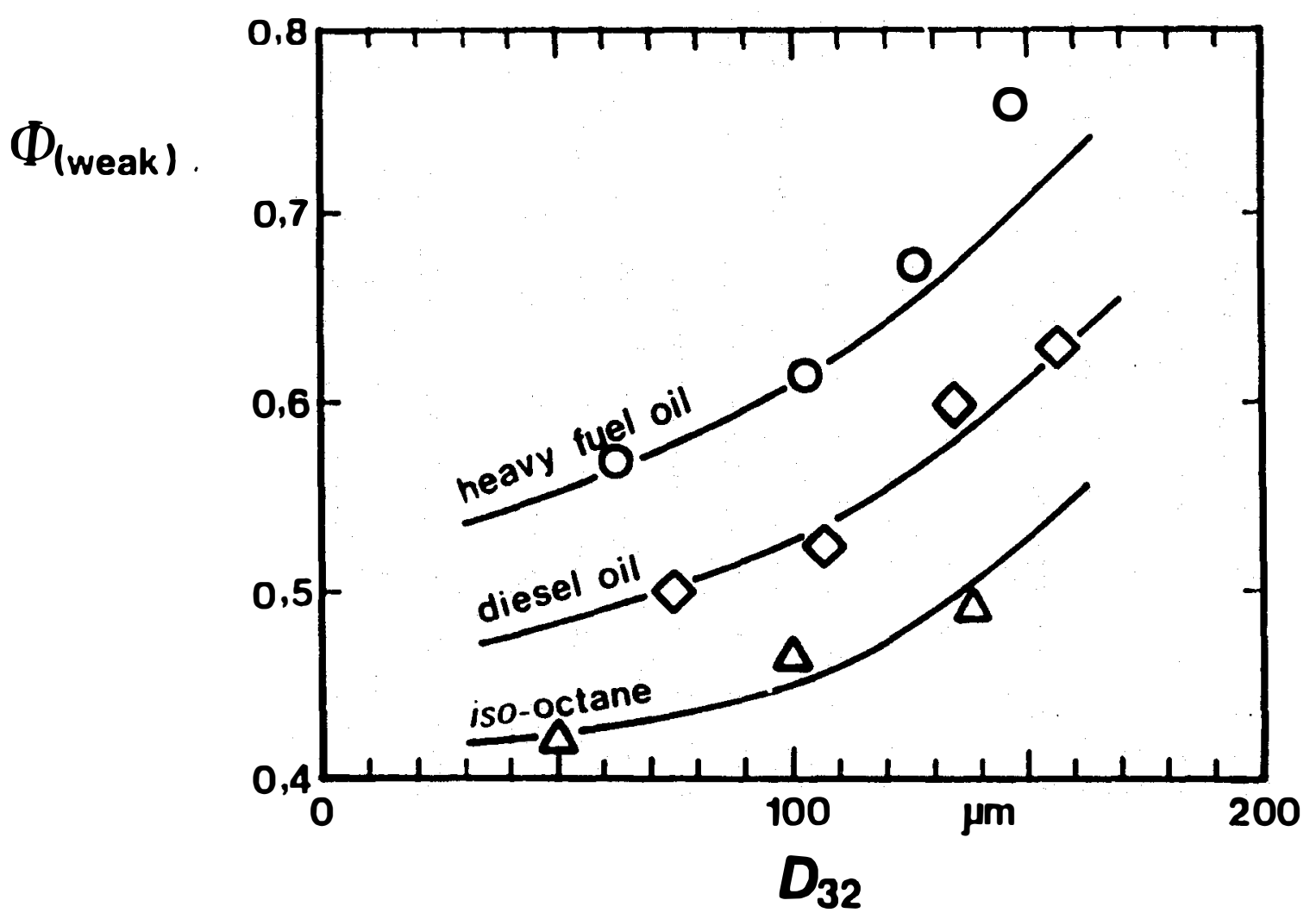

FIGURE 19. Effect of Fuel Atomization and Boiling Range on Lean Blowout Limits (Ref. 7) 


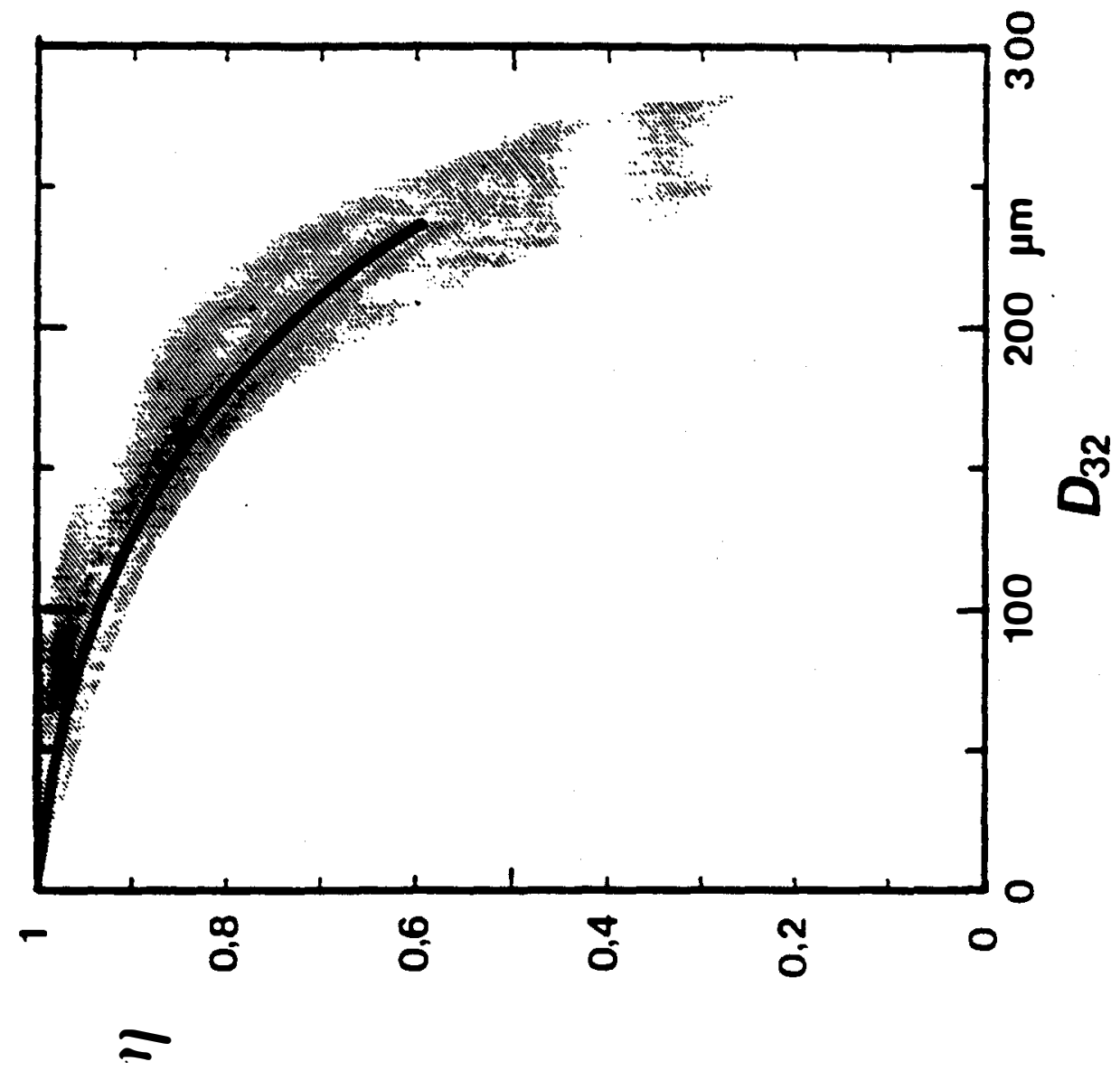


combustion. This was illustrated in Figure 2 which showed the effect of droplet size on burning time. In extreme cases, larger drops can penetrate the primary zone and impinge on the liner or blades forming a coke deposit. The effect of residence time on combustor efficiency is illustrated in Figure 21; as expected, combustors with longer residence times can burn heavier fuels more completely. This would include industrial combustors and older, low-pressure, aeroderivatives.

The general impact of fuel properties on combustion efficiency was demonstrated in the Teledyne study.(26,27) Figure 22 (from ref. 27) compares the combustion efficiency of the pyrolysis oil at two reference velocities (to vary residence time and turbulent mixing) with the base line JP-4, a very volatile jet fuel, at different temperatures representing different fuel-air ratios or power levels. In both cases the combustion efficiency of the pyrolysis oil is about 5 to 6 percent less than for the jet fuel.

Lefebvre (1) shows that, in general, combustion efficiency can be modelled in terms of three characteristic rates: an evaporation rate, a mixing rate, and a kinetic rate. For high power conditions, droplet evaporation rate is the controlling rate. Also, because combustion efficiencies are so close to 1.0, Lefebvre suggests it is more discriminating to look at fuel effects on combustion inefficiency, or $1-\eta$. Thus, to compare two fuels, the following can be used:

$$
\frac{1-\eta_{C 2}}{1-\eta_{C 1}}=\left(\frac{\rho_{2}}{\rho_{1}}\right)\left(\frac{\mu_{2}}{\mu_{1}}\right)^{0.5} \frac{\ln \left(1+B_{1}\right)}{\ln \left(1+B_{2}\right)}
$$

where $B$ is the mass transfer number defined as:

$$
B \equiv \frac{\Delta H f Y_{O \infty}+C_{p g}\left(T_{\infty}-T_{O}\right)}{L+C_{p f}\left(T_{B}-T_{R}\right)}
$$

For combustion efficiency, the relative values of the temperatures allow this to be approximated as:

$$
B \approx \frac{\Delta H f Y_{O \infty}}{L}
$$




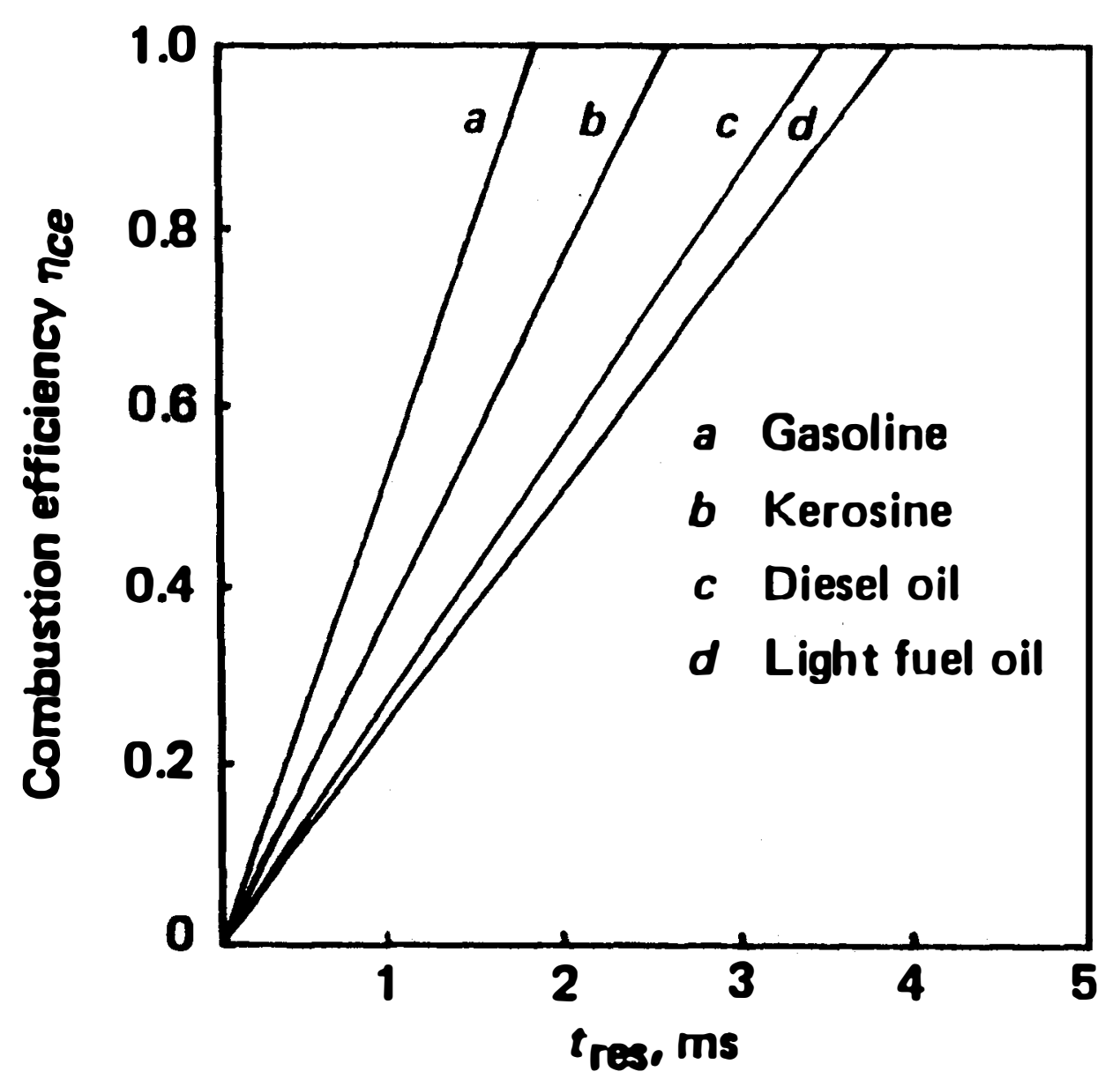

FIGURE 21. Effect of Combustor Residence Time on Combustion Efficiency (Ref. 1) 


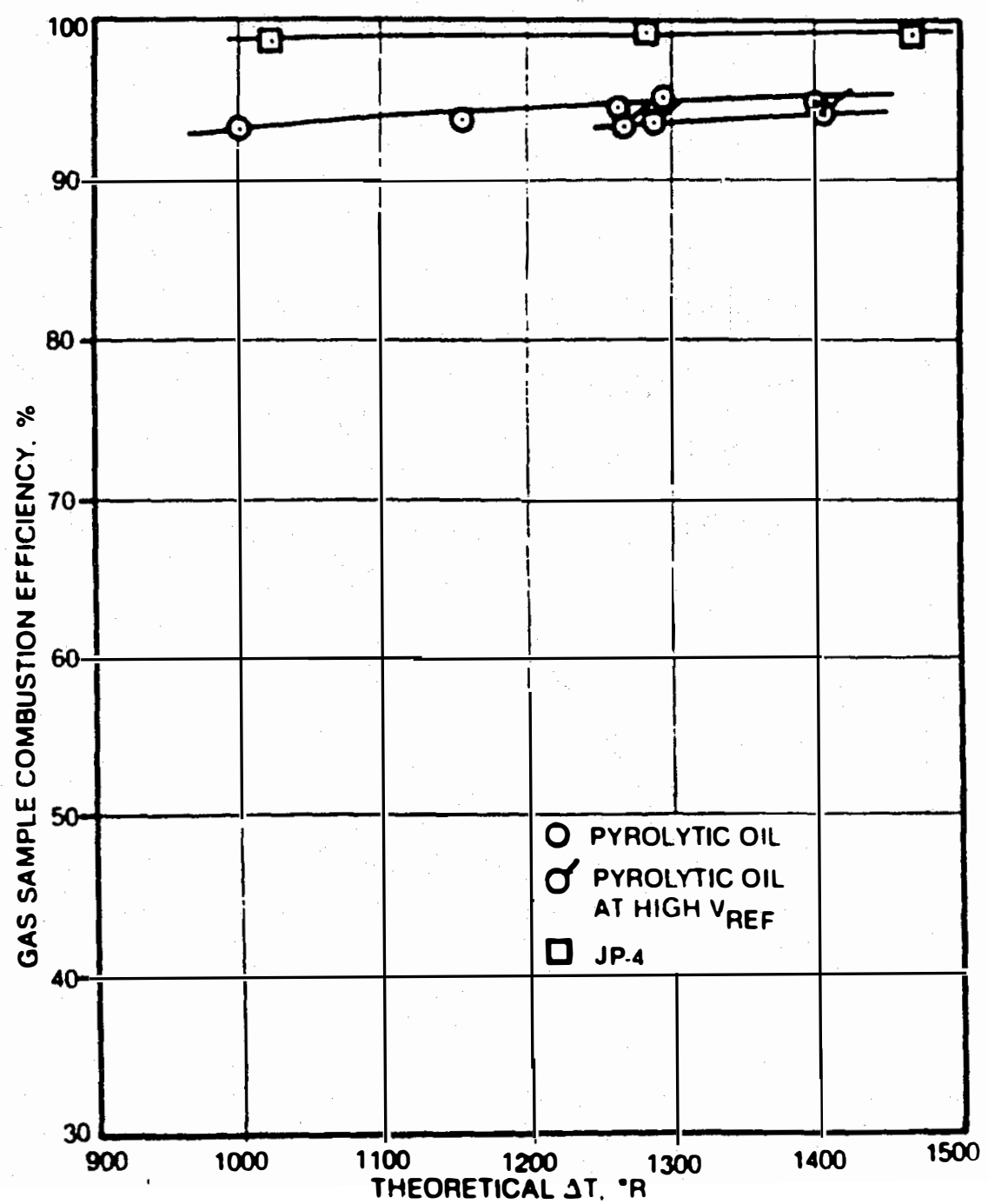

FIGURE 22. Combustion Efficiency for a Pyrolysis Liquid in a Gas Turbine (Ref. 27) 


$$
\text { where } \quad \begin{array}{lll}
\Delta \mathrm{H} & = & \text { heat of combustion } \\
\mathrm{L} & = & \text { Latent heat of vaporization } \\
\mathrm{f} & = & \mu \mathrm{C}_{\mathbf{v}} / \mathrm{k} \\
Y_{O_{\infty}} & = & \text { oxygen concentration in the flame }
\end{array}
$$

For the Teledyne results, using estimated fuel values, the ratio of inefficiencies is:

$$
\frac{1-\eta_{C 2}}{1-\eta_{C 1}}=(1.5)(50)^{0.5} \frac{\ln (1+2.5)}{\ln (1+12.5)}=4 \text { to } 5
$$

Using the data from Figure 22, the inefficiency ratio is about 5, so the methodology seems to apply for the pyrolysis liquids and shows the dominant effect of droplet evaporation rate.

\subsubsection{Effect of Char}

The presence of char in the pyrolysis oil will result in an even longer burning time. This is not only because solid char burns at a slower rate than a liquid drop of the same size, but also because in the case of a char/oil slurry, the liquid must evaporate first before the char will be exposed to the combustion gases and begin to burn. This is illustrated in Figure 23 for a base liquid with various concentrations of char. The size of the char is not important as long as it is much smaller than the initial liquid drop size. As the liquid evaporates, the many small char particles will agglomerate. The burning times for the char slurries in Figure 23 were calculated by determining the size of the agglomerated char from the initial drop size and the char concentration, calculating the burning time of a char particle of that size, and adding it to the combustion time of the initial liquid drop. (This assumes the evaporation time is longer than the kinetic time for droplet combustion.)

Based on this analysis and keeping in mind the distribution of drop sizes in a fuel spray, see Figure 3, it is certain that char will not burn out in the 3 to $5 \mathrm{msec}$ for aeroderivatives, and doubtful that industrial turbines will be able to effectively burn more than a few percent. The small amount of energy converted to useful work will not be worth the problems of higher viscosity and increased erosion. 


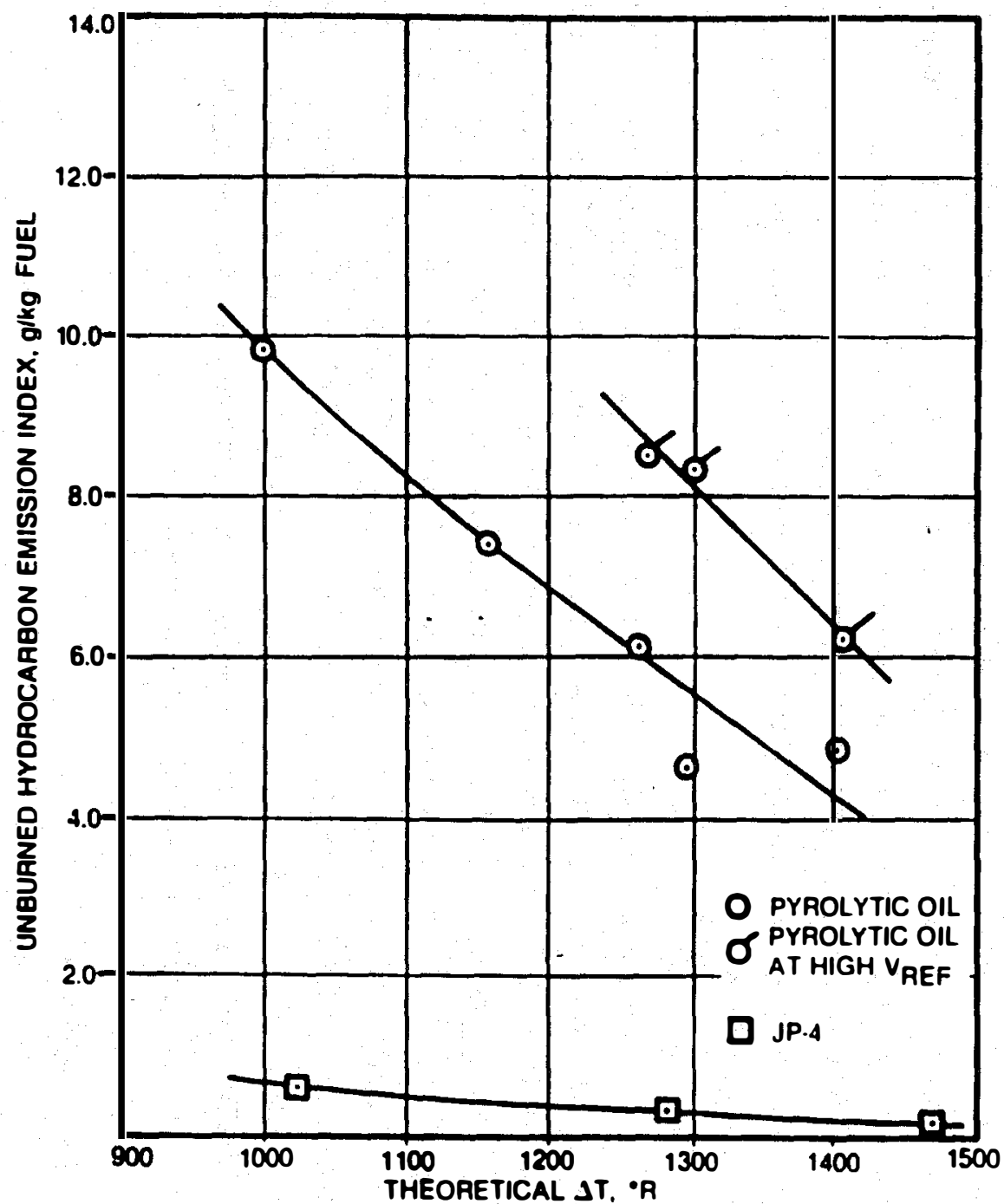

FIGURE 24. Hydrocarbon Emissions from the Combustion of a Pyrolysis Oil in a Gas Turbine (Ref. 27) 


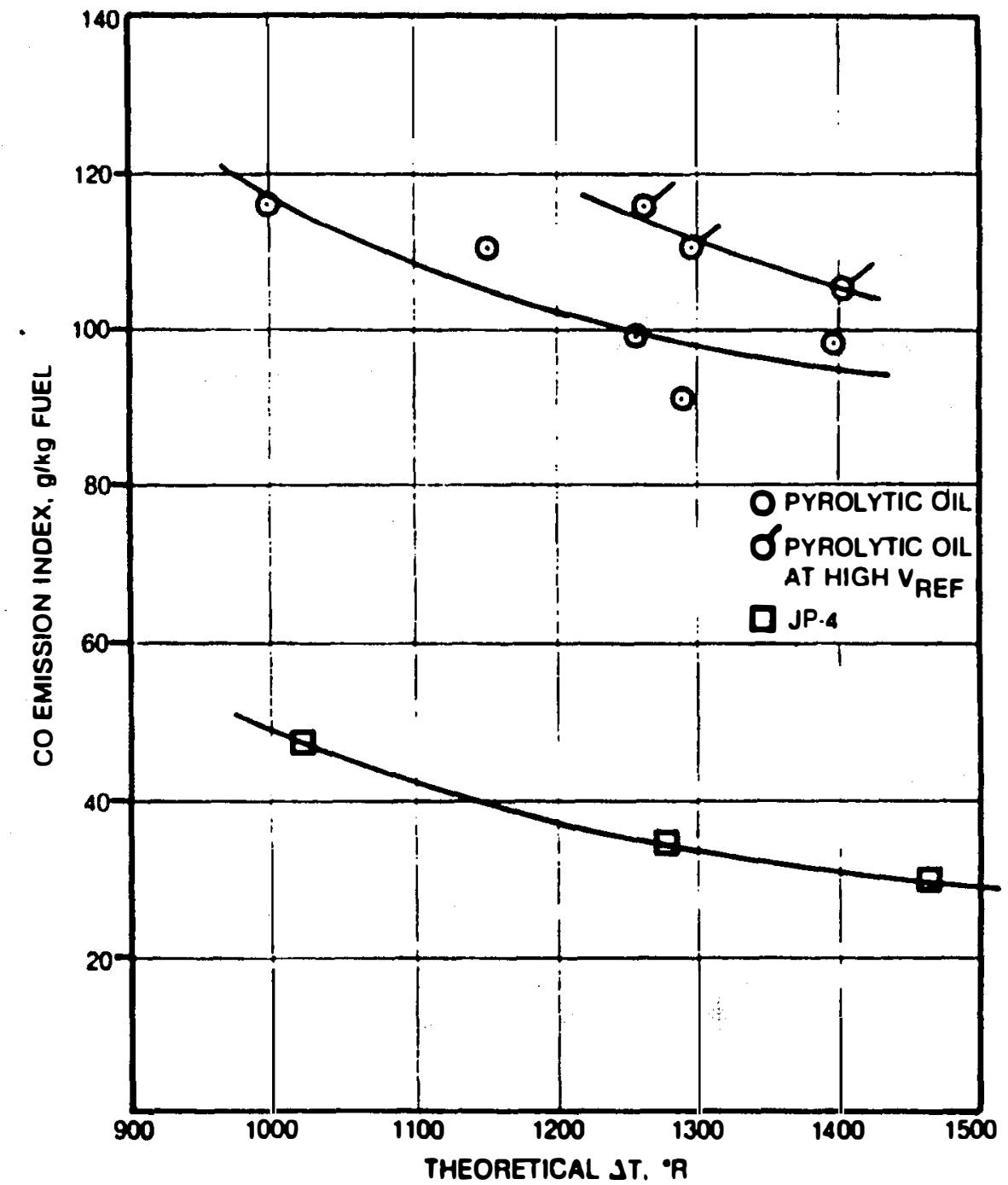

FIGURE 25. CO Emissions from the Combustion of a Pyrolysis Oil in a Gas Turbine (Ref. 27) 


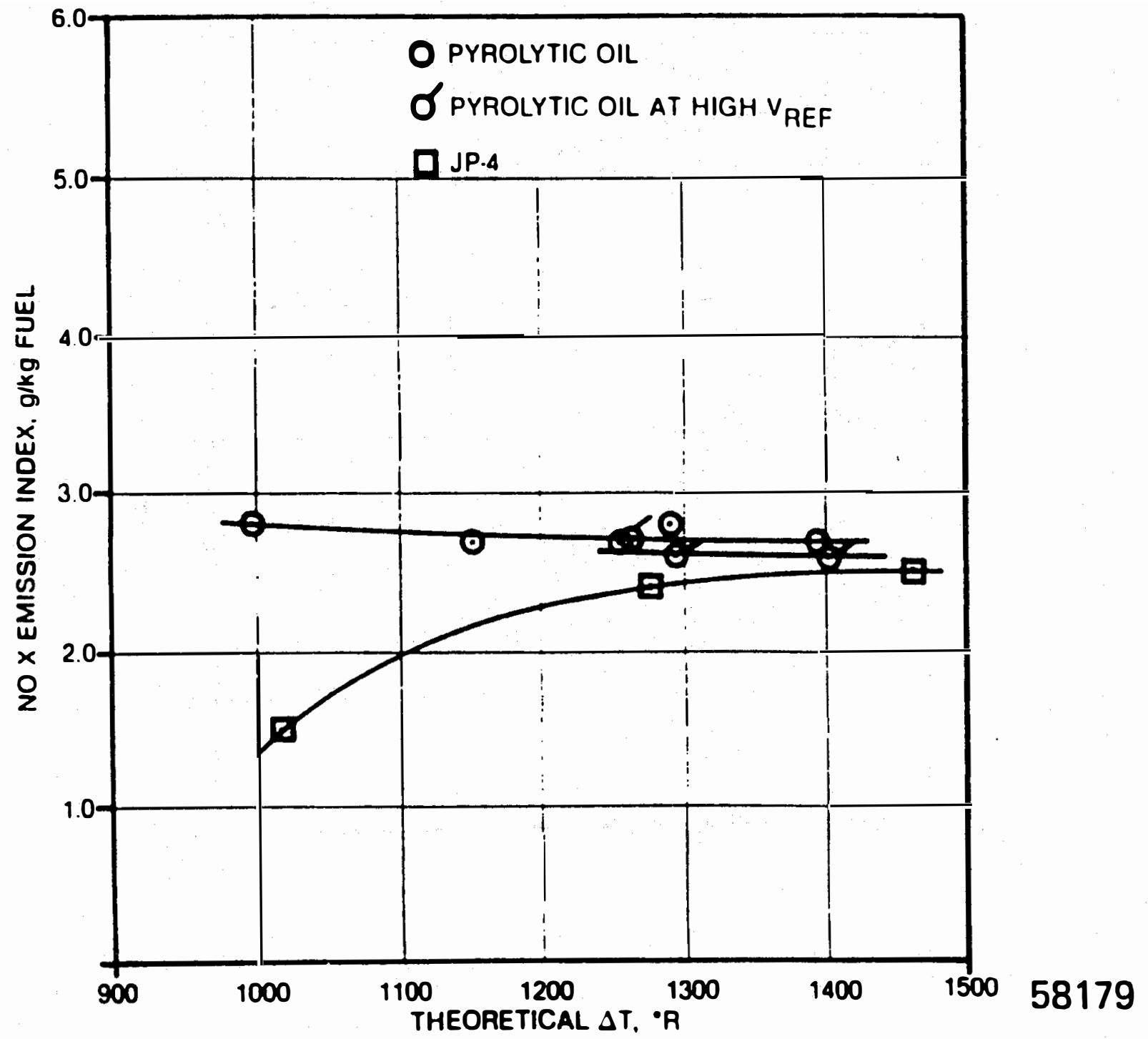

FIGURE 26. NOx Emissions from the Combustion of a Pyrolysis Oil in a Gas Turbine (Ref. 27) 
slurried into the pyrolysis liquid will significantly add to the flame radiation.

\subsubsection{Liner Temperature and Durability}

The anticipated effect on liner temperature is demonstrated in Figure 27 which is an expanded version of Figure 4 to include the data from the Teledyne demonstration $(26,27)$ in which the pyrolysis oil produce a $350^{\circ} \mathrm{K}$ increase in liner temperature over the reference jet fuel. This is a much higher increase than would be predicted by the other data shown; it can only be assumed that this large deviation is caused by the presence of tars, coke, and/or ash. No attempt was made by the Teledyne personnel to assess durability, but the data shown earlier in Figure 6 indicates a 90 percent loss of life for temperature increase of only $70^{\circ} \mathrm{K}$.

\subsubsection{Exhaust Smoke and Particulates}

Judging from Figure 7, pyrolysis liquids with a hydrogen content of about 6.0 wt percent would be expected to produce about two orders of magnitude more exhaust carbon than a diesel fuel. The data from the Teledyne demonstration $(26,27)$ support this contention. Figure 28 (27) shows the measured smoke number for the pyrolysis liquid to be very high in an otherwise smokeless combustor. Figure 29 shows a correlation between smoke number and particulate concentration (35). Using the upper curve for large particles to predict the particulate loading for the Teledyne data suggests a particulate loading of about 50 to $70 \mathrm{mg} / \mathrm{m}^{3}$ for the pyrolysis oil as compared to less than $1 \mathrm{mg} / \mathrm{m}^{3}$ for the jet fuel. This is in fairly good agreement with the prediction from Figure 7.

To summarize the anticipated effects of the low hydrogen-carbon ratio, the pyrolysis liquids shown in Table 6 are expected to produce more soot and flame radiation with corresponding increases in liner temperature, but the effect cannot be quantified because the hydrogen contents for the pyrolysis liquids are too low relative to experience with distillate fuels to extrapolate. Also the effects of the water and oxygen content and the tar, char, and ash are unknown. Whether the anticipated increase in liner temperature would result in a significant loss of liner life would depend on how the engine was used; a base load unit would be less affected than a peaking unit because of the greater number of hours per thermal cycle. (See Section 3.2.2.1 on Liner Durability)

It is therefore important in the formation and processing of the pyrolysis liquids to reduce tar, char, and ash as well as to increase hydrogen content. The effect of the water may be beneficial in this case, but needs to be confirmed. 


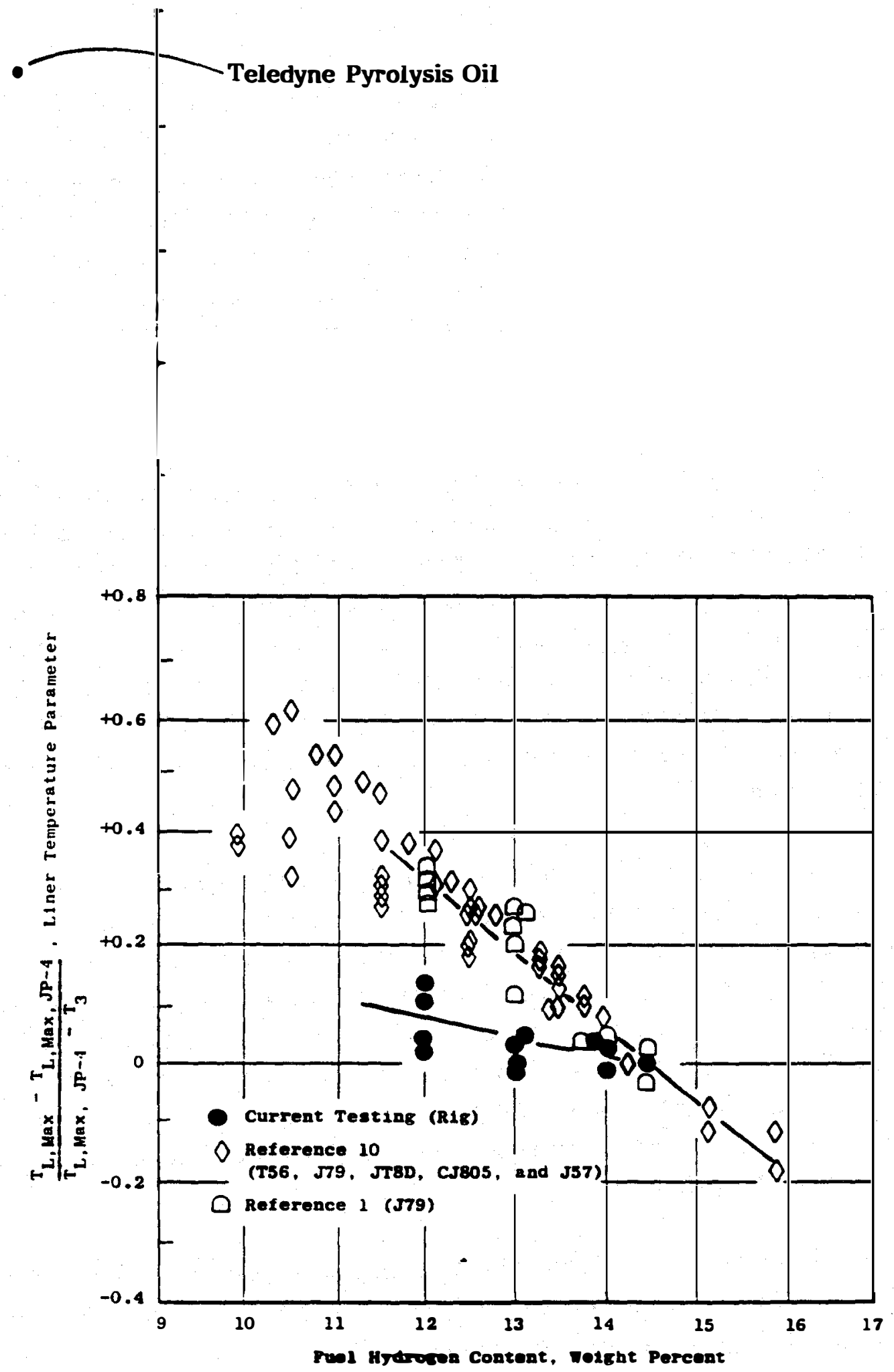

FIGURE 27. Liner Temperature parameter for the Combustion of a Pyrolysis Oil in a Gas Turbine Combustor 


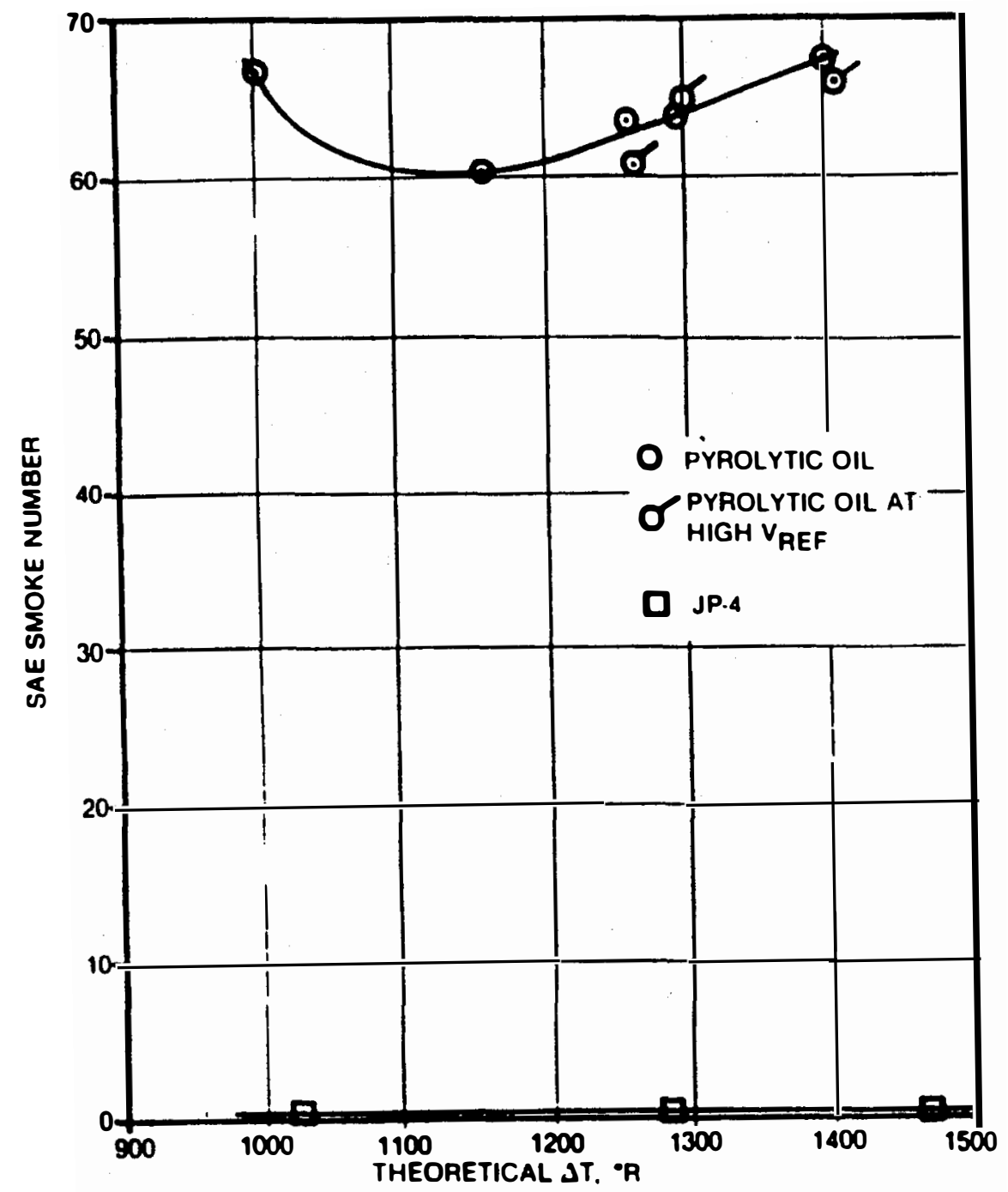

FIGURE 28. Smoke Emissions from the Combustion of a Pyrolysis Liquid in a Gas Turbine Combustor (Ref. 27) 


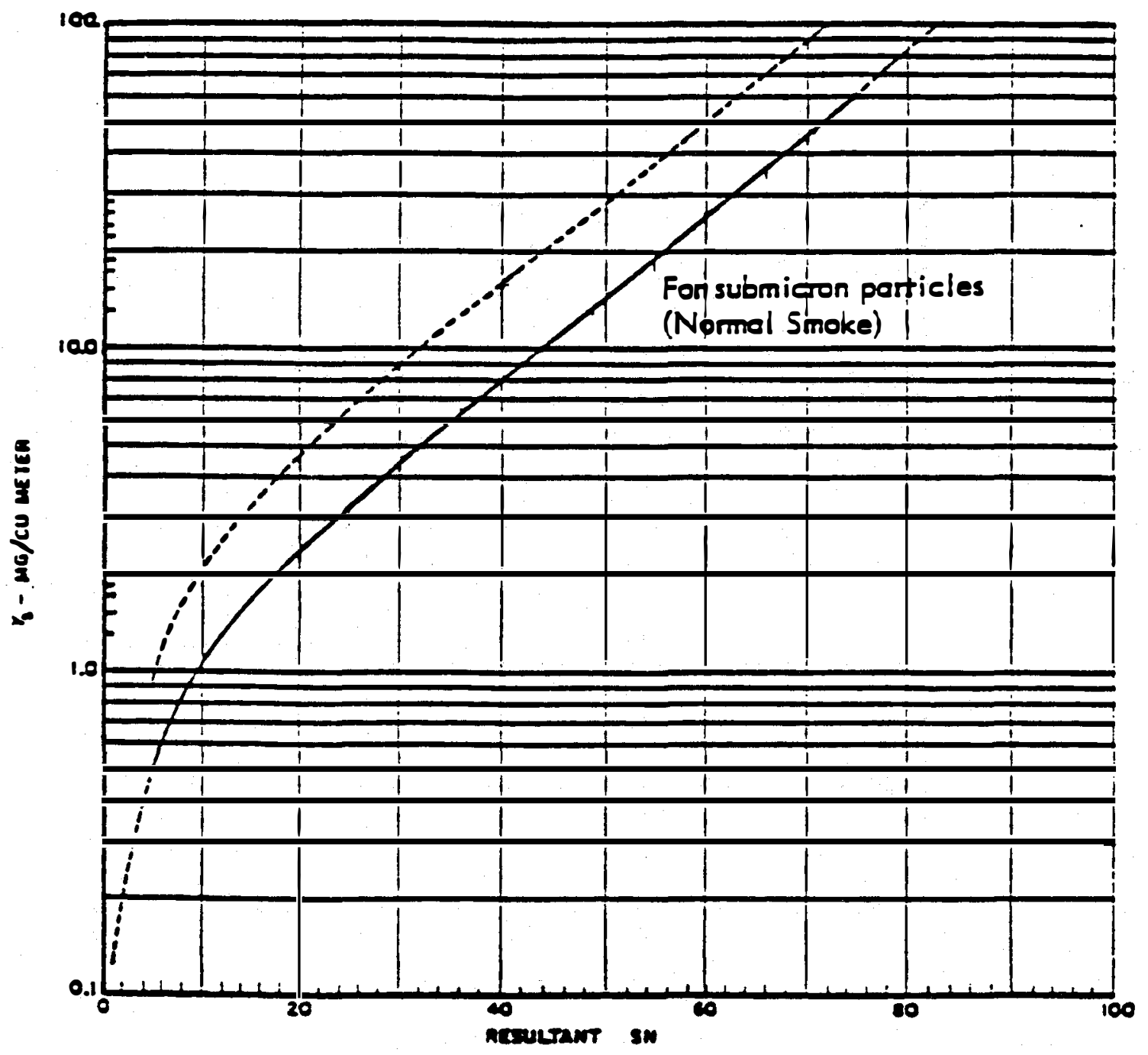

FIGURE 29. Correlation Between SAE Smoke Number and Exhaust Carbon (Ref. 37) 


\subsubsection{Thermal Stability}

Thermal stability is a measure of a fuels ability to resist reacting or decomposing to form deposits when heated. These deposits can form on critical heat transfer surfaces, in valves and fuel controls, or in small flow passages inside the fuel atomizer. Thermal stability is controlled for jet fuels with the Jet Fuel Thermal Oxidation Tester (JFTOT) in which the test fuel is flowed for five hours over a tube heated to $500^{\circ} \mathrm{F}$; to pass the test, only a very slight coloring of the tube is allowed. Diesel fuels for power plants are not subjected to such a test, but they are not used to cool aircraft and engine components as is the case for jet fuel. Special JFTOT tests have been conducted on diesel fuels to determine the temperature at which they do begin to form deposits, with results usually in the 450 to $500^{\circ} \mathrm{F}$ range.

It has been reported that some pyrolysis liquids become increasingly unstable at temperatures above $200^{\circ} \mathrm{F}$, giving off gases and polymerizing. $(26,46)$ This is cause for concern for two reasons. One, it would be advantageous to be able to heat the liquid to reduce the viscosity to enhance the atomization and improve performance as previously discussed. Also, in high-pressure-cycle aeroderivatives, it is not uncommon for atomizer metal temperatures to be well over $300^{\circ} \mathrm{F}$ since compressor discharge air is flowing around them.

Some testing should be conducted on the thermal stability and deposit-forming tendencies of biomass pyrolysis liquids to determine the range of atomizer metal temperatures that would be compatible with this class of fuels and determine if special precautions or design changes are necessary. If there is a significant problem, research could also be conducted to determine the species which are most responsible for the low thermal stability which would provide guidance for an improved pyrolysis process.

\subsubsection{Heat of Combustion}

The pyrolysis liquids shown in Table 6 have lower heating values, LHV, which are about half that of typical diesel fuels. This means that considerable upsizing of pumps, fuel controls, and atomizers would be required to handle the larger volume flow.

\subsubsection{Materials Compatibility}

Materials compatibility falls into two categories: metals, used for storage facilities and fuel system components, and elastomers which are used for seals and gaskets. 
Pyrolysis liquids tend to be quite acidic, with $\mathrm{pH}$ factors around 3 not too uncommon. This means the fuels would be quite corrosive to mild steel, a common material for storage tanks, fuel lines, valve housings, etc. This was verified in the Teledyne study $(26,27)$ which also reported no corrosion of a stainless steel after seven days at $180^{\circ} \mathrm{F}$.

The Teledyne experience was inconclusive concerning elastomer compatibility with the pyrolysis liquid used. Huffman et al found that Buna N, Viton, and Neoprene are not suitable elastomers for use with pyrolysis oils, but that EPDM, polypropylene, and Teflon are satisfactory.(48)

A fairly consistent fuel might be important here, because even though the elastomers selected might be compatible with the original fuel, another pyrolysis liquid with significant change in fuel composition might be incompatible, resulting in leaks or component damage.

\subsection{TOPICAL SUMMARY ON PYROLYSIS LIQUIDS}

In summary it would appear that pyrolysis liquids will be more difficult to use in gas turbines than the biomass-derived gases will be. It is not possible to be as definitive in this summary as with the biomass gases because the latter were much closer to fuels which have been successfully used. Only one test on pyrolysis liquids in a gas turbine combustor has been reported in the literature. Thus, the summary on liquids must be more general.

The major problems can be summarized into three areas:

- High contaminants, especially alkali

- High viscosity and boiling range

- Low hydrogen content

If the difficulties with the high alkali and ash can be resolved, the other problem areas seem to be manageable. Given that the alkali cannot be removed by normal water washing, either these contaminants must be removed in processing or modifications must be made to the engine design and/or operation. Two methods were mentioned in the text earlier: apply advanced coatings to older machines operating at lower temperatures or use the machines for peaking and accept the reduced life.

A third concept is possible, namely buming the pyrolysis oil in an external combustor with a hot gas clean-up unit between the combustor and the turbine. Such a concept has been 
developed by Allison in a program under DOE sponsorship for the direct firing of dry coal or coal-water slurries.(38) Figure 30 illustrates the concept which has been applied to a $501 \mathrm{~K}$ engine. Basically, the air is removed from the engine housing just after the compressor and diverted to a large, staged-combustion section followed by a hot-gas cleanup section, which reduces the alkali and ash to an acceptable level. The clean, hot gas is then returned to the engine housing and the turbine for expansion and work. The combustor is a rich-bum, quickquench, lean-burn system for low $\mathrm{NO}_{\mathbf{x}}$. Since the combustor is extemal to the engine housing, it can be designed with sufficient residence time to ensure complete combustion of the coal. This concept should be readily adaptable to pyrolysis liquids and represents a novel opportunity to use these difficult fuels in an aeroderivative engine.

The high viscosity and boiling range produce fuel drops which require much longer burning time than the combustors provide; the aeroderivatives will be especially sensitive. The longer burning times will degrade almost all aspects of combustor performance. These problems can be addressed by better atomization; however, it is not possible to predict how much better using current models for conventional fuels.

The low hydrogen content will produce higher soot concentrations in the combustor. This, along with the presence of ash, char, and tar, will increase the flame radiation and the liner temperature reducing combustor life. Also exhaust particulates will be increased. The presence of the high water concentrations and oxygenated species may reduce the soot formation.

The combination of high viscosity, low volatility, and low heat content is pyrolysis liquids will require that the gas turbine be started on a distillate fuel followed by switchover to the pyrolysis liquid once the machine has reached operating temperature. Pyrolysis liquids will probably have to be heated to reduce the viscosity in order to get them to flow satisfactorily. This means the fuel lines will have to be heat traced, but care must be taken not to decompose the fuel. Startup and shut down will have to be with a distillate fuel to avoid leaving the lines filled with a viscous or semi-solid fuel. It will be important to heat the distillate fuel prior to switchover to avoid thermal shock to components of the fuel system. 


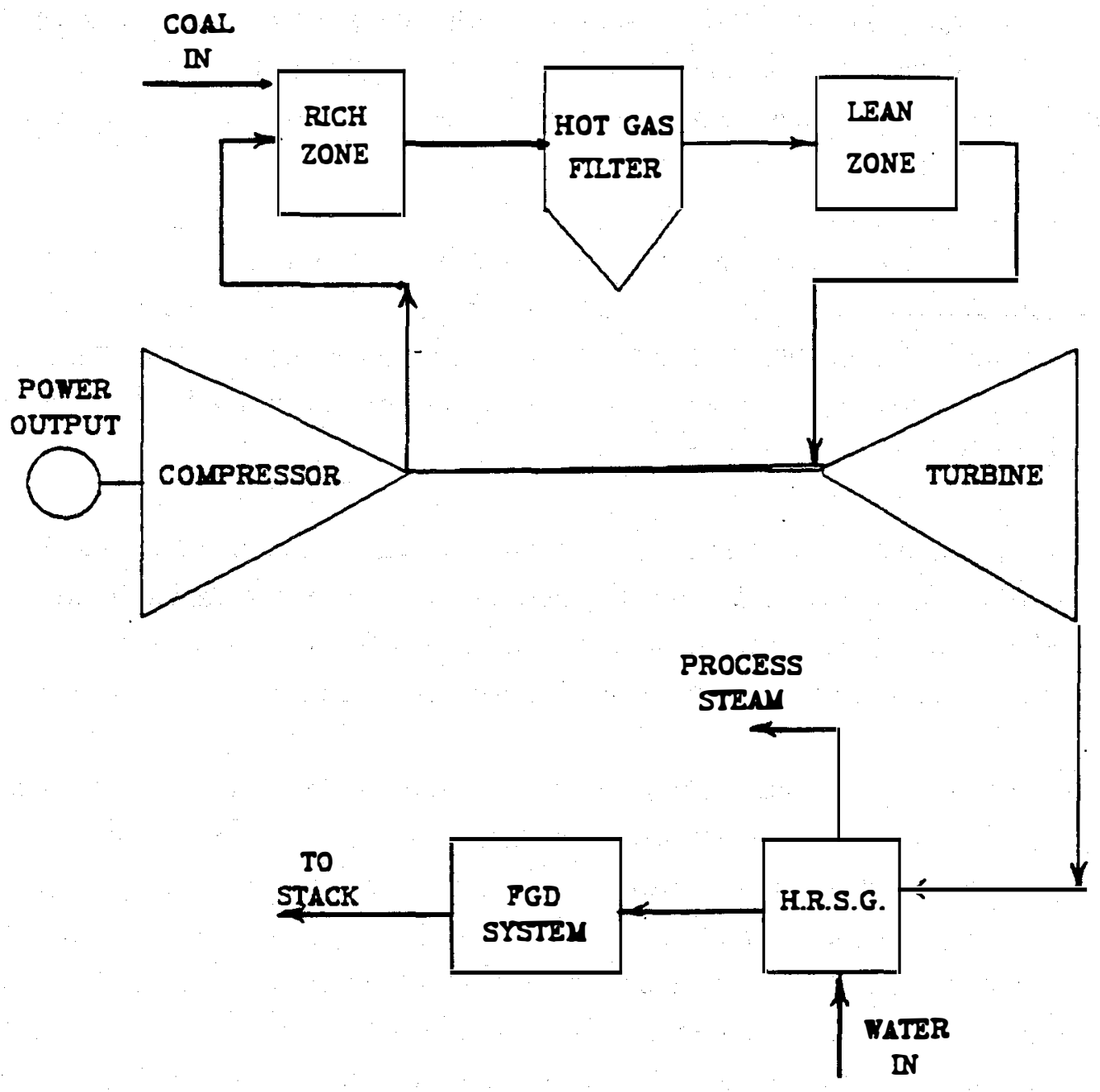

FIGURE 30. Schematic of a Gas Turbine with an Extermal Combustor and Hot-Gas Cleanup (Ref. 38) 


\subsection{CONCLUSIONS}

Technically speaking, biomass derived fuels have a potential for use in gas turbine machines for power generation, but judging from the physical and chemical fuel properties that were provided by NREL for consideration, some modifications to the machines will be necessary to obtain satisfactory performance and durability.

\subsection{GAS TURBINE SYSTEMS}

Industrial gas turbines have several general characteristics that will make them more tolerant of biomass derived fuels than aeroderivative machines. Their design and construction makes it easier to install larger fuel injectors to accommodate the low-Btu gases. Their longer residence times for combustion will allow the high viscosity liquids to bum more completely, as well as the tar and char that might be present in both types of fuel. The larger flow passages in the turbine section may be somewhat more tolerant of deposition, although any deposition is undesirable.

Although aeroderivative machines are considered more efficient than industrials, the reasons for this are what make them less tolerant of fuel variations. For example, they have more aggressive cooling schemes for the turbine blades and vanes to allow higher gas flow temperatures, but if the cooling holes become covered by deposits, then durability will suffer

significantly. Aeroderivatives should not have any significant difficulties accommodating most biomass-derived gases, although the limitation on minimum Btu content will be different for each type of machine. The aeroderivatives will require significant improvement in atomization quality, i.e, a much finer spray, to get satisfactory burnout of the pyrolysis liquids.

A gas turbine machine with an external combustor has been developed for the direct firing of coal. This concept would be the most fuel tolerant since the combustor could be designed with sufficient residence time for complete bumout of the pyrolysis liquids. This would be followed by a hot-gas cleanup to remove ash and alkali before returning the flow to the engine housing and the turbine section.

\subsection{BIOMASS GASES}

Biomass gases will be considerably easier to use in gas turbines than the pyrolysis liquids. 
There are some concerns, but solutions appear to be directly applicable from other experience with low- and medium-Btu gases.

The major concern with the use of biomass gases is the levels of contaminants, i.e., alkali, ash, char, and tar, that may be carried over from the gasifier. These contaminants have a significant effect on the durability of the turbine section. While the levels appear to be much

greater than any gas turbine can tolerate, the levels should be controllable. The level of contaminants depends upon the feedstock used for the gasifier, the type of gasifier, and its operating conditions, but some sort of hot gas cleanup may be required. It is important to note that whenever there is a change in the feedstock to the gasifier, an evaluation of these contaminants will have to be made and the operating conditions of the gasifier and cleanup system adjusted accordingly to keep these contaminants within acceptable limits.

To achieve satisfactory performance on the gases, the fuel system and the combustor would have to be modified to account for the lower heat contents of these fuels relative to natural gas. These modifications would be standard changes that are normally incorporated for the use of medium- and low-Btu gases.

The temperature of the gases will have to be kept at levels which are compatible with the materials selected. Above about $750^{\circ} \mathrm{F}$, the systems will have to be welded. No leaks can be tolerated because of the presence of hot hydrogen.

\subsection{PYROLYSIS LIQUIDS}

It is more difficult to judge the probability of using pyrolysis liquids in gas turbines than it is for the gases because several critical properties are far from the range of experience with any distillate fuel, residual fuel, or alternate fuel such as derived from coal or shale oil. Pyrolysis oils made from wood seem to have more favorable properties than those made from grasses.

As with the gases, the most critical problem is the alkali and ash content. The levels of alkali are several orders of magnitude higher than any gas turbine machine can tolerate. For conventional fuels with high alkali content, the alkali can be effectively removed by water washing. This will not be applicable to the biomass pyrolysis liquids, and no other means of alkali removal was identified. Therefore it is important to find a means to remove the alkali and ash from the oil during the pyrolysis or in postprocessing. An alternative might be to remove all of the sulfur, but this needs to be verified. 
The data bases for some pyrolysis liquids included chlorine as a contaminant. This is an important contaminant to report since alkali chlorides in the hot gas stream can accelerate corrosion, although definitive limits have not been defined.

Some pyrolysis oils have been found to contain chlorine. Caution is recommended because, while alkali chlorides accelerate the degradation of protective coatings on blades and vanes, definitive limits have nota been established.

In order to achieve satisfactory combustion, the atomization will have to be considerably better than for a distillate fuel of the same viscosity because the higher boiling point materials and tars will require longer to burn.

Char slurries should probably be avoided since the char will probably not burn efficiently in the combustor, certainly not in aeroderivatives, and they will only cause problems through increased viscosity and erosion.

The combination of high viscosity, low volatility, and low heat content is pyrolysis liquids will require that the gas turbine be started on a distillate fuel followed by switchover to the pyrolysis liquid once the machine has reached operating temperature. Pyrolysis liquids will probably have to be heated to reduce the viscosity in order to get them to flow satisfactorily. This means the fuel lines will have to be heat traced, but care must be taken not to decompose the fuel. Startup and shut down will have to be with a distillate fuel to avoid leaving the lines filled with a viscous or semi-solid fuel. It will be important to heat the distillate fuel prior to switchover to avoid thermal shock to components of the fuel system. 


\subsection{RECOMMENDATIONS}

Several critical voids have been identified in the data base which limit the conclusions which can be drawn on the use of biomass gases and pyrolysis liquids. These are:

- The effect of alkali content on hot corrosion with very low concentrations of sulfur

- The nature of the ash, i.e., size, melting point, and abrasiveness

- The effect of chlorine on oxidation and corrosion

- The thermal stability of pyrolysis liquids and the chemical factors which limit this property

- Effects of physical properties of pyrolysis liquids on atomization, burning times, and combustion efficiency

- Effects of physical and chemical properties of biomass fuels on soot formation and hence on flame radiation and liner temperature.

- Effects of the chemical composition of biomass liquids on the composition of the exhaust hydrocarbons.

The first two items are associated with both the gaseous and liquid fuels. Since these two items present the most significant barriers to utilization, these data are needed to provide more relevance to the limitations on alkali and ash. Most of the technologies that have been developed in deposition, erosion, and corrosion are oriented toward improving durability at higher temperatures on conventional fuels. Very little effort has been put into applying advanced technologies at lower temperatures to improve the tolerance to alkali. A workshop on this subject would be very beneficial, and have immediate application for biomass gases.

The last four items apply only to the pyrolysis liquids, and are needed to better evaluate the significance of these problems since the relevant properties of the biomass liquids are too far away from current experience to permit the extrapolation of accepted models. Such data should precede any engine demonstration tests. For example it will be necessary to correctly size the atomizer in order to correctly interpret the results. Experiments of this kind should be carried 
out on a small combustor for which a data base exists on fuel effects on performance and durability factors; the objective would be to extend that data base and the models into the regime of pyrolysis liquids. The extended models would then be applied to large combustors more relevant to the power industry.

If these recommendations are followed, not only will a more complete evaluation be possible, but the data will reduce the cost of testing large combustors by guiding initial design factors, such as atomization, and identifying the pertinent testing to be done. 


\subsection{REFERENCES}

1. Lefebvre A H, Gas Turbine Combustion, Hemisphere Publishing Company, New York, 1983.

2. Jasuga, A K, "Atomization of Crude and Residual Oils," ASME Paper 78-GT-83.

3. El-Shanawany and Lefebvre, A H, "Air-Blast Atomization; the Effect of Linear Scale on Mean Drop Size," ASME Paper 80-GT-74

4. Rizkalla A A and Lefebvre A H, "The Influence of Air and Liquid Properties on Air-Blast Atomization," J. of Fluids Engineering, 97,3 1975, pp 316-320.

5. Bridgewater A V and Heaton J, "Biomass Gasification Based Power Generation: Technology and Potential," Conference Proceedings: Package Power Stations for Export, Inst of Mech Engineers, Power Industry Div, Nov 7, 1985, Mechanical Engineering Publications Ltd, Bury St, Edmunds England, 1985.

6. Piscitello S, Gray E E, Bain R, and Overend R P, "Biomass Power in the USA," Power Generation Technology, ed. Richard Knox, Sterling Publications Int. Ltd., London, 1993.

7. Odgers $\mathrm{J}$ and Kretchmer D, Gas Turbine Fuels and Their Influence on Combustion, Energy and Engineering Science Series, Abacus Press, Cambridge Mass, 1986.

8. Meir J G, Hung W S Y, and Sood V M, "Development and Application of Industrial Gas Turbines for Medium-Btu Gaseous Fuels," ASME Paper No. 85-GT-28.

9. Cutrone M B, Savelli J F, and Doering H V E, "Evaluation of Medium-Btu Gas Combustion," General Electric Company, Gas Turbine Division, Schenectady NY, Final Report No. DOE/RA/50552--1220 Vol. 4, February 1982.

10. Koblish T R and Nucci L M, "High Temperature Combustor Designed for Operation with Coal Derived Low Btu Gaseous Fuels," ASME Paper No. 80-GT-187, 1980.

11. Provided by B. C. Schlein during visit to Pratt \& Whitney December 15, 1992.

12. Pillsbury P W and Lin S S, Advanced Coal Gasification System for Electric Power Generation--Development of Full-Size Gas Turbine Combustors Using Synthetic Low-Btu 
Gas at 350 F," Westinghouse Electric Corporation, Lester, PA, ERDA Technical Status Report FE-1514-52, UC-90c, July 1976.

13. Vogt R L, "Low Btu Coal Gas Combustion in High Temperature Turbines," ASME Paper 80-GT-170, 1980.

14. Battista R A and Farrel R A, "Development of an Industrial Gas Turbine Combustor Buming a Variety of Coal-Derived Low Btu Fuels and Distillate," ASME Paper No. 79-GT-172, 1979.

15. Zeldovich J, "The Oxidation of Nitrogen in Combustion and Explosions," Acta Physicochimica U.R.S.S, Vol. XXI, No. 4, 1946, pp. 577-628.

16. Schiefer R B and Sullivan D A, "Low Btu Fuels for Gas Turbines," ASME Paper 74-GT-21, 1974.

17. Corman J C and Horner M W, "Hot Gas Clean-Up for a Moving Bed Gasifier," Chapter 14 in Proceedings of 5th Annual Contractors' Conference on Coal Gasification, AP-4680, Electric Power Research Institute, Palo Alto CA, 1986.

18. Williams R H and Larson E D, "Advanced Biomass Power Generation," presented at Conference on Technologies for a Greenhouse Constrained Society, Oak Ridge TN, proceedings published by Lewis Publishers, Chelsea MI, June 11-13, 1991.

19. Mingle J G and Junge D C, "Investigation of the Viability and Cost Effectiveness of Solid Fuel Gasifiers Close Coupled to Internal Combustion Engines for $200 \mathrm{KWe}$ Power Generation," Technical Progress Report No. 9, Prepared for US DOE Division of Fossil Fuel Utilization under Contract No. EY-76-C-06-2227, Task Agreement 22, Oregon State University, Corvallis OR, January 1976.

20. ASTM D 2880, "Standard Specification for Gas Turbine Fuel Oils," Annual Book of ASTM

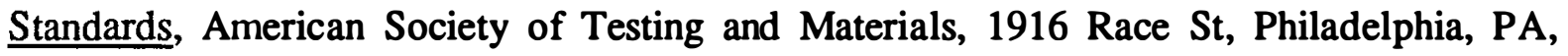
19103

21. "Liquid Fuel for GE Aircraft Engines Derivative Gas Turbines in Industrial Applications," MID-TD-0000-2, GE Aircraft Engines, Marine \& Industrial Engine Projects Department, Cincinnati, OH, November 1991. 
22. Heavy Distillate Fuel, Marine \& Industrial" PWA 539, Pratt \& Whitney Aircraft Division, East Hartford CT, March 1970.

23. Military Specification, MIL-T-5624, "Turbine Fuel, Aviation, Grades JP-4, JP-5, and JP-5/JP8 ST," POSF, Wright-Paterson AFB, OH, 45433.

24. Military Specification, MIL-T-83133, "Turbine Fuels, Aviation, Kerosene Types, NATO F-34 (JP-8) and NATO F-35," POSF, Wright-Patterson AFB, OH 45433.

25. ASTM D 1655, "Standard Specification for Aviation Fuels," Annual Book of ASTM Standards, American Society of Testing and Materials, 1916 Race St, Philadelphia, PA, 19103.

26. Kasper J M, Jasas G B, and Trauth R L, "Use of Pyrolysis-Derived Fuel in a Gas Turbine Engine," ASME Paper No. 83-GT-96, 1983.

27. Jasas G B, Kasper J M, and Trauth R L, "Gas Turbine Demonstration of Pyrolysis-Derived Fuels," Final Report DOE Contract No. DE-AC03-78ET13333, Teledyne CAE, Toledo OH, April 1983.

28. Russell J A, Moses C A, and Schwalb J A, "Residual Fuel Oil User's Guidebook, Volume 3: Residual Oil-Fired Gas Turbines" EPRI Report No. EPRI AP-5826, Southwest Research Institute, San Antonio, TX, May 1988.

29. Earnst R and Andreadis D, "Fuel Effects on Gas Turbine Engine Combustion," AFWAL-TR83-2048, Wright Aeronautical Laboratory, Wright-Patterson AFB, June 1983.

30. Naegeli D W and Moses C A, "Effects of Fuel Properties on Soot Formation in Turbine Combustion," SAE Paper 781026, November 1978.

31. Naegeli D W and Moses C A, "Fuel Microemulsions for Jet Engine Smoke Reduction," ASME Paper 82-GT-33, May 1982.

32. Wenglarz R A, "Deposition, Erosion, and Corrosion Protection for Coal-Fired Gas Turbines," ASME Paper No. 85-IGT-61, 1985. 
33. "Gas Fuel Specification, Combustion Turbines," Westinghouse Electric Corporation, Generation Systems Division, Lester, PA.

34. Henry J F, Talib A, and Ford K, "Handbook of Biomass Conversion Technologies for Developing Countries," United Nations Industrial Development Organization Report No. PB85-105427, Vienna, Austria, April 1984.

35. Czernik S, Johnson D K, and Black S, "Stability of Wood Pyrolysis Oil," NREL, manuscript in preparation.

36. Moses C A and Stavinoha L E, "Gas Chromatographic Analysis of Exhaust Hydrocarbons from a Gas Turbine Combustor," Southwest Research Institute, San Antonio TX, presented before the Western States Section Meeting of the Combustion Institute, Stanford Research Institute, Palo Alto CA, October 1975.

37. Champagne D L, "Standard Measurement of Aircraft Gas Turbine Engine Exhaust Smoke," ASME Paper No. 71-GT-88, 1971.

38. Ali S A, "Fuel Flexible Combustion Turbines for Industrial Customers," Presented at the ASME Industrial Power Conference, Allison Gas Turbine Division, Indianapolis, IN, Oct 1990.

39. Gleason C G, Oller T L, Shayeson M W, and Bahr D W, "Evaluation of Fuel Character Effects on the F101 Engine Combustion System," Report No. AFAPL-TR-79-2018, Air Force Aeropropulsion Laboratory, Wright-Patterson AFB, OH, June 1979.

40. Moses C A and Karpovich P A, "Fuel Effects on Flame Radiation and Hot-Section Durability," NATO/AGARD Conference Proceedings No. 422, Combustion and Fuels in Gas Turbine Engines, Chania, Crete, Greece, October 1987.

41. Wenglarz R A, "Evaluations of Particulate Fouling in Gas Turbines and Fuel Cells," Proceedings of the Engineering Foundation Conference on Fouling of Heat Exchange Surfaces, White Haven, PA, 31 October to 5 November, 1982, pp. 277-287.

42. Bernstein $\mathrm{H} \mathrm{L}$ and Allen J M, "A Review of High Temperature Coatings for Combustion Turbine Blades," to be published in the Proceedings of the EPRI Steam and Combustion Turbine Blading Conference, pp. 6-19 to 6-47, 1992. 
43. Schirmer R M and Quigg H T, "Effect of Very Low Sulfur in JP-5 Fuel on Hot Corrosion," Proceedings of the Tenth National Conference on Environmental Effects on Aircraft and Propulsion Systems," 1971, pg. 1-1

44. Boothe W A and McMullen J C, "Heavy Duty Gas Turbine Design Changes is Use with Low Btu Coal Gas, ASME Paper No. 79-GT-198, 1978

45. Lefebvre A H, Atomization and Sprays, Hemisphere Publishing Corporation, New York, 1989

46. Piskorz J, Scott D S, and Radlein D, "Composition of Oils Obtained by Fast Pyrolysis of Different Woods," Chapter 16, Pyrolysis Oils from Biomass. E.J. Soltes and T.A. Milne, ed. ACS Symposium Series 376, 1988.

47. Foltz $\mathrm{H} \mathrm{L}$ and Kenworthy $\mathrm{M} \mathrm{J}$, "A Procedure for Evaluating Fuel Composition Effects on Combustor Life," ASME Paper No. 82-GT-296, May 1982.

48. Huffman D R, Vogiatzis A J, Graham R G, and Freel B A, "The characterization and Combustion of Fast Pyrolysis Bio-Oils," first European forum on Electricity Production from Biomass and Solid Wastes by Advanced Technologies, Florence, Italy, 1991.

49. Paton N E, Robertson W M, and Mansfeld F, "High Temperature Behavior of Superalloys Exposed to Sodium Chloride: I. Mechanical Properties," Metallurgical Transactions, Vol. 4, pp. 317-320, January 1973.

50. Jones $\mathrm{R} \mathrm{L}$ and Gadomski S T, "The Hot Corrosion of CoCrAlY Turbine Blade Coatings by $\mathrm{Na}_{2} \mathrm{SO}_{4}$ and Vaporous NaCl," Solid-State Science and Technology, Vol. 124, No. 10, pp. 1641-1648, October 1977.

51. Smeggil J G and Bornstein N S, "The Effect of $\mathrm{NaCl}(\mathrm{g})$ on the Oxidation of NiAl," SolidState Science and Technology, Vol. 125, No. 8, pp. 1283-1290, August 1978.

52. "Current Awareness Bulletin," Issue No. 202, Metal and Ceramics Information Center, Battelle Memorial Laboratories, Columbus, OH, June 1990. 
APPENDIX A

CORROSION, EROSION, DEPOSITION, AND

HIGH-TEMPERATURE COATINGS 


\section{CORROSION, EROSION, DEPOSITION, AND \\ HIGH-TEMPERATURE COATINGS}

Deposition, erosion, and corrosion (DEC) involve the interaction of particles and chemicals in the gas stream with the surfaces of the gas turbine hardware, particularly the blades and vanes. In deposition, the particles and chemicals accumulate on the surfaces of the airfoils, whereas in erosion, the particles remove a small portion of the surface of the airfoils. ${ }^{1}$ In corrosion, the particles and chemicals that have been deposited attack the airfoil surfaces by various chemical reactions. All three processes can be very destructive to either the gas turbine integrity or performance. Deposition and erosion are competing processes in that erosion removes the deposits, and the deposits protect the base metal from the erodants.

There is a large amount of literature on DEC and high-temperature coatings. Four writeups served as primary sources for this section. These are three writeups on High-Temperature Coatings and high-temperature attack by Bernstein, et al. [1-3]. The fourth writeup is a summary paper by Wenglarz [4].

This section is divided into six sub-sections: High-Temperature Environmental Attack; Protective Coatings; Deposition, Erosion and Corrosion; Contaminants; Impact of Biomass Fuels on DEC; and Recommendations. Each of the first four sub-sections gives a brief summary of the topic as it relates to the use of biomass fuels. The sub-section on "Contaminants" addresses fuel specifications. The sub-section on "Impact of Biomass Fuels on DEC" attempts to tie the previous four sub-sections together as they relate to the use of biomass fuels. The last sub-section on "Recommendations" gives a number of specific items and actions to consider and a brief rationale for each one.

\subsection{HIGH-TEMPERATURE ENVIRONMENTAL ATTACK}

There are three forms of high-temperature environmental attack that gas turbines are subjected to. These are high-temperature oxidation, high-temperature hot corrosion

1 The term "airfoils" refers to both blades and vanes. 
(or Type I hot corrosion), and low-temperature hot corrosion (or Type II hot corrosion). Figure 1 is a schematic of the range of temperatures in which these types of environmental attack occur. ${ }^{2}$ Variation in these temperature ranges is due to the specific chemistries of the base metal and the gas stream.

All three types of attack are possible in a gas turbine. High-temperature oxidation will always occur to a greater or lesser extent depending upon the surface metal temperature of the airfoils. High-temperature hot corrosion in the first or second stage of the turbine can be followed by low-temperature hot corrosion in the latter stages, which are cooler. And, for large, air-cooled, heavy duty, industrial gas turbine blades, all three forms of attack are possible on the same blade due to large temperature differences that can exist over the blade.

\subsection{High-Temperature Oxidation}

High-temperature oxidation is the oxidation of the metal and its alloying elements. It results in the formation of an external oxide scale that may or may not be protective. In addition, an internally oxidized region may exist beneath the metal surface. Internal oxidation is caused by the diffusion of oxygen into the metal. High-temperature oxidation accelerates with higher temperatures.

Protection from high-temperature oxidation is provided by the formation of a compact, adherent aluminum oxide $\left(\mathrm{Al}_{2} \mathrm{O}_{3}\right)$ scale. This scale is a barrier between the high-temperature gases and the underlying metal. Chromium oxide $\left(\mathrm{Cr}_{2} \mathrm{O}_{3}\right)$ scales can be used, but they are less protective above 1550 to $1600^{\circ} \mathrm{F}$ because their oxidation rate is relatively high [5].

\subsection{Hot Corrosion}

There are two types of hot corrosion, high-temperature hot corrosion and low-temperature hot corrosion. High-temperature hot corrosion, also called Type I hot corrosion, occurs at metal temperatures between $1500^{\circ} \mathrm{F}$ to $1750^{\circ} \mathrm{F}$ when sulfur is present along with potassium or sodium. It is most severe at temperatures between

2 All temperatures refer to the surface metal temperature. 
$\omega$

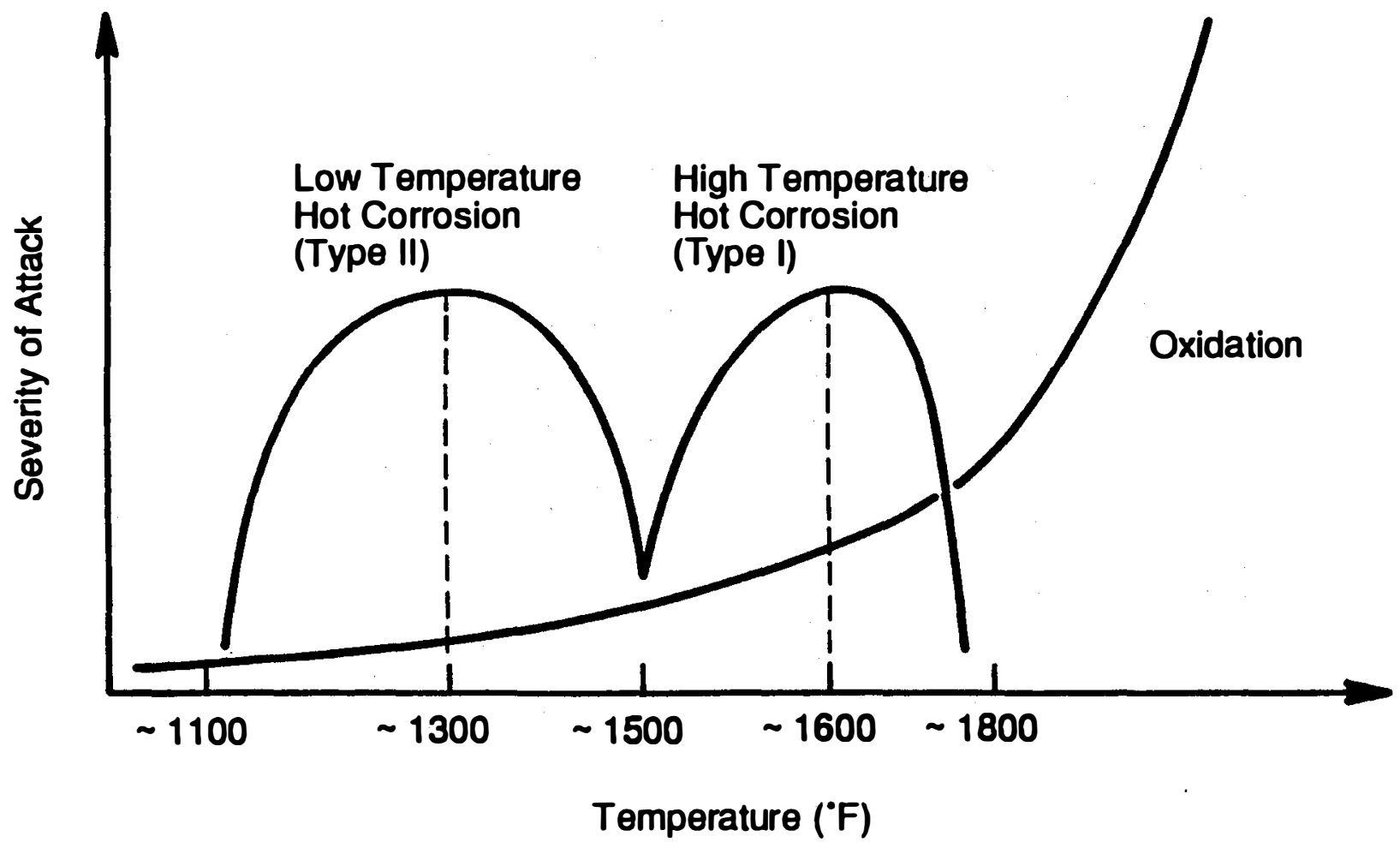

FIGURE 1. Types of High-Temperature Attack: Approximate Temperature Regimes and Severity of Attack (3) 
1600 to $1700^{\circ} \mathrm{F}$. High-temperature hot corrosion is caused by the formation of alkali metal salts, such as sodium sulfate $\left(\mathrm{Na}_{2} \mathrm{SO}_{4}\right)$ or potassium sulfate $\left(\mathrm{K}_{2} \mathrm{SO}_{4}\right)$, which melt and form a liquid salt on the surface of the airfoil. This molten salt destroys the protection provided by the oxide scale, allowing sulfidation and oxidation of the metal. High-temperature hot corrosion results in the rapid destruction of the metal surface.

High-temperature hot corrosion has two stages: an incubation stage and a propagation stage. In the incubation stage, a protective oxide scale is present, and prevents attack of the base metal or coating. After this scale has been attacked and breached by the molten salt on the surface, the propagation stage of high-temperature hot corrosion commences. ${ }^{3}$ In the propagation stage, the characteristic features of high-temperature hot corrosion are found. Sulfur diffuses into the metal and reacts with alloying elements to form metal sulfides. Oxygen then diffuses into the metal and reacts with the metal sulfides to form metal oxides. The sulfur is then released and diffuses deeper into the metal, repeating this process. As shown in Figure 2, the amount of attack during the incubation stage is very low, but it is high in the propagation stage.

Protection from high-temperature hot corrosion is provided by the formation of an adherent aluminum oxide $\left(\mathrm{Al}_{2} \mathrm{O}_{3}\right)$ scale, which is free of impurities, such as $\mathrm{Mo}$ and W. Simple aluminide coatings are not resistant to high-temperature hot corrosion. The addition of chromium to an aluminide coating significantly improves its resistance to high-temperature hot corrosion. Platinum-aluminide coatings are resistant to high-temperature hot corrosion, as are overlay coatings containing aluminum and chromium.

Low-temperature hot corrosion, also called Type II hot corrosion, occurs at temperatures between $1100^{\circ} \mathrm{F}$ to $1500^{\circ} \mathrm{F}$ with a maximum rate of attack between $1250^{\circ} \mathrm{F}$ to $1350^{\circ} \mathrm{F}$. It is caused by the mixture of sodium sulfate with alloy metal sulfates, such as $\mathrm{CoSO}_{4}$ or $\mathrm{NiSO}_{4}$, and requires a significant partial pressure of $\mathrm{SO}_{3}$. Low-temperature hot corrosion results in pitting of the metal surface; a porous, layered scale; little base metal depletion; and few internal sulfides. The rate of pitting can be as

3 Various mechanisms for the incubation stage exist, but are not always agreed upon. These mechanisms involve complex, high-temperature chemical reactions. 


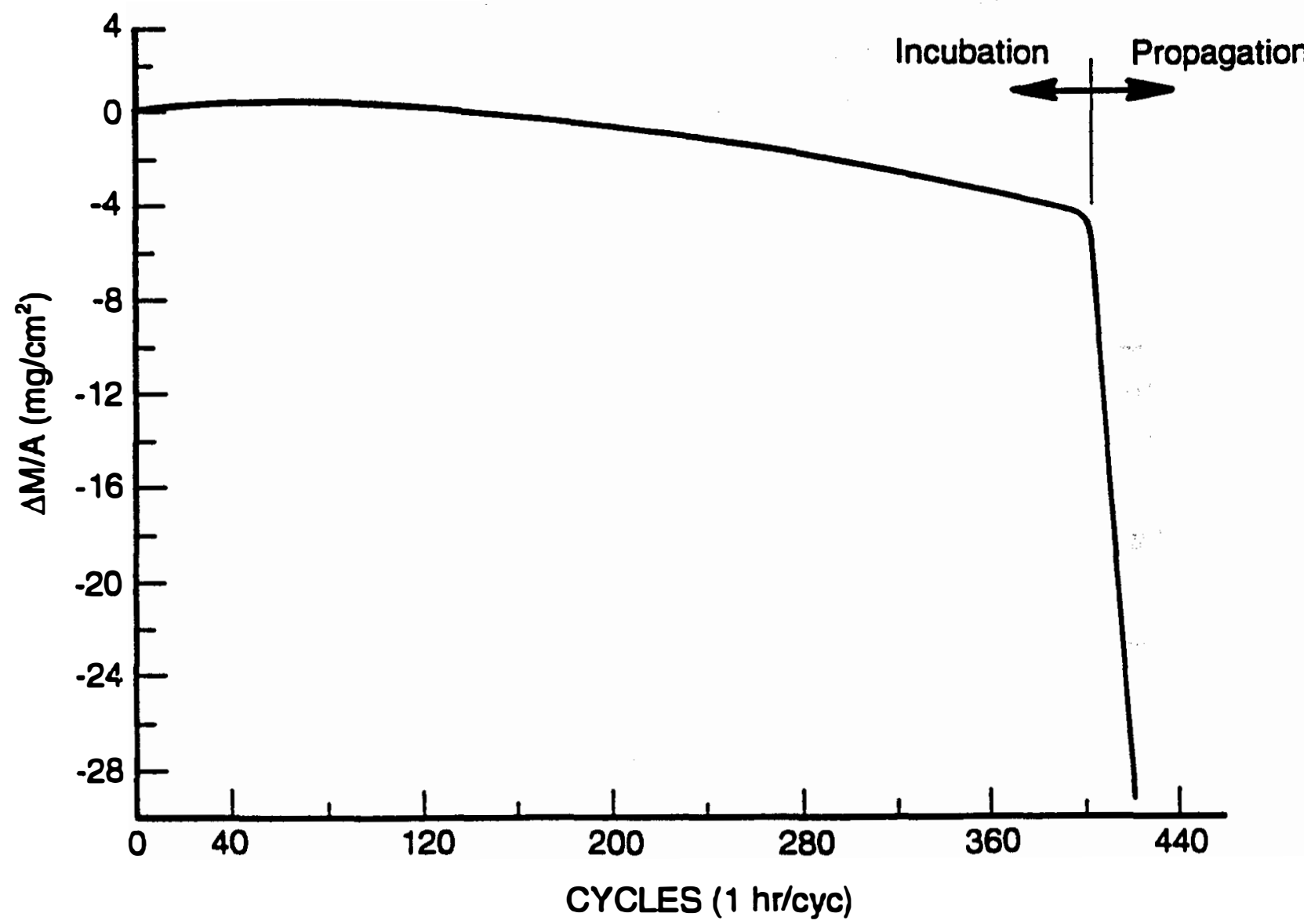

FIGURE 2. IVeight Change Versus Time for the Cyclic Hot Corrosion of $\mathrm{Na}_{2} \mathrm{SO}_{4}$-Coated (applied every $20 \mathrm{~h}$ ) $\mathrm{Ni30Cr}-4 \mathrm{Al}$ in Air (34) 
great as the rate of attack of high-temperature hot corrosion. Goward [6] has reviewed low-temperature hot corrosion and protective coatings for this type of attack.

Protection from low-temperature hot corrosion is provided by the formation of an adherent chromium oxide $\left(\mathrm{Cr}_{2} \mathrm{O}_{3}\right)$ scale. $\mathrm{Cr}_{2} \mathrm{O}_{3}$ is not attacked by the molten sulfates and serves as a barrier between the metal and the sulfate. Simple aluminide coatings are not resistant to low-temperature hot corrosion. The addition of chromium, silicon or platinum to the simple aluminide coating is of some benefit. Overlay coatings having high chromium contents, diffusion chrome coatings, and chrome plate coatings are all resistant to low-temperature hot corrosion. 


\subsection{PROTECTIVE COATINGS}

There are two basic types of coatings used on the hot section airfoils. These are diffusion coatings and overlay coatings. These coatings are sacrificial in that they are attacked instead of the base metal. They are more resistant to high-temperature attack than the base metal because they contain large amounts of aluminum and chromium. Aluminum and chromium form aluminum-oxide and chromium-oxide scales that are stable and adherent. These scales act as a physical barrier that reduces the rate of high-temperature attack to very low values. When these scales are lost due to thermal cycling, erosion, or other damage, a new scale forms from the extra aluminum and chromium in the coating. When all the aluminum and chromium in the coating has been consumed (actually when the amount of these elements falls below a minimum level for protection), then the coating ceases to protect the base metal and the airfoil must be refurbished. The thickness of the coating usually shows no change until these elements are depleted, after which there is a rapid loss of the coating.

The major elements in coatings are aluminum and chromium because they form the protective oxide scale. Nickel and cobalt are the base metal in coatings. A number of other elements are used in coatings, but in smaller quantities. These elements are silicon, platinum, rhodium, palladium, yttrium, hafnium, and tantalum. Silicon improves the hot corrosion resistance. Platinum, rhodium and palladium improve both the oxidation and hot corrosion resistance of the coating. Tantalum improves the oxidation resistance.

Both yttrium and hafnium improve the adherence of the oxide scale to the substrate and are used extensively in overlay coatings. They reduce the amount of the oxide that spalls off during a thermal cycle. These elements are sometimes called "active elements" in the coating because of their affinity for oxygen.

\subsection{Diffusion Coatings}

Diffusion coatings are nickel-aluminide, NiAl, and cobalt-aluminide, CoAl. $\mathrm{NiAl}$ forms on nickel-base superalloys and CoAl forms on cobalt-base superalloys. Diffusion chrome coatings are also used.

Diffusion coatings are formed by depositing a layer of aluminum on the metal 
surface and heating the component in a furnace for a period of time. During this heat treatment, the aluminum and metal atoms migrate, or diffuse, into each other, which is the reason these coatings are called diffusion coatings. This processing is usually performed by a pack cementation process, in which the aluminum deposition and the heat treatment occur simultaneously. Slurry processes can also be used to deposit the aluminum, after which the diffusion heat treatment is performed.

Aluminide coatings for industrial gas turbines are usually modified by the addition of chromium, silicon, platinum, or other noble metals. Chromium imparts resistance to high-temperature hot corrosion to the aluminide coating and some resistance to low-temperature hot corrosion. Silicon also provides some resistance to low-temperature hot corrosion, although its role is less well defined. Platinum significantly improves the resistance to high-temperature oxidation and high-temperature hot corrosion. Rhodium and palladium are sometimes substituted for platinum in order to decrease the cost of the coating, but their performance is not as good as that of platinum.

\subsection{Overlay Coatings}

Overlay coatings consist of a thin layer of a discrete alloy composition applied to the metal surface. The coating alloy can be chosen for maximum environmental resistance since it does not form from the base metal, as do diffusion coatings. In addition, overlay coatings can be made thicker than diffusion coatings, which provides more protection to the base metal. There are a wide variety of coating compositions, but the coatings are frequently called the MCrAlY (pronounced M crawl-ee) coatings, since chromium, aluminum and yttrium are almost always present and $\mathrm{M}$ can be $\mathrm{Ni}, \mathrm{Co}$, or a mixture of these elements. The concentrations of the coating elements depend on the intended use of the coating. Other elements such as silicon, hafnium, tantalum, and platinum are sometimes added to the coating to improve the performance. The aluminum forms an intermetallic compound with the nickel or cobalt, $\mathrm{NiAl}$ or $\mathrm{CoAl}$. Overlay coatings, such as $\mathrm{NiCrSi}$, also can be made without aluminum or yttrium and can protect airfoils up to $1560^{\circ} \mathrm{F}$ [7].

Chromium and aluminum provide the oxidation and corrosion resistance of the coating. Their levels are adjusted to provide maximum resistance to one or another form of attack, or a compromise can be reached to provide protection from several 
types of attack. Higher aluminum levels are used for oxidation protection, and higher chromium levels are used for protection from low-temperature hot corrosion. In order to be fatigue resistant, the aluminum and chromium levels should be kept as low as possible to achieve adequate protection from high-temperature attack.

The base metal composition of the coating is cobalt, nickel, or a combination of the two. Cobalt is better for hot corrosion than nickel, but nickel is better in high-temperature oxidation than cobalt. A mixture of both cobalt and nickel is a compromise for protection from both types of attack. Nickel overlay coatings are more ductile than cobalt overlay coatings, but a nickel-cobalt overlay coating can be more ductile than either [8]. CoCrAlY coatings containing high levels of aluminum are prone to cracking [9].

Overlay coatings are generally applied by plasma spray, although other procedures such as electron beam physical vapor deposition, chemical vapor deposition and cladding are available, but usually are not economical for large airfoils. To obtain the highest quality coatings, the plasma spraying must be done in a protective environment, usually a vacuum chamber containing an inert gas at a low pressure. ${ }^{4}$ Special procedures have also been developed that use an argon shroud to protect the hot spray from oxidizing [10]. Frequently, a diffusion anneal treatment is carried out after coating to insure inner diffusion between coating and substrate to provide good bonding, and to eliminate the as-sprayed microstructure.

\subsection{Duplex Coatings}

Duplex coatings are a combination of an overlay and diffusion aluminide. The overlay coating is applied first and provides protection from hot corrosion. Then a diffusion aluminide coating is applied on top of the overlay coating to provide increased protection from high-temperature oxidation. Duplex coatings can also be made by applying the diffusion aluminide first, followed by the overlay. Rairden found that a diffusion aluminide layer applied on top of MCrAlY coatings greatly increased the high-temperature hot corrosion resistance of these coatings [11].

4 This process is called vacuum plasma spraying (VPS) or low-pressure plasma spraying (LPPS). 


\subsection{Thermal Barrier Coatings}

Thermal Barrier Coatings (TBCs) are ceramic coatings applied over metal substrates to insulate them from high temperatures. They consist of zirconium oxide, $\mathrm{ZrO}_{2}$, stabilized by about $8 \mathrm{wt} \%$ yttria, $\mathrm{Y}_{2} \mathrm{O}_{3}$ or magnesia, $\mathrm{MgO}$. They are applied over a bond coat that is usually an MCrAlY overlay coating, where $\mathrm{M}$ is $\mathrm{Ni}$ and/or Co. The ceramic layer is typically 5 to 15 mils thick, and the bond coat is usually 3 to 5 mils thick [12].

The role of the bond coat is twofold. First, it improves the adhesion of the ceramic coating to the substrate by acting as an intermediary layer. Second, the bond coat prevents oxidation of the metal substrate, since the ceramic coating is porous to oxygen. The bond coat is applied in the same manner as for overlay coatings.

The ceramic layer is normally plasma sprayed in an air environment. TBCs made by electron beam physical vapor deposition (EB-PVD) for the ceramic layer have been developed and are being put into use on aircraft engines. The TBC made by this process is a columnar grained ceramic layer that is more resistant to spalling than the plasma-sprayed TBC [13].

The TBC protects the metal by acting as an insulator between the metal and the hot gases it is exposed to. The thermal conductivity of the ceramic is one to two orders of magnitude lower than the metal. Furthermore, the ceramic has a higher reflectivity than the metal. This means that more of the radiative heat is reflected away [14].

During start-up and shutdown, the TBC improves the thermal fatigue life by reducing the magnitude of the temperature transients the metal is exposed to. A 10-mil thick TBC on airfoils in experimental aircraft engines has achieved a $300^{\circ} \mathrm{F}$ reduction of metal temperature [15]. (Such dramatic reductions in temperature cannot be achieved in the much larger, thick-walled blades used in heavy duty, industrial turbines.) During steady state operation, the TBC lowers the temperature of the underlying metal, thereby improving its durability. It also reduces the severity of hot spots.

TBCs have been used in industrial engines to coat combustion liners and transition pieces and are being tried on first stage vanes. TBCs are being used on vanes in civilian aircraft engines and are being developed for blades. Lackey, et al. $[16,17]$ 
have made a review of the state of the art in thermal barrier coatings as of 1984, as have Liebert and Miller [18].

The yttria-stabilized zirconia coating may not be resistant to hot corrosion. It can be attacked by vanadium salts and sulfur trioxide. The yttria is leached out of the coating, leading to destabilization of the coating and subsequent fatigue failure [19-21]. No stabilizing oxide has been found to resist these types of attack. Molten sodium sulfate can enter the pores and microcracks in the ceramic coating. Although it does not react with the coating, it has a different thermal expansion coefficient than the coating, causing additional cracking and reducing the thermal cycling life [22].

More recent studies have shown good performance of thermal barrier coatings in hot corrosion atmospheres [23]. Yttria-stabilized zirconia coatings, both plasma sprayed and EB-PVD, were tested in burner rig corrosion tests for both low-temperature and high-temperature hot corrosion. Neither form of attack was found on the bond coat after $\mathbf{2 0 0 0}$ hours; the ceramic layer was not attacked by the molten salts; and the ceramic layer did not spall off. Engine tests of plasma-sprayed TBCs supported these findings, in which non-coated parts had extensive high-temperature hot corrosion; but TBC-coated parts were free of hot corrosion.

\subsection{Future Developments in Coatings}

New developments in high-temperature coatings can be expected to occur at a fairly rapid rate in the 1990s. This development will be spurred by the strong business climate for industrial gas turbines, the more demanding higher temperature engines being introduced, and the lack of a durable, general purpose coating. New developments that are occurring are the use of duplex coatings, coating of interior cooling surfaces, incorporation of yttrium into diffusion aluminide coatings, and the introduction of overlay coatings used in aircraft as their patents expire.

Thermal barrier coatings will continue to be explored for application to nozzle vanes. Initial applications to eliminate burning of the leading edge of some first stage vanes appear to be promising. Other applications will have to be carefully evaluated to determine the actual benefits of TBCs. The use of biomass-derived fuels with thermal barrier coatings is one such application. 


\subsection{DEPOSITION, EROSION, AND CORROSION}

Deposition and erosion will be discussed below. Corrosion has been described in detail on the sections on High-Temperature Attack. Since deposition and erosion require that particles in the gas stream first contact the surface of airfoils, it is useful to describe this process.

\subsection{Particle Delivery}

In order for DEC to occur, it is necessary for the particles in the gas stream to contact the surfaces of the airfoils. There are four processes by which this can occur, depending upon the particle size. These processes are:

- Inertial Impact

- Turbulent Eddy Diffusion

- Brownian Diffusion

- Thermophoresis

Inertial impact is the striking of the surface by a particle because its inertia is so great that the gas stream airflow cannot prevent it moving onto the surface of the airfoil. For particles larger than a few microns in diameter, inertial impact is greatest on the pressure surfaces and the leading edge, as shown in Figure 3. Models for inertial impact have been developed using particle equations of motion with the appropriate flow parameters of the turbine [24].

Turbulent eddy diffusion is the transport of particles by turbulent flows in the boundary layers at the airfoil surfaces. Although these flows dissipate as they approach the surface, the particles continue to move and impact the surface due to their inertia. Turbulent eddy diffusion is important for particles of a few microns in diameter down to a size that is a function of the cooling of the airfoil. Turbulent eddy diffusion predominates on suction surfaces away from the leading edge, since inertial impact cannot occur. (Inertial impact can occur from particles rebounding from adjacent pressure surfaces, which requires rather large particles of perhaps 10 microns or greater in diameter.) Models for turbulent eddy diffusion are available [25].

Brownian diffusion is the transport of particles by thermally agitated gas molecules. 


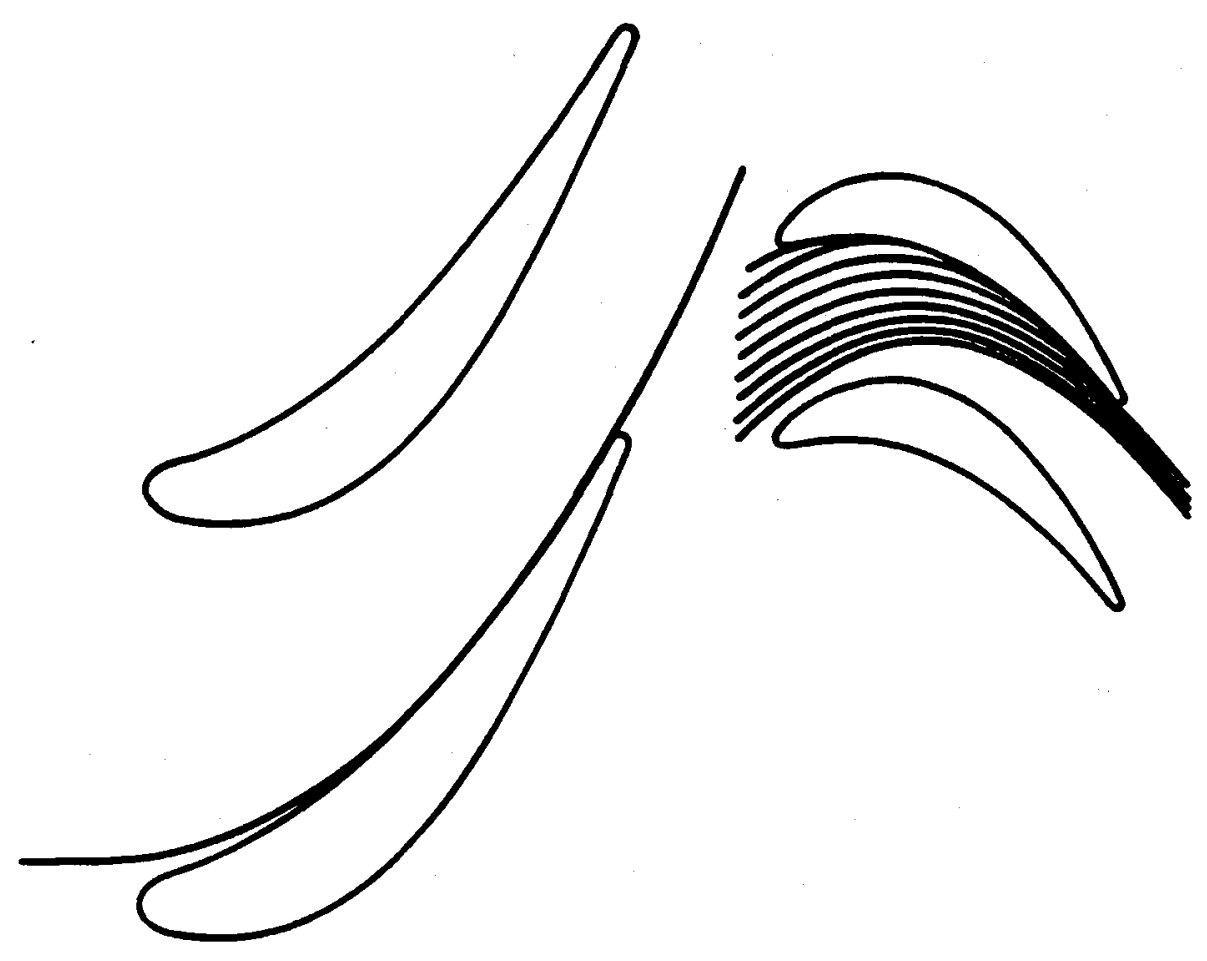

FI(GURE 3. Trajectories for 6 um Particles in the First State of a $50 \mathrm{Mw}$ Turbine (10:1 pressure ratio) (35)

13 
It is important for particles smaller than 0.05 to 0.1 micron in diameter. Models for Brownian diffusion are also available [25].

Thermophoresis is the delivery of particles due to thermal gradients in the boundary layers on the airfoil. As these gradients become larger for greater cooling, thermophoresis becomes greater, such that for highly cooled surfaces, particles perhaps as large as 0.5 microns in diameter are delivered [26].

Of these four mechanisms of particle delivery, inertial impact is by far the most important for particles greater than a few microns in diameter, because of the high delivery rates to the pressure and leading edge surfaces. Figure 4 shows the fraction of particles in the gas stream that strike the airfoil by inertial impact as a function of particle size. This graph is for a $50 \mathrm{Mw}$ (10 to 1 pressure ratio) type of engine. Many more particles strike the rotating blade because of the greater turning angle of the blade compared to the stationary vane. As the size of the flow passages is reduced (or the size of the engine is reduced) a greater fraction of the particles strike the airfoils.

\subsection{Erosion}

Erosion is the removal of material on the surface by the action of moving particles. It is important in gas turbines because it can accelerate environmental attack of the surface by removing protective oxide scales or protective coatings, and it can cause thinning of trailing edges, which reduces their mechanical strength.

Primary variables that influence erosion include the speed, size, shape, and hardness of the erodants, and the hardness of the surface that is being eroded. As the speed, size, and hardness of the erodants increase, the wear rate increases. Irregularly shaped particles cause more erosion than spherical particles. In general, softer surfaces are eroded more than harder surfaces.

Calculated trailing edge erosion for a $50 \mathrm{MW}$ turbine (10 to 1 pressure ratio) is shown in Figure 5. There is a significant reduction in erosion for smaller size particles. This reduction is due to a smaller percentage of the small particles striking the surface, as well as a reduced amount of wear due to the physically smaller size of the particles.

In order to reduce the amount of erosion in gas turbines, it is necessary to reduce 


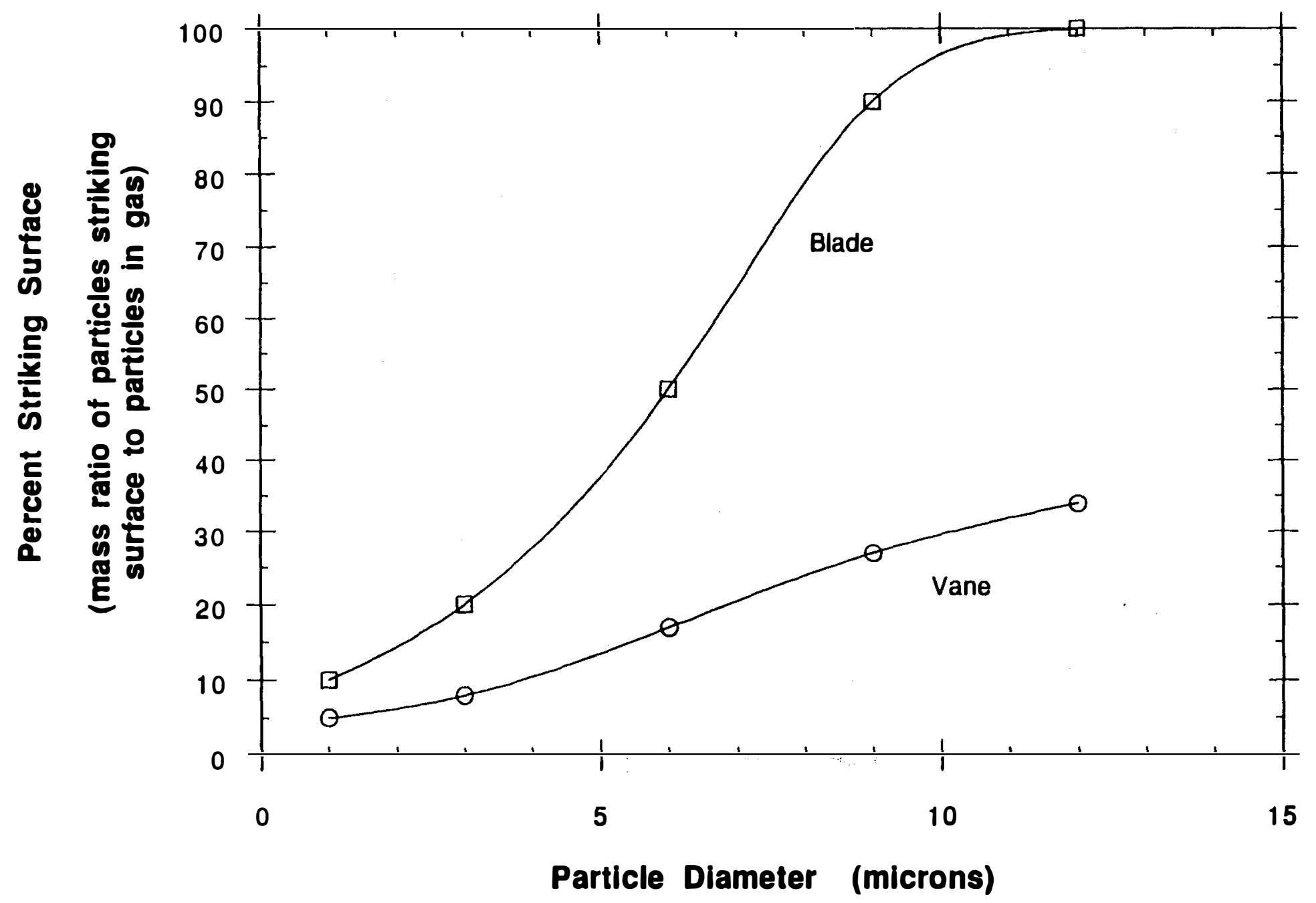

FI(GURE 4. Effect of Particle Size on Impingement of Particles on Airfoils 


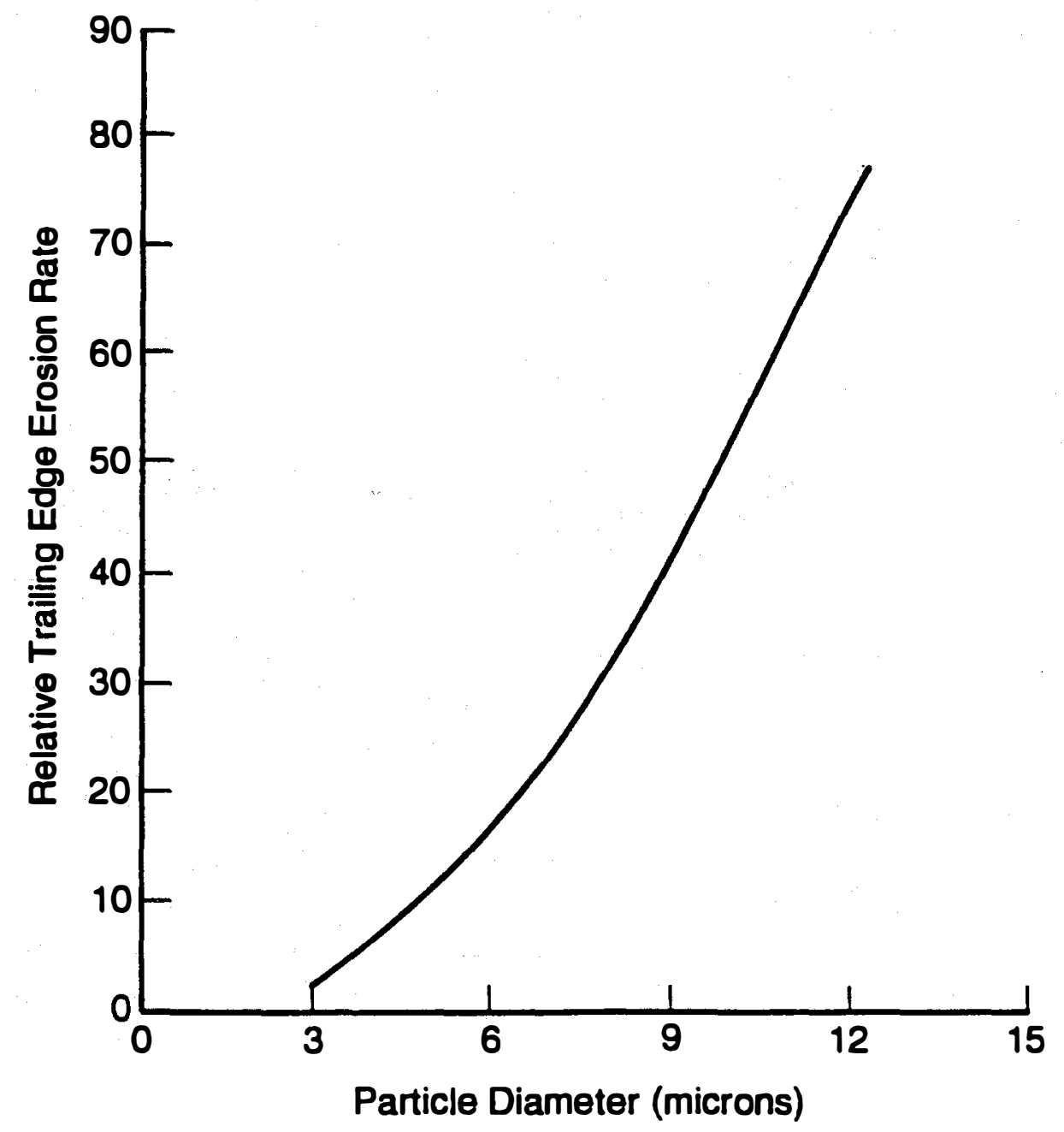

FIGURE 5. Relative Trailing Edge Erosion Rate on First Rotor of a $50 \mathrm{Mw}$ Turbine (10:1 pressure ratio) (4) 
both the size and number of the erodants in the gas stream. Specifications on fuels of ten include limits on the amount of particles as a function of size.

\subsection{Deposition}

Deposition is the accumulation of foreign material on the surface of a blade or vane. It is caused by the sticking of particles in the gas stream to the surface of the airfoils. Deposition is of importance to gas turbines because it can significantly degrade their performance by reducing flow areas, increasing trailing edge thickness, and increasing surface roughness. Sufficiently dirty fuels can reduce the performance of a gas turbine by over $10 \%$ in just a few hours.

Deposits generally form from molten or semi-molten particles in the gas stream. These accumulate, or stick, to the airfoil surfaces, whereas solid particles rebound from the surface (although smaller particles can sometimes be captured by sticky deposits). Deposits can also form from liquid phases in the combustion gases that condense on the airfoils. Deposits formed can be extremely difficult to remove during engine operation. Also, these deposits are the first step in the hot corrosion attack of the airfoil surfaces.

Deposition is controlled by eliminating or reducing the number of molten and semi-molten particles. Condensing species are controlled by reducing the amount of the chemicals that make up these species. 


\subsection{CONTAMINANTS}

Contaminants in gas turbines can be most widely classified as any foreign material that is ingested or injected into the gas turbine that is harmful to the engine or its performance. These contaminants are chemical species and particles that cause deposition, erosion, and/or corrosion. Sources of contaminants are the fuel; the intake air; water that is used for NOx control or compressor cleaning; steam that is used for NOx control and/or power augmentation; and chemicals that are used for cleaning of the engine. In this report, the focus will be upon the fuels, and in particular the types of contaminants found in biomass fuels.

The total allowable contaminant load in a gas turbine is the sum of contaminants that come from all sources air, fuel, water, and steam. ${ }^{5}$ This contaminant load is usually expressed in terms of a fuel equivalent quantity, where the amounts of air and water (or steam) are expressed in terms of how much is used per unit of fuel. It should be kept in mind that gas turbines, particularly the large turbines used for power generation, ingest very large quantities of air and water (or steam), so that small quantities of a contaminant can rapidly accumulate to rather large amounts. For example, $1 \mathrm{ppm}$ of sodium in the fuel can accumulate to 1 pound in 30 hours of operation [27].

\subsection{Chemical Contaminants}

Chemical contaminants for gas turbines include vanadium, lead, sulfur, potassiurn, sodium, and calcium. Vanadium and lead are problems that are more associated with fuel oils than with biomass fuels. Both vanadium and lead form compounds that rapidly attack the metal. They can be controlled in fuel oils by lead removal and by tying up the vanadium with magnesium additions.

Sulfur, potassium and sodium combine to produce hot corrosion. Potassium and sodium can substitute for one another, so that the sum of these contaminants must be considered. (If lithium is present, it must also be included since it is an alkali metal.) In general, if there is sufficient sulfur, then the sum of the potassium and sodium must

5 If contaminants are present in cleaners, then the typical approach is to remove them from the cleaner or use a cleaner free of contaminants. 
be kept to extremely low levels of 0.5 to $1 \mathrm{ppm}$ on a fuel-equivalent basis. Higher levels result in severe hot corrosion that in general cannot be tolerated by the gas turbine, even with protective coatings.

Allowable sulfur levels depend upon the presence of potassium and sodium. If the sum of potassium and sodium exceed 0.5 to $1.0 \mathrm{ppm}$ on a fuel-equivalent basis, then low levels of sulfur must be maintained to avoid hot corrosion. Little information is available on allowable sulfur levels in the presence of potassium and sodium. One study that looked at sulfur removal in fuels for aviation gas turbines (jet engines) found that sulfur had to be reduced to $0.004 \%$, or $4 \mathrm{ppm}$, before hot corrosion was significantly reduced [28]. Such low levels of sulfur were not economically achievable for jet fuels, which are liquid hydrocarbons.

Data from this study suggests that, in some cases, hot corrosion can be reduced for sulfur levels greater than $4 \mathrm{ppm}$, compared to hot corrosion at $400 \mathrm{ppm}$. In Figure 6 the weight loss as a function of sulfur level in the fuel is shown for aluminide-coated Mar M-246 after 50 and 80 hours of testing in a burner rig. ${ }^{6}$ The amount of weight loss at both times shows a strong dependence on sulfur level, such that a significant reduction in the rate of attack can be obtained by a reduction of sulfur. However, in another case, the results are less clear. In Figure 7, data for IN-738 and Mar M-246, both coated by a chromium modified aluminide coating, show a marked reduction in hot corrosion for Mar M-246 by reducing the sulfur from 400 to $40 \mathrm{ppm}$, whereas for IN-738, there is no effect. ${ }^{7}$ Although the data are not conclusive, a reduction in sulfur levels may offer an opportunity to reduce the corrosiveness of biomass derived fuels.

Allowable sulfur levels when potassium and sodium are not present, have been given in some fuel specifications. These levels depend on whether the exhaust gases are used in a heat recovery steam generator, since high levels of sulfur can damage this equipment. Natural gas containing $\mathrm{H}_{2} \mathrm{~S}$ is burned by many gas turbines with apparently no adverse consequences. However, little research has been found on the effect of $\mathrm{H}_{2} \mathrm{~S}$

6 Mar M-246 is a nickel-base superalloy widely used in aircraft engines. It is not especially resistant to hot corrosion, and the aluminide coating also is not very resistant to hot corrosion.

7 IN-738 is a nickel-base superalloy widely used in industrial engines. It is optimized for increased corrosion resistance. The chromium modified aluminide coating is more corrosion resistant than the aluminide coating. 


\section{Aluminide Coating}

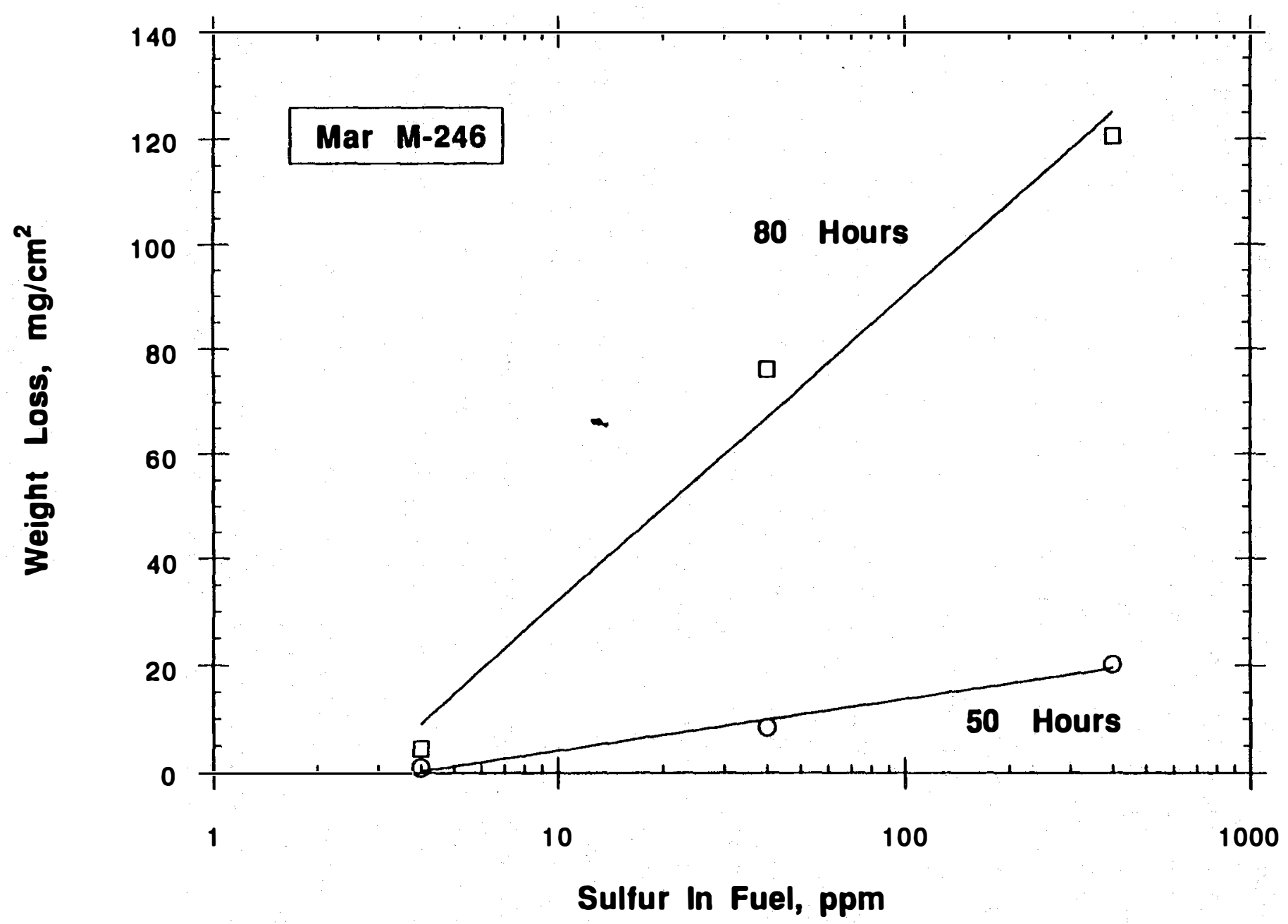

FI(GURE 6. Weight Loss Due to High-Temperature Hot Corrosion as a Function of Sulfur Level for Aluminide-Coated MAR M-246 (28) 
Chromium Modified Aluminide Coating

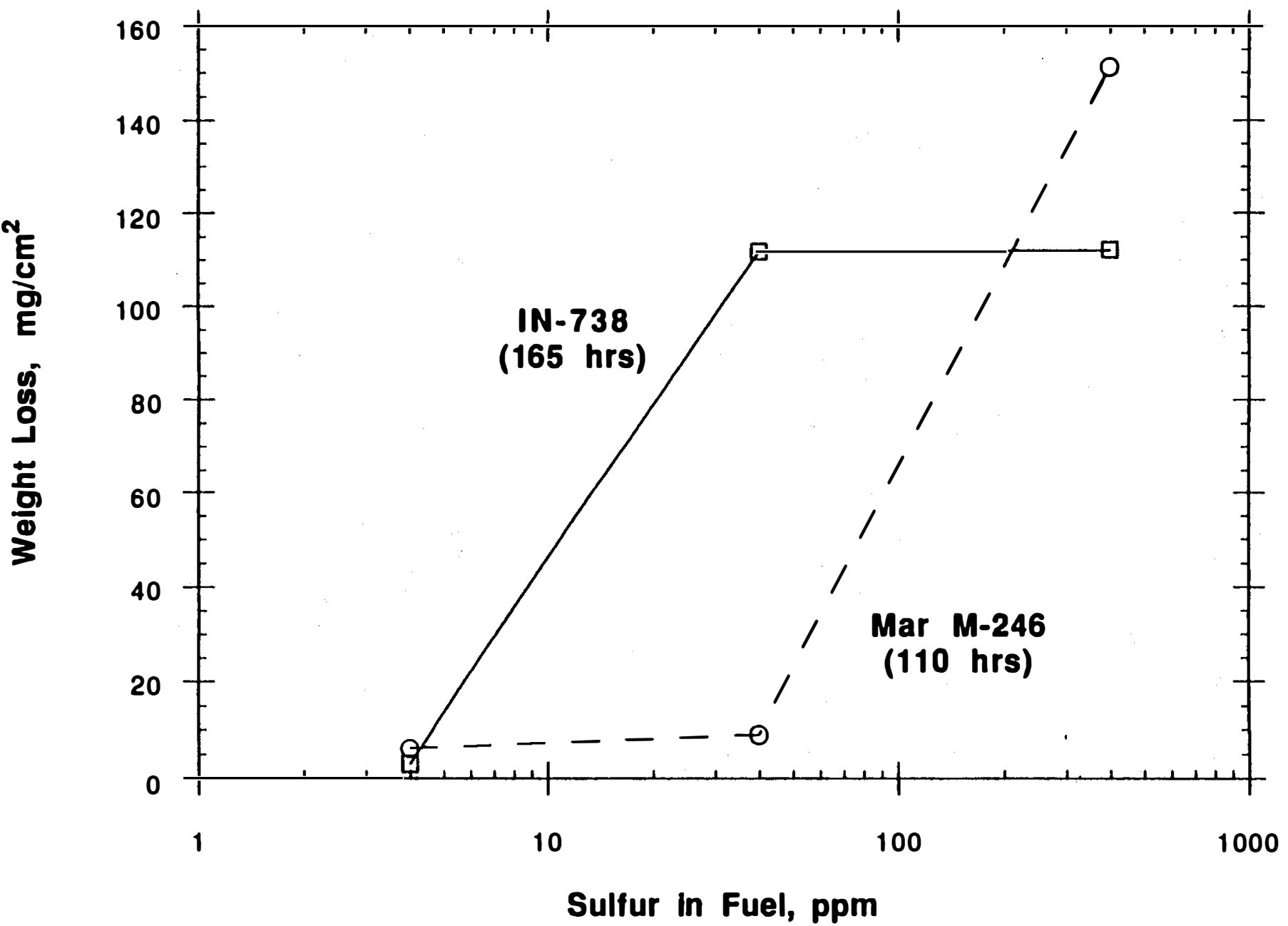

FIGURE 7. Weight Loss Due to High-Temperature Hot Corrosion as a Function of Sulfur Level for Chromium-Modied Aluminide-Coated IN-738 and MAR M-246 (28) 
on the gas turbine airfoils.

Calcium has been identified as a contaminant in gas turbines, but its role is not as clear as the elements discussed above. Calcium can form hard deposits on the airfoils, which lead to loss of performance. If these deposits break off, they go downstream and can cause foreign object damage. Calcium does not appear to cause hot corrosion, but it may modify the rate of hot corrosion. Allowable calcium levels have been given in some fuel specifications, and are between 0.5 to $10 \mathrm{ppm}$. Additional research on the role of calcium is needed to better define allowable $\mathrm{Ca}$ levels.

Other elements, such as chlorine, silicon, and fluorine do not appear to be intrinsic contaminants, but they appear to accelerate high-temperature attack. Chlorine has been shown to accelerate high-temperature oxidation, most likely by interacting with and destabilizing the protective oxide scale [29]. The effect of chlorine in hot corrosion is not clear, with some studies showing a beneficial effect [30] and other studies showing a detrimental effect [31]. The role of other elements is less clear. In very large quantities, these elements are likely to cause high-temperature attack in themselves, but how much of the element is required is uncertain. The role of these elements also needs more research, which would aid in determining allowable levels.

\subsection{Particulate Contaminants}

Particulates in the hot gas stream cause deposition and erosion. Deposition is usually due to molten or partially molten particles. Particles that have been vaporized are not usually a concern unless they can condense on the airfoils. Particles that are still solid generally do not form deposits, unless trapped by sticky deposits already on the airfoil. Instead these solid particles act to erode the airfoil.

The erosiveness of the particles depends upon their chemistry, size, shape, and quantity. In general, greater erosion occurs for larger, harder, and more irregularly shaped particles. And, the more particles there are, the greater the erosion that will occur. The chemistry of the particle and the temperature primarily determine its hardness.

Particulates that cause erosion must be limited to an acceptably low number to achieve adequate life of the gas turbine between scheduled overhauls. Exact 
requirements depend upon the specific operation and economics of the installation. In general, thin-walled airfoils have less tolerance to erosion than thick-walled or solid airfoils.

Particulates that cause deposition, must also be limited to acceptably low numbers to achieve adequate performance of the gas turbine between scheduled maintenance intervals, either cleaning or teardowns. Again, exact requirements depend upon the specific operation and economics of the installation. In general, narrow flow passages have less tolerance to deposition than wide flow passages.

\subsection{Fuel Specifications}

Existing fuel specifications are rather stringent for allowable contaminant levels. Six representative fuel specifications have been tabulated in Table 1, covering both liquid fuel and natural gas. (Contaminant levels are expressed in ppm by weight or \% by weight, unless otherwise noted.)

Fuel specifications are written to provide trouble-free operation for the time between major overhauls, when the airfoils are refurbished. For heavy duty, industrial gas turbines, these intervals can range from 12,000 to 64,000 hours, with 24,000 hours being the typical interval for higher temperature engines. (These intervals represent 1.5 to 8 years of continuous operation, with 3 years being typical.) To achieve such long-term operation, stringent control of contaminants is required. If shorter overhaul intervals can be justified, then it may be possible to allow higher contaminant levels. This justification is primarily economic and must be considered on a case-by-case basis.

Sulfur levels in natural gas are, in general, not limited except in terms of their corrosiveness to the fuel handling equipment and any heat recovery units. If alkali metals are present, then the sulfur level is limited to keep the alkali metal sulfate level to about $0.6 \mathrm{ppm}$ or less.

Sodium and potassium levels are strictly limited in all fuel specifications to very low levels. No specification allows more than $1.0 \mathrm{ppm}$ of these elements added together. This is to avoid hot corrosion. 
TABLE 1. REPRESENTATIVE FUEL SPECIFICATIONS

\begin{tabular}{|c|c|c|c|c|c|c|}
\hline \multirow[t]{2}{*}{ ITEM } & ASTM \#1 [36] & OEM \#1 & OEM \#2 & OEM \#3 & OEM \#4 & OEM \#5 \\
\hline & Liquid Fuel & Liquid Fuel & Natural Gas & Petroleum & Natural Gas & General \\
\hline & & Aeroderivative & Aeroderivative & Heavy Duty & Heavy Duty & \\
\hline$S$ & & $1.0 \%^{1}$ & no limit ${ }^{2}$ & & no $\operatorname{limit}^{3}$ & \\
\hline $\mathrm{Na}+\mathrm{K}^{4}$ & $0.5 \mathrm{ppm}$ & $0.1-0.2 \mathrm{ppm}^{5}$ & $0.2^{6}$ & $1.0 \mathrm{ppm}$ & $0.5 \mathrm{ppm}$ & $1.0 \mathrm{ppm}$ \\
\hline V & $0.5 \mathrm{ppm}$ & $0.5 \mathrm{ppm}$ & & $0.5 \mathrm{ppm}$ & & $0.5 \mathrm{ppm}$ \\
\hline $\mathrm{Pb}$ & $0.5 \mathrm{ppm}$ & $1.0 \mathrm{ppm}$ & & $1.0 \mathrm{ppm}$ & & $1.0 \mathrm{ppm}$ \\
\hline $\mathrm{Ca}$ & $0.5 \mathrm{ppm}$ & $2.0 \mathrm{ppm}$ & & $2.0 \mathrm{ppm}$ & $10 \mathrm{ppm}$ & $1 \mathrm{ppm}$ \\
\hline Other & & & & & see note ${ }^{7}$ & \\
\hline Ash & $0.01-0.03 \%$ & $0.01 \%$ & & & & \\
\hline Particulates & & $10.0 \mathrm{mg} / \mathrm{gal}$ & $30 \mathrm{ppm}$ & $3.0 \mathrm{ppm}^{8}$ & & \\
\hline Particle size & & 20 microns & see spec. ${ }^{9}$ & & & \\
\hline
\end{tabular}

NOTES: All quantities are in wt\% or ppm by weight.

All quantities are maximum allowable.

All quantities are total contaminant levels and calculated on a fuel equivalent basis.

Blank entries mean that no value was given in the specification.

1) Consult OEM if $S$ is greater.

2) If alkali metals are present, then sulfur is limited so that alkali metal sulfates do not exceed $0.6 \mathrm{ppm}$.

3) Special fuel system components required if sulfur greater than 5 mole \%. For heat recovery units, $\mathrm{H}_{2} \mathrm{~S}$ limited to $5 \mathrm{wt} \%$.

4) $\mathrm{Na}+\mathrm{K}$, or total of all alkali metals

5) $\quad 0.1 \mathrm{ppm}$ for standard coating and $0.2 \mathrm{ppm}$ for corrosion-resistant coating.

6) For corrosion-resistant coating

7) $\mathrm{Si} \leq 18 \mathrm{ppm}, \mathrm{Cl} \leq 6 \mathrm{ppm}, \mathrm{Fe} \leq 0.1 \mathrm{ppm}, \mathrm{Cu} \leq 0.1 \mathrm{ppm}$

8) Particulate size greater than 10 micron

9) Size and density requirements given in terms of a test method 
Vanadium and lead levels are also strictly limited to between 0.5 to $1.0 \mathrm{ppm}$. This is to avoid the severe attack that these elements can cause.

Calcium levels range from 0.5 to $10 \mathrm{ppm}$. Since calcium is more of a problem with deposition, tolerance to calcium depends upon engine design. In general, heavy duty industrial gas turbines have greater tolerance for deposition than aeroderivative engines.

Allowable ash levels are also fairly small, ranging from 0.01 to 0.03 percent. Particulate levels (ash is a particulate) are generally given in terms of both quantity and size. Quantity of particulates is from 3 to $30 \mathrm{ppm}$, and size is limited to 20 microns or less. Sometimes the fuel specification is written in terms of maximum amount at a given size. 


\subsection{IMPACT OF BIOMASS-DERIVED FUELS ON DEC}

Biomass fuels can contain all the ingredients necessary to cause severe deposition, erosion and corrosion in the gas turbine. Table 2 is a summary of the allowable contaminant levels in the fuel specifications in Table 1, and the levels of these contaminants found in pyrolysis liquids, a type of biomass fuel. The last two columns of this table show whether the minimum or maximum level of these contaminants meet the maximum allowable value in current fuel specifications. Comparing the data form Table 5 in the main text with theses limits, the contaminant level of pyrolysis liquids exceeds all allowable fuel specifications by a wide margin for all contaminants except sulfur, which has no limit by itself. The minimum contaminant level of the pyrolysis liquids is marginally acceptable for calcium and ash, but still not acceptable for sodium plus potassium. Although the minimum level for calcium and ash in the pyrolysis liquids is still above the maximum level allowed by the fuel specifications, it is about the same order of magnitude, and, thus, judged to be marginally acceptable. (These higher levels may shorten the maintenance intervals but should not preclude using these fuels.) However, if the heating value of the biomass fuels is substantially lower than that of natural gas or distillate fuel oils, then significantly greater quantities of biomass fuel will be required to produce similar power output. These larger quantities of fuel will require lower impurity levels to obtain similar impurity loading of the gas turbine. Thus, the marginally acceptable impurity levels may become unacceptable for lower heating value biomass fuels.

Allowable sulfur and alkali metal levels depend upon the amount of alkali metal sulfates formed in the gas turbine. It may be possible to tolerate higher alkali levels if the sulfur levels can be kept low enough to prevent significant sulfate formation. And, conversely, sulfur levels can be increased if the alkali metal level can be kept sufficiently low.

Although not shown in Table 2, the number of large particles in the biomass fuel must be controlled as well. This is to prevent both deposition and erosion.

Residual fuel oils, such as Bunker $\mathrm{C}$, were widely used in utility gas turbines in the 1970s. The experience with this fuel was unfavorable, due to a large number of hot corrosion problems. Since this time, utilities have generally refrained from using these fuels in their gas turbines. However, improved high-temperature coatings have been 
TABLE 2. COMPARISON OF CONTAMINANTS IN PYROLYSIS LIQUIDS TO FUEL SPECIFICATIONS

\begin{tabular}{|c|c|c|c|c|}
\hline ITEM & Fuel Specs & Pyrolysis Liquids & $\begin{array}{c}\text { Allowable } \\
\text { for Minimum } 1\end{array}$ & $\begin{array}{c}\text { Allowable } \\
\text { for Maximum }\end{array}$ \\
\hline$S$ & no limit $^{2}$ & $100-700 \mathrm{ppm}$ & yes; see note 1 & yes; see note 1 \\
\hline $\mathrm{Na}+\mathrm{K}^{3}$ & $0.2-1.0 \mathrm{ppm}$ & $\begin{array}{c}20-50 \mathrm{ppm} \mathrm{Na} \\
20-1400 \mathrm{ppm} \mathrm{K}\end{array}$ & no & no \\
\hline $\mathrm{Ca}$ & $0.5-10 \mathrm{ppm}$ & $20-600 \mathrm{ppm}$ & marginal & no \\
\hline Ash & $0.01-0.03 \%$ & $0.05-5.0 \%$ & marginal & no \\
\hline
\end{tabular}

NOTES: All quantities are in wt\% or ppm by weight

All quantities are maximum allowable

All quantities are total contaminant levels and calculated on a fuel equivalent basis

Blank entries mean that no value was given in the specification

1) Allowable for minimum/maximum means that the minimum/maximum level of contaminant in the pyrolysis liquid is allowable by the range of fuel specifications. Marginal means that the contaminant level of the pyrolysis liquid is greater than the maximum level allowed by the fuel specification, but it is of the same order of magnitude. Allowables will be lowered if heat content of biomass gas is significantly lower than natural gas or fuel oils.

2) If alkali metals are present, then sulfur is limited so that alkali metal sulfates do not exceed $0.6 \mathrm{ppm}$. Special fuel system components are required if sulfur is greater than 5 mole\%. For heat recovery units, $\mathrm{H}_{2} \mathrm{~S}$ is limited to $5 \mathrm{wt} \%$.

3) $\mathrm{Na}+\mathrm{K}$, or total of all alkali metals. 
developed to provide greater resistance to hot corrosion.

In summary, deposition, erosion and corrosion are very real and substantial problems with the use of biomass fuels. These problems rapidly increase as the impurity level of the fuel increases. Suggestions for the use of biomass fuels are given in the next section on Recommendations. 


\subsection{RECOMMENDATIONS}

The most significant finding in this study is the potentially large contaminant loading of the gas turbine from the use of biomass fuels. The large number of contaminants potentially present in the fuel can result in severe deposition, erosion, and corrosion in the hot section of the combustion turbine. This severe attack could make the use of these fuels impractical.

The recommendations provided in this section are divided into two groups: Recommendations on Using Biomass Fuels and Recommendations on Additional Research. A Summary of the recommendations is provided at the end.

\subsection{Recommendations on Using Biomass Fuels}

The recommendations in this section are directed to mitigating, or eliminating the DEC problems posed by the use of biomass fuels. It assumes that contaminant levels in the fuel are not reduced to currently allowable levels.

The economical use of biomass fuels will depend upon the balance that can be achieved between the costs associated with the fuel itself, engine maintenance, and capital investment; and the income derived from the energy produced, be it electricity, steam, process heat or mechanical power. The largest unknown in this equation is the cost of engine maintenance as a function of operation. Currently, the need to refurbish the high-temperature coating on the first stage blades determines the maintenance interval. Biomass fuels are likely to increase the maintenance costs by their adverse effects on this coating.

1. The use of lower turbine inlet temperatures is recommended to reduce the high-temperature oxidation in the turbine hot section. Newly introduced aeroderivative and heavy duty gas turbines, which operate at the highest turbine inlet temperatures ever used, are expected to have a number of oxidation related concems. Biomass fuels should be expected to aggravate these concerns due to greater erosion. The high-temperature coatings used on some of the aeroderivative engines are not currently lasting their intended life while running on natural gas [32]. It is recommended that engine tests on biomass fuels first be conducted at lower temperatures to minimize these oxidation problems. 
2. Special high-temperature coatings, optimized for resistance to high-temperature hot corrosion, are recommended provided sufficient protection from high-temperature oxidation is maintained. Lower operating temperatures will reduce the amount of oxidation protection required.

3. It is recommended that the heavy duty, industrial gas turbines be used for test engines instead of aeroderivative engines. The industrial gas turbines are designed to handle dirtier fuels and have greater resistance to DEC. These engines have wider flow passages that reduce the performance loss associated with deposition, and have less erosion due to rebounding particles. These passages also permit thicker high-temperature coatings to be used, which provide greater protection from environmental attack. The heavy wall blades in these engines have greater resistance to failure due to environmental attack. Aeroderivative engines were originally designed to operate on clean jet fuels and were optimized for minimum weight by reducing blade wall thickness. Consequently, they have less inherent resistance to environmental attack. Furthermore, their blading employs extensive film cooling to keep the metal temperature acceptable. Deposition poses a threat to this cooling by restricting or plugging the cooling holes. Because of these problems, it has been recommended not to use residual fuels in aeroderivative engines [33].

4. Reduction of sulfur levels may be more feasible than reduction of alkali levels to below $1.0 \mathrm{ppm}$. Hot corrosion may be manageable if the amount of sulfur is kept sufficiently low so that the formation of alkali metal sulfates is less than $1.0 \mathrm{ppm}$.

5. Low-temperature hot corrosion may not be an issue for low sulfur levels because the partial pressure of $\mathrm{SO}_{3}$ is not high enough. High partial pressures of $\mathrm{SO}_{3}$ are required for low-temperature hot corrosion to occur.

6. Fuel specifications need to be developed specifically for biomass fuels. Existing specifications are extremely stringent and are directed to liquid hydrocarbons or natural gas. Fuel specifications for biomass fuels should be optimized to specific engine types and temperatures, as well as specific biomass fuels.

7. Fuel specifications for biomass fuels must address allowable particulate levels in terms of the allowable distribution of particle size and number as a function of the 
particle chemistry. Softer particles will not be as eroding as harder particles, although deposition must be considered.

8. An application that may be attractive for biomass fuels is utility peaking operation. Running time for this application is relatively short, usually less than $\mathbf{1 0 0 0}$ hours per year. Thus, this type of operation may be able to tolerate shorter intervals between overhauls, because long periods of time will elapse prior to reaching the number of hours recommended for overhaul. However, this type of operation is probably not feasible, if startup times are relatively long or capital equipment costs are high.

\subsection{Recommendations for Additional Research}

The recommendations in this section are directed to obtaining information that would permit reliable operation of gas turbines on biomass fuels.

1. There will be a strong need to quantify the cost of DEC caused by the contaminants in biomass fuels. The cost to clean up these contaminants must be balanced by the cost to maintain the engine. Thus, some quantitative method is needed to predict the degradation of the hot section components as a function of operation and impurity levels. These models must consider the cojoint action of erosion, deposition, hot corrosion, and oxidation upon the high-temperature protective coatings. Currently, such models do not exist. Instead, empirical correlations are used based upon past engine experience. These correlations are considered proprietary by the engine manufacturers, and are not available outside the engine manufacturers. ${ }^{8}$

2. The use of themal barrier coatings as a means of reducing hot corrosion and erosion is promising. These coatings should be tried with biomass fuels. They should be assessed first in burner rigs, and, then if promising, in test engines.

3. Utility and industrial experience with residual fuels should provide a good guide to

8 Currently models for degradation of high-temperature coatings on industrial gas turbine blades by high-temperature oxidation are under development at Southwest Research Institute for EPRI under RP3064-01, "Advanced Life Management System for Combustion Turbines." Results from the model to date are very encouraging. 
many of the problems with biomass fuels. It is recommended that this experience be reviewed.

4. Much of the corrosion data are for the propagation stage of hot corrosion and not the incubation stage. For reliable turbine operation, hot corrosion should be kept in the incubation stage and not be allowed to move to the propagation stage. High-temperature coatings, allowable contaminant levels, and maintenance schedules should be based upon the incubation period of hot corrosion. If sufficient incubation data is not available, which is the author's opinion, then this data will need to be generated.

5. Higher levels of alkali metals may be tolerable in the presence of lower sulfur levels. Additional research should be conducted to determine allowable sulfur at various alkali metal levels. Due to short residence times in the turbine, it is expected that reaction kinetics will be as important for the formation and subsequent deposition of sulfates, as are thermodynamic equilibrium calculations.

6. The effect of large levels of calcium is not well defined. Additional work to quantify the deposition of calcium compounds is needed.

7. The role of chlorine has been to accelerate high-temperature oxidation, and, perhaps, hot corrosion. However, this effect has not been well quantified, and additional work is needed. This is important even if chlorine is not in the fuel, because seaside locations ingest large quantities of $\mathrm{NaCl}$ from the air.

8. The extent of attack on an airfoil cannot be determined until the attack is so severe that the airfoil cannot be refurbished. One of the primary purposes of maintenance is to remove the airfoil in time so that it can be refurbished. (Replacement costs of airfoils are very high.) Currently, there are no non-destructive evaluation (NDE) methods that assess the condition of the high-temperature coating or the base metal. If NDE methods were available, in conjunction with degradation models, then periodic inspections could determine when to remove the airfoils so they could be refurbished. This ability would allow confident operation on biomass fuels. 


\subsection{Summary of Recommendations}

The most important recommendations involve how to operate gas turbines with fuels that have high contaminant levels. This question is essentially an economic one, since the income derived must be sufficiently greater than the cost of operation. The technical issues that go into this economic calculation are the basis for the recommendations provided above.

Anything that reduces the severity of the operation and increases the robustness of the engine will reduce the likelihood of engine damage or failure. Thus, lower temperature operation, use of heavy duty, industrial engines, and use of special high-temperature coatings all will promote better operation. Perhaps the most important change that can be made is to shorten maintenance intervals. If intervals short enough to preclude removal of the coating by hot corrosion or erosion can be tolerated, then higher contaminant levels may be permissible.

It is likely that levels on particulates will have to be met to preclude significant performance loss by deposition. This will require control of larger particles and lower melting point particles.

The principal area of research that needs to be pursued involves the development of data and models to predict the degradation of the turbine by DEC. Current models are primarily empirical and contain numerous correction factors that are obtained from actual engine operation. Methods are required to reduce the uncertainty of these models and their strong dependence upon actual engine tests. 


\subsection{REFERENCES}

1. H. L. Bernstein, S. Schwab, and J. Russell, "High Temperature Coatings," Chapter 8, in Air Force High Technology Metals Handbook, Kelly Air Force Base, TX, to be published.

2. H. L. Bernstein, "Gas Turbine Blade and Vane Coatings Technology," in Guidebook and Software for Specifying High-Temperature Coatings for Combustion Turbines, GS-7334-L, EPRI Research Project 2465-2, Final Report, June 1991.

3. H. L. Bernstein and J. M. Allen, "A Review of High Temperature Coatings for Combustion Turbine Blades," to be published in the Proceedings of the EPRI Steam and Combustion Turbine Blading Conference, pp. 6-19 to 6-47, 1992.

4. R. A. Wenglarz, "Deposition, Erosion and Corrosion Protection for Coal-Fired Gas Turbines," ASME Paper No. 85-IGT-61, 1985.

5. C. S. Giggins and F. S. Pettit, J. Electrochem. Soc., Vol. 118, 1971, p. 1782.

6. G. W. Goward, "Low Temperature Hot Corrosion in Gas Turbines," J. Eng. Gas Turbines \& Power, Vol. 108, April 1986, pp. 421-425.

7. R. Bauer, K. Schneider, and H. W. Grünling, "Experience with Platinum Aluminide Coatings in Land-Based Gas Turbines," High Temperature Technology, Vol. 3, No. 3, May 1985, pp. 59-64.

8. R. J. Hecht, G. W. Goward, and R. C. Elam, "High Temperature NiCoCrAlY Coatings," United States Patent No. 3,928,026, December 23, 1975.

9. I. Linask and J. Dierberger, "A Fracture Mechanics Approach to Turbine Airfoil Design," ASME Paper 75-GT-79, 1975.

10. T. A. Taylor, M. P. Overs, B. J. Gill, and R. C. Tucker, Jr., "Experience with MCrAl and Thermal Barrier Coatings Produced Via Inert Gas Shrouded Plasma Deposition," J. Vac. Sci. Tech. A., Vol. 3, No. 6, Nov./Dec. 1985, pp. 2526-2531.

11. J. R. Rairden, "Hot-Corrosion-Resistant Duplex Coatings for a Superalloy," Thin Solid Films, Vol. 53, 1978, pp. 251-258.

12. John H. Wood and Edward H. Goldman, Superalloys II, Chester T. Sims, Norman S. Stoloff, and William C. Hagel, eds, Boston: John Wiley \& Sons, 1987, pp. 359-384. 
13. K. D. Sheffler and D. K. Gupta, "Current Status and Future Trends in Turbine Application of Thermal Barrier Coatings," Journal of Engineering for Gas Turbines and Power, Vol. 110, October 1988, pp. 605-609.

14. C. H. Liebert, Thin Solid Films, Vol. 53, 1978, pp. 235-240.

15. William J. Brindley and Robert A. Miller, "TBCs for Better Engine Efficiency," Advanced Materials \& Processes, Vol. 136, No. 2, August 1989, pp. 29-33.

16. W. J. Lackey, D. P. Stinton, G. A. Cerney, L. L. Fehrenbacher, and A. C. Schaf fhauser, Ceramic Coatings for Heat Engine Materials--Status and Future Needs, ORNL/TM-8959, Oak Ridge National Laboratory, Oak Ridge, TN, December 1984.

17. W. J. Lackey, D. P. Stinton, G. A. Cerny, A. C. Schaffhauser, and L. L. Fehrenbacher, "Ceramic Coatings for Advanced Heat Engines--A Review and Projection," Advanced Ceramic Materials, Vol. 2, No. 1, January 1987, pp. 24-30.

18. Curt H. Liebert and Robert A. Miller, "Ceramic Thermal Barrier Coatings," Ind. Eng. Chem. Prod. Res. Dev., Vol. 23, 1984, pp. 344-349.

19. S. K. Lau and R. J. Bratton, "Degradation Mechanisms of Ceramic Thermal Barrier Coatings in Corrosive Environments," in Conference Proceedings of the Metallurgical Society of AIME, Subhash C. Singhal, ed., Pittsburgh, Pennsylvania, 1983, pp. 305-317.

20. S. R. Levine, R. A. Miller, and P. E. Hodge, "Thermal Barrier Coatings for Heat Engine Components," SAMPE Quarterly, December 1, 1980, p. 20.

21. R. Stevens, An Introduction to Zirconia, U.K.: Sherwin River Ltd., 1983.

22. J. D. Reardon and M. R. Dorfman, "Advanced Thermal Barrier Coating Systems," J. Materials for Energy Systems, Vol. 8, No. 4, March 1987, pp. 414-419.

23. B. A. Nagaraj, A. F. Maricocchi, D. J. Wortman, J. S. Patton and R. L. Clarke, "Hot Corrosion Resistance of Thermal Barrier Coatings," ASME Paper No. 92-GT-44, 1992.

24. M. Menguturk and E. F. Sverdrup, "Calculated Tolerance of a Large Electric Utility Gas Turbine to Erosion Damage by Coal Gas Ash Particles," Erosion: Prevention and Useful Applications, ASTM STP 665, W. F. Adler, Ed., 1979, pp. 192-224. 


\begin{tabular}{|c|c|c|c|}
\hline $\begin{array}{l}\text { Document Control } \\
\text { Page }\end{array}$ & $\begin{array}{l}\text { 1. NREL Report No. } \\
\text { NREL/TP-430-6085 }\end{array}$ & $\begin{array}{l}\text { 2. NTIS Accession No. } \\
\text { DE94000261 }\end{array}$ & 3. Recipient's Accession No. \\
\hline \multirow{2}{*}{\multicolumn{3}{|c|}{$\begin{array}{l}\text { 4. Title and Subtitle } \\
\text { Impact Study on the use of Biomass-Derived Fuels in Gas Turbines for Power } \\
\text { Generation }\end{array}$}} & $\begin{array}{l}\text { 5. Publication Date } \\
\text { January } 1994\end{array}$ \\
\hline & & & 6. \\
\hline \multicolumn{3}{|c|}{$\begin{array}{l}\text { 7. Author(s) } \\
\text { Dr. Clifford A. Moses, Dr. Henry Bernstein }\end{array}$} & $\begin{array}{l}\text { 8. Performing Organization Rept. No. } \\
\text { TP-430-6085 }\end{array}$ \\
\hline \multirow{2}{*}{\multicolumn{3}{|c|}{$\begin{array}{l}\text { 9. Performing Organization Name and Address } \\
\text { Southwest Research Institute } \\
6220 \text { Culebra Road } \\
\text { P.O. Drawer } 58210 \\
\text { San Antonio, Texas } 78284\end{array}$}} & $\begin{array}{l}\text { 10. Project/Task/Work Unit No. } \\
\text { BP311.34392 }\end{array}$ \\
\hline & & & $\begin{array}{l}\text { 11. Contract (C) or Grant (G) No. } \\
\text { (C)AV-2-12148-1 } \\
\text { (G) }\end{array}$ \\
\hline \multirow{2}{*}{\multicolumn{3}{|c|}{$\begin{array}{l}\text { 12. Sponsoring Organization Name and Address } \\
\text { National Renewable Energy Laboratory } \\
1617 \text { Cole Blvd. } \\
\text { Golden, CO } 80401-3393\end{array}$}} & $\begin{array}{l}\text { 13. Type of Report \& Period Covered } \\
\text { Technical Report }\end{array}$ \\
\hline & & & 14. \\
\hline \multicolumn{4}{|c|}{$\begin{array}{l}\text { 15. Supplementary Note } \\
\text { NREL technical monitor: Dr. Thomas Milne, (303) 231-7000, x1440 }\end{array}$} \\
\hline \multicolumn{4}{|c|}{$\begin{array}{l}\text { 16. Abstract (Limit: } 200 \text { words) } \\
\text { This report evaluates the properties of fuels derived from biomass, both gaseous and liquid, against the fuel requirements of gas } \\
\text { turbine systems for gernating electrical power. The report attempts to be quantitative rather than merely qualitative to establish } \\
\text { the significant variations in ther properties of biomass fuels from those of conventional fuels. Three general categories are } \\
\text { covered: performance, durability, and storage and handling. }\end{array}$} \\
\hline \multirow{3}{*}{\multicolumn{4}{|c|}{$\begin{array}{l}\text { 17. Document Analysis } \\
\text { a. Descriptors } \\
\text { biomass fuels, biomass combustion, power generation, gas turbines }\end{array}$}} \\
\hline & & & \\
\hline & & & \\
\hline \multirow{2}{*}{\multicolumn{2}{|c|}{$\begin{array}{l}\text { 18. Availability Statement } \\
\text { National Technical Information Service } \\
\text { U.S. Department of Commerce } \\
5285 \text { Port Royal Road } \\
\text { Springfield, VA } 22161\end{array}$}} & & $\begin{array}{l}\text { 19. No. of Pages } \\
132\end{array}$ \\
\hline & & & $\begin{array}{l}\text { 20. Price } \\
\text { A07 }\end{array}$ \\
\hline
\end{tabular}

Form No. 0069E (6-30-87) 